Forschungszentrum Karlsruhe Technik und Umwelt

Wissenschaftliche Berichte FZKA 5603

\title{
Stellar Neutron Capture Cross Sections of the Tin Isotopes
}

K. Wisshak, F. Voss, Ch. Theis, F. Käppeler, K. Guber, L. Kazakov, N. Kornilov, G. Reffo Institut für Kernphysik 



\section{FORSCHUNGSZENTRUM KARLSRUHE}

Technik und Umwelt

Wissenschaftliche Berichte

FZKA 5603

\section{STELLAR NEUTRON CAPTURE CROSS SECTIONS OF THE TIN ISOTOPES}

K. WISSHAK, F. VOSS, Ch. THEIS, F. KÄPPELER, K. GUBER ${ }^{1}$, L. KAZAKOV ${ }^{2}$, N. KORNILOV ${ }^{2}$, and G. REFFO ${ }^{3}$

Institut für Kernphysik

${ }^{1}$ Oak Ridge National Laboratory, Oak Ridge, TN 37831-6371, USA

${ }_{2}^{2}$ Institute for Physics and Power Engineering, Obninsk, Kaluga Region, Russia

${ }^{3}$ ENEA, Centro Dati Nucleari, Via Martiri di Monte Sole 4, I-40138 Bologna, Italy

Forschungszentrum Karlsruhe GmbH, Karlsruhe 1995 
Als Manuskript gedruckt

Für diesen Bericht behalten wir uns alle Rechte vor

Forschungszentrum Karlsruhe $\mathrm{GmbH}$

Postfach 3640, 76021 Karlsruhe

ISSN 0947-8620 


\section{ABSTRACT}

The neutron capture cross sections of ${ }^{114} \mathrm{Sn},{ }^{115} \mathrm{Sn},{ }^{116} \mathrm{Sn},{ }^{117} \mathrm{Sn},{ }^{118} \mathrm{Sn}$, and ${ }^{120} \mathrm{Sn}$ were measured in the energy range from 3 to $225 \mathrm{keV}$ at the Karlsruhe $3.75 \mathrm{MV}$ Van de Graaff accelerator. Neutrons were produced via the ${ }^{7} \mathrm{Li}(\mathrm{p}, \mathrm{n})^{7}$ Be reaction by bombarding metallic Li targets with a pulsed proton beam. Capture events were registered with the Karlsruhe $4 \pi$ Barium Fluoride Detector, which was improved by replacing crystals with high $\alpha$ background. This allowed to lower the threshold in sum energy and resulted in a significantly increased efficiency for capture events. The experiment was difficult due to the small $(n, \gamma)$ cross sections of the proton magic tin isotopes, and due to the comparably low enrichment of the rare isotopes ${ }^{114} \mathrm{~S}_{\mathrm{n}}$ and ${ }^{115} \mathrm{~S}$. This caused significant corrections for capture of scattered neutrons and for isotopic impurities, but the high efficiency and the spectroscopic quality of the $\mathrm{BaF}_{2}$ detector allowed to determine these corrections reliably. Typical overall uncertainties of $1-2 \%$ could be achieved for the cross section ratios, five times smaller compared to existing data. Based on these results, Maxwellian averaged $(\mathrm{n}, \gamma)$ cross sections were calculated for thermal energies between $\mathrm{kT}=10 \mathrm{keV}$ and 100 keV. 


\section{ZUSAMMENFASSUNG}

\section{DIE STELLAREN $(\mathrm{n}, \gamma)$ QUERSCHNITTE DER ZINNISOTOPE}

Die Neutroneneinfangquerschnitte von ${ }^{114} \mathrm{Sn},{ }^{115} \mathrm{Sn},{ }^{116} \mathrm{Sn},{ }^{117} \mathrm{Sn},{ }^{118} \mathrm{Sn}$ und ${ }^{120} \mathrm{Sn}$ wurden im Energiebereich von 3 bis $225 \mathrm{keV}$ am Karlsruher Van de Graaff Beschleuniger relativ zu Gold als Standard gemessen. Neutronen wurden über die ${ }^{7} \mathrm{Li}(\mathrm{p}, \mathrm{n})^{7} \mathrm{Be}-$ Reaktion durch Beschuß metallischer Li-Targets mit einem gepulsten Protonenstrahl erzeugt. Der zum Nachweis von Einfangereignissen benutzte Karlsruher $4 \pi$-Bariumfluorid-Detektor wurde verbessert, indem Kristalle mit hohem $\alpha$-Untergrund ersetzt wurden. Dadurch konnte die Energieschwelle für den Nachweis von Einfangereignissen reduziert und die Nachweiswahrscheinlichkeit entsprechend verbessert werden. Die Messung wurde durch die kleinen Einfangquerschnitte der protonemmagischen Zimnisotope und die relativ niedrige Anreicherung der seltenen Isotope ${ }^{114} \mathrm{Sn}$ und ${ }^{115} \mathrm{Sn}$ erschwert. Dies hatte signifikante Korrekturen für Streuneutronen und Isotopeneffekte zur Folge, die jedoch aufgrund der hohen Nachweiswahrscheinlichkeit und der spektroskopischen Qualität des $\mathrm{BaF}_{2}$ Detektors zuverlässig durchgeführt werden konnten. Für die Unsicherheiten der Querschnittsverhältnisse ergaben sich Werte von 1-2\%, was im Vergleich zu früheren Arbeiten einer Verbesserung um einen Faktor fünf entspricht. Mit diesen Ergebnissen wurden die stellaren $(\mathrm{n}, \gamma)$-Querschnitte für thermische Energien von $\mathrm{kT}=10 \mathrm{keV}$ bis $100 \mathrm{keV}$ berechnet. 


\section{Contents}

1 INTRODUCTION 1

2 EXPERIMENT 3

2.1 Experimental Method . . . . . . . . . . . . . . . . . . . 3

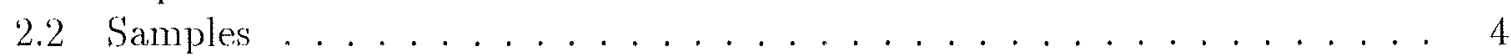

2.3 Measurements . . . . . . . . . . . . . . . . . 6

3 DATA ANALYSIS $\quad 6$

3.1 Total Cross Sections . . . . . . . . . . . . . . . . 6

3.2 Capture Cross Sections . . . . . . . . . . . . . . 7

4 RESULTS FOR THE NEUTRON CAPTURE CROSS SECTIONS 32

$5 \quad$ DISCUSSION OF UNCERTAINTIES

6 MAXWELLIAN AVERAGED CROSS SECTIONS 46

7 SUMMARY 51

8 ACKNOWLEDGMENTS

REFERENCES 


\section{INTRODUCTION}

The origin of the stable isotopes in the $\mathrm{C} d-\mathrm{In}-\mathrm{Sn}$ region is characterized by a complex mixture of contributions from the various processes of nucleosynthesis and is presently not well understood $[1,2]$. This rather complicated pattern results partly from the influence of the numerous isomers on the reaction flow as illustrated in Fig. 1.

At first one conld assume that the s-process neutron captures run through the stable Cd isotopes up to ${ }^{114} \mathrm{C} d$. Therefore, ${ }^{115} \mathrm{In}$ and ${ }^{116} \mathrm{Sn}$ should be the lightest isotopes of these elements produced by the s-process. The bypassed isotopes ${ }^{113} \mathrm{In},{ }^{114} \mathrm{Sn}$ and ${ }^{115} \mathrm{Sn}$ are also shielded from the $\mathbf{r}-$ process by their stable isobars. Since only even isotopes can survive the hot environment where the p-process is supposed to occur $[3,4]{ }^{113} \mathrm{In}$ and ${ }^{115} \mathrm{Sn}$ would not exist at all in such a naive picture. Accordingly, it was suggested $[5,6]$ that these isotopes owe their existence to the long lived isomers indicated in Fig. 1. These isomers can be fed either by the s-process or by the $r$-process, thus providing a possibility for producing these critical isotopes.

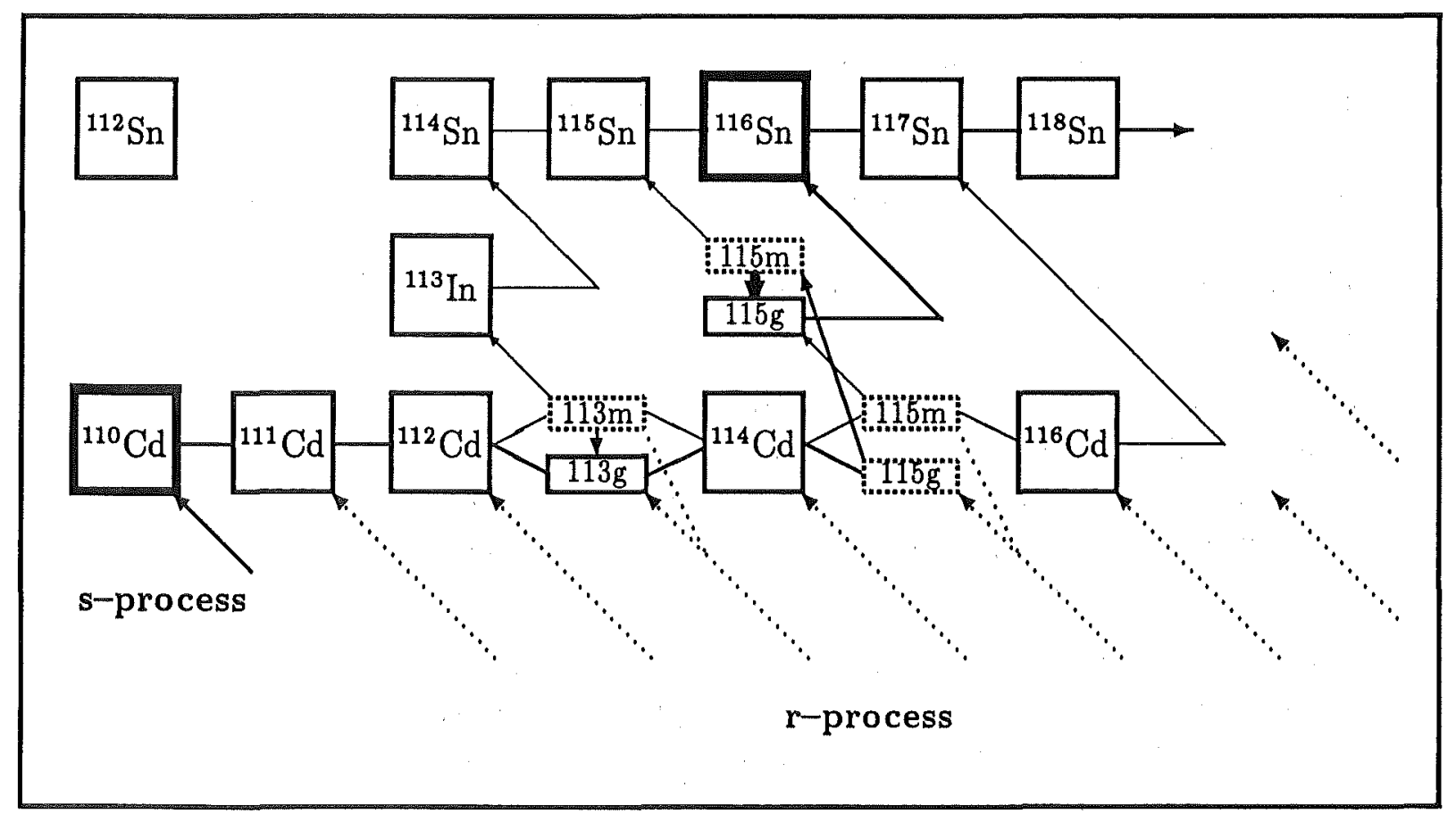

Figure 1: Possible s- and $\mathrm{r}$-process paths in the $\mathrm{Cd}-\mathrm{In}-\mathrm{Sn}$ region. Only temperature independent branchings are indicated. (Solid lines: s-process path, dashed lines: post $\mathrm{r}$-process $\beta$-decays) 
A detailed stidy $[1,2]$ of the branching at ${ }^{113} \mathrm{Cd}$, based on new experimental results for the level scheme of this isotope, showed that only $17 \%$ of the observed ${ }^{113} \mathrm{In}$ abundance, $6 \%$ of ${ }^{114} \mathrm{Sn}$ and $\sim 50 \%$ of ${ }^{115} \mathrm{Sn}$ can be explained by a combined analysis of the $\mathrm{s}-$ and $\mathrm{r}$-processes. To attribute the remaining fraction to the p-process is problematic, however, at least for the odd isotopes, which are not produced in due amounts by recent p-process calculations $[3,4]$.

The aim of the present experiment was to improve this situation by an accurate determinination of the stellar cross sections of the tin isotopes which is an essential prerequisite for detailed s-process analyses. Apart from the puzzling origin of ${ }^{113} \mathrm{In}$ and ${ }^{115} \mathrm{Sn}$, there is a general interest in accurate data for ${ }^{116} \mathrm{Sn}$, an s-only isotope that is not affected by branchings and can, therefore, be used as a normalization point of the $\mathrm{N}_{s}<\sigma>$ curve, similar to the previously measured ${ }^{124} \mathrm{Te}$ [7] and ${ }^{150} \mathrm{Sm}$ [8]. In addition, the complete data set allows for a new determination of the s-abundances of all tin isotopes and for an improved separation of $\mathrm{s}$ - and $\mathrm{r}$-process residuals in this mass region.

The experimental situation for the capture cross sections of the tin isotopes is more favorable than in other cases investigated recently $[9,10]$. There exists a complete set of data by Timokhov et al. [11] with typical uncertainties of 5 to $8 \%$. In general, older results are in agreement with these data $[12,13]$, significant discrepancies being found only in case of ${ }^{120} \mathrm{Sn}$, where an activation experiment by Schanz et al. $[14,15]$ yielded a $20 \%$ lower value compared to the data of Timokhov et al. [11]. Unfortunately, the existing data were only determined for neutron energies above $20 \mathrm{keV}$ with rather large uncertainties around this lower limit. Therefore, reliable stellar cross sections could only be calculated for thermal energies larger than $\mathrm{kT}=30 \mathrm{keV}$, while stellar model calculations require these data also around $\mathrm{kT}=10 \mathrm{keV}[16,17]$.

The present experiment was performed in the neutron energy range from 3 to 225 $\mathrm{keV}$, thus significantly extending the investigated energy range. The uncertainties were reduced to $\sim 1 \%$ by using the Karlsruhe $4 \pi \mathrm{BaF}_{2}$ detector for the registration of capture events.

The measurement of the $(\mathrm{n}, \gamma)$ cross sections of the tin isotopes is complicated for two reasons:

- The cross sections of the even isotopes are very small due to the magic proton number $\mathrm{Z}=50$. In fact, ${ }^{120} \mathrm{~S}$ n exhibits the smallest cross section measured with the Karlsruhe $4 \pi \mathrm{BaF}_{2}$ detector up to now. Correspondingly, the ratio of total to capture cross section is unfavorably large, giving rise to large corrections for capture of scattered neutrons.

- The isotopes ${ }^{114} \mathrm{Sn}$ and ${ }^{115} \mathrm{Sn}$ have low natural abundances of $0.7 \%$ and $0.4 \%$, respectively. Therefore, the available sample material was only enriched to $70 \%$ in ${ }^{114} \mathrm{Sn}$ and to $45 \%$ in ${ }^{115} \mathrm{Sn}$, resulting in large corrections for isotopic impurities.

While these problems are difficult to handle with conventional TOF methods, the present setup is well suited for treating both corrections properly. This was demonstrated at the more extreme examples of the barium isotopes [9], where the background due to capture of scattered neutrons was even larger, and of the gadolinium isotopes [10] where the corrections for isotopic impurities were also larger than in the present case. 
Experiment and data analysis are described in Secs. 2 and 3. The differential cross sections are presented in Sec. 4, the uncertainties are discussed in Sec.5, and the determination of the stellar cross sections follows in Sec. 6. This report is devoted to a presentation of the experimental results. The astrophysical implications will be addressed in a forthcoming publication [18].

\section{EXPERIMENT}

\subsection{Experimental Method}

The neutron capture cross sections of the tin isotopes 114 to 118 and 120 have been measured in the energy range from 3 to $225 \mathrm{keV}$ using gold as a standard. Since the experimental method has been published in detail $[7,8,19,20]$, only a more general description is given here, complemented with the specific features of the present measurement. Neutrons were produced via the ${ }^{7} \mathrm{Li}(\mathrm{p}, \mathrm{n}){ }^{7} \mathrm{Be}$ reaction by bombarding metallic $\mathrm{Li}$ targets with the pulsed proton beam of the Karlsruhe 3.75 MV Van de Graaff accelerator. The neutron energy was determined by time of flight (TOF), the samples being located at a flight path of $79 \mathrm{~cm}$. The important parameters of the accelerator were: pulse width $<1 \mathrm{~ns}$, repetition rate $250 \mathrm{kHz}$, and average beam current $1.5 \mu \mathrm{A}$. In different runs, the proton energies were adjusted 30 and $100 \mathrm{keV}$ above the threshold of the ${ }^{7} \mathrm{Li}(\mathrm{p}, \mathrm{n})^{7} \mathrm{Be}$ reaction at $1.881 \mathrm{MeV}$. In this way, continuous neutron spectra in the energy range of interest for s-process studies were obtained, ranging from 3 to $100 \mathrm{keV}$, and 3 to $200 \mathrm{keV}$, respectively. The lower maximum neutron energy offers a significantly better signal to background ratio at lower energies.

Capture events were registered with the Karlsruhe $4 \pi$ Barium Fluoride Detector via the prompt capture $\gamma$-ray cascades. This detector consists of 42 hexagonal and pentagonal crystals forming a spherical shell of $\mathrm{BaF}_{2}$ with $10 \mathrm{~cm}$ inner radius and $15 \mathrm{~cm}$ thickness. It is characterized by a resolution in $\gamma$-ray energy of $7 \%$ at $2.5 \mathrm{MeV}$, a time resolution of $500 \mathrm{ps}$, and a peak efficiency of $90 \%$ at $1 \mathrm{MeV}$. For a comprehensive description see Ref.[19].

In the present experiment, 6 crystals with high intrinsic background rates due to a natural radium contamination $(\sim 1000$ counts/s for the integral of the four $\alpha$ lines) have been replaced. Two of the new cristals have background rates of 200 counts/s as most of the others, but four crystals exhibit very low radium impurities giving rise to less than 10 counts/s only. With this change the total intrinsic background could be reduced by almost a factor of two. This means that the threshold in the sum energy spectrum of the detector could be reduced from 2.4 to $1.6 \mathrm{MeV}$ while recording the same integral count rate. This improvement has led to a significantly increased detection efficiency (see Sec. 3).

The experiment was divided into three runs, two with the conventional data acquisition technique with the detector operated as a calorimeter, and one with the ADC system for obtaining more detailed spectroscopic information. 


\subsection{Samples}

The samples were metal disks of $22 \mathrm{~mm}$ diameter, which were prepared from isotopically enriched metallic tin powder. The relevant parameters of the samples are compiled in Table 1. In addition to the six tin samples, a gold sample, a graphite sample, and an empty position in the sample ladder were used in all runs. A second, three times thinner ${ }^{116} \mathrm{Sn}$ sample was prepared in order to check the corrections for neutron multiple scattering and self-shielding effects.

Table 1: SAMPLE C'HARACTERISTICS

\begin{tabular}{lcccc}
\hline Sample $^{1}$ & $\begin{array}{c}\text { Thickness } \\
\left(10^{-3} \text { at/barn }\right)^{2}\end{array}$ & $\begin{array}{c}\text { Weight } \\
(\mathrm{g})\end{array}$ & $\begin{array}{c}\text { Neutron Binding } \\
\text { Energy }(\mathrm{MeV})\end{array}$ \\
\hline${ }^{116} \mathrm{Sn}^{3}$ & 2.8 & 10.2780 & 7.529 & 6.944 \\
Graphite & 1.4 & 11.9881 & 0.909 & \\
${ }^{114} \mathrm{Sn}$ & 1.0 & 3.5616 & 2.589 & 7.546 \\
${ }^{115} \mathrm{Sn}$ & 0.3 & 1.0303 & 0.755 & 9.562 \\
${ }^{197} \mathrm{Au}$ & 0.25 & 1.5048 & 1.871 & 6.513 \\
${ }^{117} \mathrm{Sn}$ & 0.39 & 1.2434 & 0.919 & 9.326 \\
${ }^{118} \mathrm{Sn}$ & 1.8 & 6.3581 & 4.737 & 6.484 \\
${ }^{\mathrm{Empty}}$ & & & & \\
${ }^{120} \mathrm{Sn}$ & 3.7 & 13.5715 & 10.280 & 6.171 \\
\hline${ }^{116} \mathrm{Sn}^{4}$ & 0.90 & 3.3404 & 2.447 & 6.944 \\
\hline
\end{tabular}

${ }^{1}$ All samples $22 \mathrm{~mm}$ in diameter

${ }^{2}$ For tin samples: sum of all $\mathrm{Sn}$ isotopes

${ }^{3}$ Used in runs 1 and 3

${ }^{4} U_{\text {sed }}$ in run 2

The isotopic compositions provided by the supplier are listed in Table 2. As already pointed out, the enrichments in ${ }^{114} \mathrm{Sn}$ and ${ }^{115} \mathrm{Sn}$ of $70.2 \%$ and $45.3 \%$ are comparably low. respectively.

The neutron transmissions of the samples were calculated with the SESH code[21], and are generally larger than $95 \%$ except for the thick ${ }^{116} \mathrm{Sn}$ and the ${ }^{120} \mathrm{Sn}$ samples (Table 3). Normalization of the spectra to equal neutron flux was performed for all samples by means of a ${ }^{6} \mathrm{Li}$-glass monitor located close to the neutron target. The spectra measured with a second ${ }^{6} \mathrm{Li}$-glass detector at a flight path of $260 \mathrm{~cm}$ were used for a rough determination of the total cross sections. Though the accuracy of this method is inferior to that obtained in a dedicated experiment as performed by Timokhov et al. [11], the derived total cross sections can be used to test the normalization to equal neutron flux (Sec. 3). 
Table 2: ISOTOPIC COMPOSITION (\%)

\begin{tabular}{ccccccccccc}
\hline Sample & & & \multicolumn{8}{c}{ Isotope } \\
& ${ }^{112} \mathrm{Sn}$ & ${ }^{114} \mathrm{Sn}$ & ${ }^{115} \mathrm{Sn}$ & ${ }^{116} \mathrm{Sn}$ & ${ }^{117} \mathrm{Sn}$ & ${ }^{118} \mathrm{Sn}$ & ${ }^{119} \mathrm{Sn}$ & ${ }^{120} \mathrm{Sn}$ & ${ }^{122} \mathrm{Sn}$ & ${ }^{124} \mathrm{Sn}$ \\
\hline${ }^{114} \mathrm{Sn}$ & 0.26 & 70.2 & 0.50 & 10.23 & 2.40 & 6.39 & 1.94 & 6.68 & 0.66 & 0.74 \\
${ }^{115} \mathrm{Sn}$ & 0.11 & 0.57 & 45.3 & 33.27 & 5.21 & 6.83 & 1.85 & 5.68 & 0.56 & 0.62 \\
${ }^{116} \mathrm{Sn}$ & $<0.03$ & 0.01 & 0.04 & 97.6 & 0.69 & 0.96 & 0.16 & 0.47 & 0.03 & 0.04 \\
${ }^{117} \mathrm{Sn}$ & $<0.01$ & $<0.01$ & $<0.01$ & 0.84 & 92.1 & 5.81 & 0.39 & 0.76 & 0.05 & 0.05 \\
${ }^{118} \mathrm{Sn}$ & $<0.06$ & $<0.03$ & $<0.06$ & 0.07 & 0.14 & 98.5 & 0.78 & 0.51 & $<0.04$ & $<0.04$ \\
${ }^{120} \mathrm{Sn}$ & $<0.01$ & $<0.01$ & $<0.01$ & 0.04 & 0.03 & 0.18 & 0.09 & 99.6 & 0.03 & 0.03 \\
\hline
\end{tabular}

Table 3: NEUTRON TRANSMISSION ${ }^{1}$

\begin{tabular}{lcccc}
\hline Sample & \multicolumn{4}{c}{ Neutron Energy (keV) } \\
& 10 & 20 & 100 & 200 \\
\hline${ }^{197} \mathrm{Au}$ & 0.972 & 0.976 & 0.984 & 0.987 \\
${ }^{114} \mathrm{Sn}$ & 0.985 & 0.985 & 0.984 & 0.983 \\
${ }^{115} \mathrm{Sn}$ & 0.997 & 0.997 & 0.997 & 0.997 \\
${ }^{116} \mathrm{Sn}^{2}$ & 0.983 & 0.982 & 0.981 & 0.981 \\
${ }^{116} \mathrm{Sn}^{3}$ & 0.949 & 0.948 & 0.944 & 0.942 \\
${ }^{117} \mathrm{Sn}$ & 0.993 & 0.993 & 0.993 & 0.993 \\
${ }^{118} \mathrm{Sn}$ & 0.970 & 0.969 & 0.967 & 0.966 \\
${ }^{120} \mathrm{Sn}$ & 0.931 & 0.930 & 0.927 & 0.926 \\
\hline
\end{tabular}

1 Monte Carlo calculation with SESH code [21].

2 Thin sample

3 Thick sample

Table 4: PARAMETERS OF THE INDIVIDUAL MEASUREMENTS

\begin{tabular}{cccccccc}
\hline Run & $\begin{array}{c}\text { Flight } \\
\text { Path }\end{array}$ & $\begin{array}{c}\text { TOF } \\
\text { Scale }\end{array}$ & $\begin{array}{c}\text { Number } \\
\text { of } \\
\text { Cycles }\end{array}$ & $\begin{array}{c}\text { Maximum } \\
\text { Neutron } \\
\text { Energy } \\
(\mathrm{keV})\end{array}$ & $\begin{array}{c}\text { Measuring } \\
\text { Time }\end{array}$ & $\begin{array}{c}\text { Average } \\
\text { Beam } \\
\text { Current } \\
(\mu \mathrm{A})\end{array}$ & $\begin{array}{c}\text { Threshold } \\
\text { in Sum } \\
\text { Energy } \\
(\mathrm{MeV})\end{array}$ \\
\hline 1 & 786.5 & 0.7360 & 263 & 100 & 29.6 & 1.2 & 1.6 \\
2 & 785.9 & 0.7359 & 293 & 200 & 26.6 & 1.4 & 1.6 \\
3 & 786.2 & 0.7133 & 295 & 100 & 22.0 & 1.7 & 1.6 \\
\hline
\end{tabular}




\section{$2.3 \quad$ Measurements}

The samples were moved cyclically into the measuring position by a computer controlled sample changer. The data acquisition time per sample was about $10 \mathrm{~min}$, a complete cycle lasting about $1.5 \mathrm{~h}$. From each event, a 64 bit word was recorded on DAT tape containing the sum energy and TOF information together with 42 bits identifying those detector modules that contributed. Three runs were performed using neutron spectra with different maximum energies. The relevant parameters are compiled in Table 4 . The data in Run 3 were recorded with the ADC system. The overall recorded information was 27 Gbyte.

\section{DATA ANALYSIS}

\subsection{Total Cross Sections}

The total cross sections of the tin isotopes were determined in the neutron energy range from 10 to $200 \mathrm{keV}$ via the TOF spectra measured with the ${ }^{6} \mathrm{Li}$ glass detector at a flight path of $260 \mathrm{~cm}$. The total cross sections and the related uncertainties were obtained as described in Ref.[8], and are listed in Table 5. The values deduced for the carbon sample agree with the data from the Joint Evaluated File (JEF) [22] within $\pm 3.0 \%$, similar to the results reported in Ref.[8]. The uncertainties were again calculated with the assumption that they are inversely proportional to the fraction of neutrons interacting in the sample, $\mathrm{A}=1-\mathrm{T}$, where $\mathrm{T}$ is the transmission. For the carbon sample, $\mathrm{A}=5.4 \%$ and an uncertainty of $3 \%$ estimated from the comparison with the JEF data. Correspondingly, the $A=0.9 \%$ of the ${ }^{117} \mathrm{~S} n$ sample yields an uncertainty of $18 \%$ for the total cross section. For the samples with low enrichment, the uncertainty was attributed to the main isotope after correction for isotopic impurities. This explains the $36 \%$ uncertainty estimated for the ${ }^{115} \mathrm{Sn}$ sample, which has the same transmission as the ${ }^{117} \mathrm{Sn}$ sample, but where ${ }^{115} \mathrm{Sn}$ contributes only $50 \%$.

The data of Timokhov et al. [11], which were obtained in a dedicated experiment using thick samples with transmissions between $60 \%$ and $80 \%$, exhibit uncertainties of $0.8-1.4 \%$. Within the accuracy of the present experiment, there is good agreement for ${ }^{114} \mathrm{Sn},{ }^{115} \mathrm{Sn},{ }^{117} \mathrm{Sn}$, and ${ }^{120} \mathrm{Sn}$, whereas our results for ${ }^{116} \mathrm{Sn}$ and ${ }^{118} \mathrm{Sn}$ are higher by $12-$ $15 \%$. This overall agreement confirms that the uncertainties were estimated reasonably, in particular since the uncertainties of Timokhov et al. at low neutron energies might be larger than the quoted averages due to the poor statistics.

The present setup allows to measure the total cross section with uncertainties between $\sim 2 \%$ and $\sim 20 \%$ for sample transmissions between $0.92 \%$ and $0.99 \%$, respectively. This can be taken as an independent proof for the accuracy obtained in normalizing the spectra of the individual samples to equal neutron flux, since the above results can only be obtained if the uncertainty of this correction is smaller than $0.2 \%$. 


\subsection{Capture Cross Sections}

The analysis was carried out in the same way as described previously [7, 8, 20]. All events were sorted into two-dimensional spectra containing 128 sum energy versus 2048 TOF channels according to various event multiplicities (Evaluation 1). In Evaluation 2, this procedure was repeated by rejecting those events, where only neighboring detector modules contributed to the sum energy signal. With this option, background from the natural radioactivity of the $\mathrm{BaF}_{2}$ crystals and from scattered neutrons can be reduced. For all samples, the resulting spectra were normalized to equal neutron flux using the count rate of the ${ }^{6} \mathrm{Li}$ glass monitor close to the neutron target. The corresponding normalization factors are below $1.0 \%$ for all runs. The calculation of the two-dimensional spectra from the data recorded with the $\mathrm{ADC}$ system is slightly more complicated and was performed as described in Ref. [8].

In the next step of data analysis, the spectra measured with the empty sample canning were subtracted to remove sample-independent backgrounds. A remaining constant background was determined at very long flight times, where no time-correlated events are expected. In spite of the relatively small $(n, \gamma)$ cross sections of the tin isotopes, there was no problem in subtracting this background as in case of the barium experiment [9]. The use of metallic samples ensured a significantly smaller scattering to capture ratio, thus avoiding systematic uncertainties due to a TOF overlap with events from the previous pulse.

The two-dimensional spectra of run 3 containing all events with multiplicity $>2$ are shown in Figs. 2,3, and 4. Events at low sum energy and large TOF are suppressed by the preprocessing unit coupled to the ADC system.

At this point, the spectra contain only events that are correlated with the sample. The next correction to be made is for isotopic impurities (see Ref.[8] for details). The respective coefficients are compiled in Table 6 . Since experimental data exist only for the six investigated isotopes, the following assumptions were made in order to account for the

Table 5: THE MEASURED TOTAL CROSS SECTIONS ${ }^{1}$

\begin{tabular}{ccccccccc}
\hline $\begin{array}{c}\text { Neutron Energy } \\
(\mathrm{keV})\end{array}$ & ${ }^{114} \mathrm{Sn}$ & ${ }^{115} \mathrm{Sn}$ & ${ }^{116} \mathrm{Sn}$ & ${ }^{117} \mathrm{Sn}$ & ${ }^{118} \mathrm{Sn}$ & ${ }^{120} \mathrm{Sn}$ & ${ }^{12} \mathrm{C}$ & ${ }^{197} \mathrm{Au}$ \\
\hline $10-15$ & 7.32 & 9.19 & 6.32 & 9.09 & 5.78 & 5.28 & 5.13 & 19.4 \\
$15-20$ & 6.07 & 9.00 & 6.69 & 6.73 & 5.47 & 5.58 & 4.64 & 13.5 \\
$20-30$ & 7.26 & 10.2 & 6.59 & 7.08 & 5.72 & 5.69 & 4.93 & 14.1 \\
$30-40$ & 7.54 & 9.06 & 7.23 & 7.93 & 6.13 & 5.31 & 4.90 & 14.3 \\
$40-60$ & 6.55 & 8.74 & 6.71 & 6.55 & 5.70 & 5.58 & 4.70 & 12.2 \\
$60-80$ & 6.92 & 7.61 & 6.90 & 7.18 & 6.23 & 6.01 & 4.58 & 11.1 \\
$80-100$ & 7.07 & 8.19 & 6.68 & 7.56 & 6.43 & 5.86 & 4.59 & 10.5 \\
$100-150$ & 7.39 & 12.2 & 7.21 & 7.47 & 6.46 & 6.17 & 4.38 & 10.8 \\
$150-200$ & 6.70 & 8.08 & 6.13 & 6.79 & 6.94 & 6.83 & 4.14 & 9.6 \\
\hline Uncertainty & $9.2 \%$ & $36 . \%$ & $2.6 \%$ & $18 . \%$ & $4.2 \%$ & $2.1 \%$ & $3.0 \%$ & $8.5 \%$
\end{tabular}

${ }^{1}$ determined from the count rate of the ${ }^{6} \mathrm{Li}$ glass neutron monitor at $260 \mathrm{~cm}$ flight path 
Table 6: MATRIX FOR THE ISOTOPIC CORRECTION (\%)

\begin{tabular}{cccccccc}
\hline $\begin{array}{c}\text { Corrected } \\
\text { Spectrum }\end{array}$ & ${ }^{114} \mathrm{Sn}$ & ${ }^{115} \mathrm{Sn}$ & ${ }^{116} \mathrm{Sn}^{1}$ & ${ }^{117} \mathrm{Sn}$ & ${ }^{118} \mathrm{Sn}$ & ${ }^{120} \mathrm{Sn}$ & $\begin{array}{c}\text { Corrected Sample } \\
\text { Thickness }\left(10^{-3} \text { at/barn }\right)\end{array}$ \\
\hline${ }^{114} \mathrm{Sn}$ & 100 & -3.785 & -3.489 & -10.633 & -3.406 & -1.956 & 2.5142 \\
${ }^{115} \mathrm{Sn}$ & -0.302 & 100 & -3.400 & -5.407 & -0.995 & -0.467 & 0.4665 \\
${ }^{116} \mathrm{Sn}^{2}$ & -0.038 & -0.879 & 100 & -6.968 & -1.482 & -0.378 & $10.0273 / 3.2590$ \\
${ }^{117} \mathrm{Sn}$ & & +0.001 & -0.104 & 100 & -1.152 & -0.073 & 1.1477 \\
${ }^{118} \mathrm{Sn}$ & & & -0.041 & -3.491 & 100 & -0.237 & 6.2601 \\
${ }^{120} \mathrm{Sn}$ & & & -0.053 & -1.008 & -0.378 & 100 & 13.5224 \\
& & & & & & & \\
\hline
\end{tabular}

\footnotetext{
${ }^{1}$ This column refers to the evaluation of runs 1 and 3 . In case of run 2 it has to be multiplied by a factor of 3.077 to account for the smaller sample mass.

${ }^{2}$ This line refers to the evaluation of runs 1 and 3 . In case of run 2 it has to be divided by a factor of 3.077 to account for the smaller sample mass
}

remaining four stable tin isotopes as well: ${ }^{112} \mathrm{Sn}$ was approximated by the spectrum of ${ }^{114} \mathrm{Sn},{ }^{119} \mathrm{Sn}$ by that of ${ }^{117} \mathrm{Sn}$, and ${ }^{122,124} \mathrm{Sn}$ by the ${ }^{120} \mathrm{Sn}$ spectrum, as the respective isotopes have very similar binding energies. The abundances of these four impurity isotopes were scaled by factors of $1.54,0.63,0.92$, and 0.44 , respectively, according to the their cross section ratios, which were adopted from the work of Timokhov et al. [11]. This simplified treatment was possible because the abundances of the four critical impurity isotopes are always less than $2 \%$.

It is obvious from Table 2 that the ${ }^{114} \mathrm{Sn}$ and ${ }^{115} \mathrm{Sn}$ samples required rather large corrections for isotopic impurities. The left part of Fig. 5 shows the projection of the two-dimensional spectra of ${ }^{114} \mathrm{Sn},{ }^{115} \mathrm{Sn}$, and ${ }^{116} \mathrm{Sn}$ on the sum energy axis before this correction. The ${ }^{114} \mathrm{Sn}$ and ${ }^{115} \mathrm{Sn}$ spectra exhibit structures which are obviously caused by the isotopic impurities. The right part of Fig. 5 shows the same spectra after the corresponding corrections. The spectra of the ${ }^{116} \mathrm{Sn}$ sample in the lower part of the figure, illustrate the situation if the correction for isotopic impurities is small (the events around channel 100 are due to capture of scattered neutrons in the odd barium isotopes of the scintillator). In all three cases, the resulting sum energy spectra exhibit very similar shapes, demonstrating the reliability of this correction.

Closer inspection of the spectra in Fig. 5 reveals a feature, which is due to the fact that the first excited states of the compound nuclei ${ }^{115} \mathrm{Sn},{ }^{116} \mathrm{Sn}$, and ${ }^{117} \mathrm{Sn}$ occur at 0.5 $\mathrm{MeV}, 1.3 \mathrm{MeV}$, and $0.16 \mathrm{MeV}$, respectively. Since the first excited state is populated in many cascades (see Table 9 ), and since there is a probability of $\sim 6 \%$ that the $\gamma$-rays from the transition to the ground state escape from the detector, some of the capture events are not registered at the neutron binding energy but displaced by the energy of the first excited state. Corresponding structures are clearly visible for the ${ }^{114} \mathrm{Sn}$ and ${ }^{115} \mathrm{Sn}$ 
samples, while the resolution is not sufficient in case of ${ }^{116} \mathrm{Sn}$.

The corrections are indicated in Fig. 6 , where the TOF spectra before subtraction of the background from isotopic impurities are shown together with this background. Here, these corrections are much smaller than for the gadolinium isotopes [10], where up to $50 \%$ of the measured events had to be subtracted. In the ${ }^{114} \mathrm{Sn}$ and ${ }^{115} \mathrm{Sn}$ spectra, about $20 \%$ of the observed effect is due to isotopic impurities, whereas it is only $2 \%$ for ${ }^{116} \mathrm{Sn}$, and even less for the other isotopes, which are not shown explicitely.

Following the correction for isotopic impurities, the background due to capture of sample scattered neutrons was removed from the spectra by means of the data measured with the carbon sample. This correction is sizable due to the large ratios of total and capture cross sections in the tin isotopes, and was performed in the same way as described in the samarium measurement [8]. The correction is easily evaluated for the even isotopes, but there are some problems with the odd ones. The binding energies of ${ }^{115} \mathrm{Sn}$ and ${ }^{117} \mathrm{Sn}$ are 9.5 and $9.3 \mathrm{MeV}$ respectively, and thus even larger than those of the odd barium isotopes of the scintillator. Therefore, normalization of this correction has to be performed via the even barium isotopes as described in Ref.[7], which is more difficult because of the smaller capture rates of the even barium isotopes. This holds especially for the ${ }^{115} \mathrm{Sn}$ sample, where the low sample mass and the comparably large correction for isotopic impurities lead to a reduced statistical accuracy, which makes it difficult to determine this correction reliably at low neutron energies. Therefore, the resulting ${ }^{115} \mathrm{Sn}$ data are affected by systematic uncertainties below $10 \mathrm{keV}$ which are hard to evaluate.

After this last correction, the final spectra contain only the net capture events of the respective isotopes (bottom spectra in Figs. 2, 3, and 4).

The corrections for capture of scattered neutrons are shown in Fig. 7, and their influence at different neutron energies is given in Table 7 for the runs with maximum neutron energies of $100 \mathrm{keV}$ and $200 \mathrm{keV}$. Comparison with the respective spectra from the barium experiment [9] shows that the signal to background ratio is significantly better in the present case in spite of the fact that the cross section of ${ }^{120} \mathrm{Sn}$ is nearly a factor of two smaller than those of ${ }^{136} \mathrm{Ba}$ and ${ }^{137} \mathrm{Ba}$. This reduction of background from scattered neutrons results from the use of metallic samples instead of the carbonate, that had to be used for the barium samples. At $10 \mathrm{keV}$ neutron energy, for example, the signal to background ratio for ${ }^{120} \mathrm{Sn}$ is better by factors of 5 and 10 compared to ${ }^{136} \mathrm{Ba}$ and ${ }^{137} \mathrm{Ba}$, respectively.

Figure 2: The different steps of background subtraction in the two-dimensional sum energy $\times$ TOF spectra. The data are shown for ${ }^{114} \mathrm{Sn}$ and ${ }^{115} \mathrm{Sn}$ measured in run 3 with $100 \mathrm{keV}$ maximum neutron energy and an event multiplicity $>2$. (The original resolution of $128 \times 2048$ channels was compressed into $64 \times 64$ channels for better readability. Events at low sum energy and large TOF were cut off by the preprocessing unit of the ADC system). 


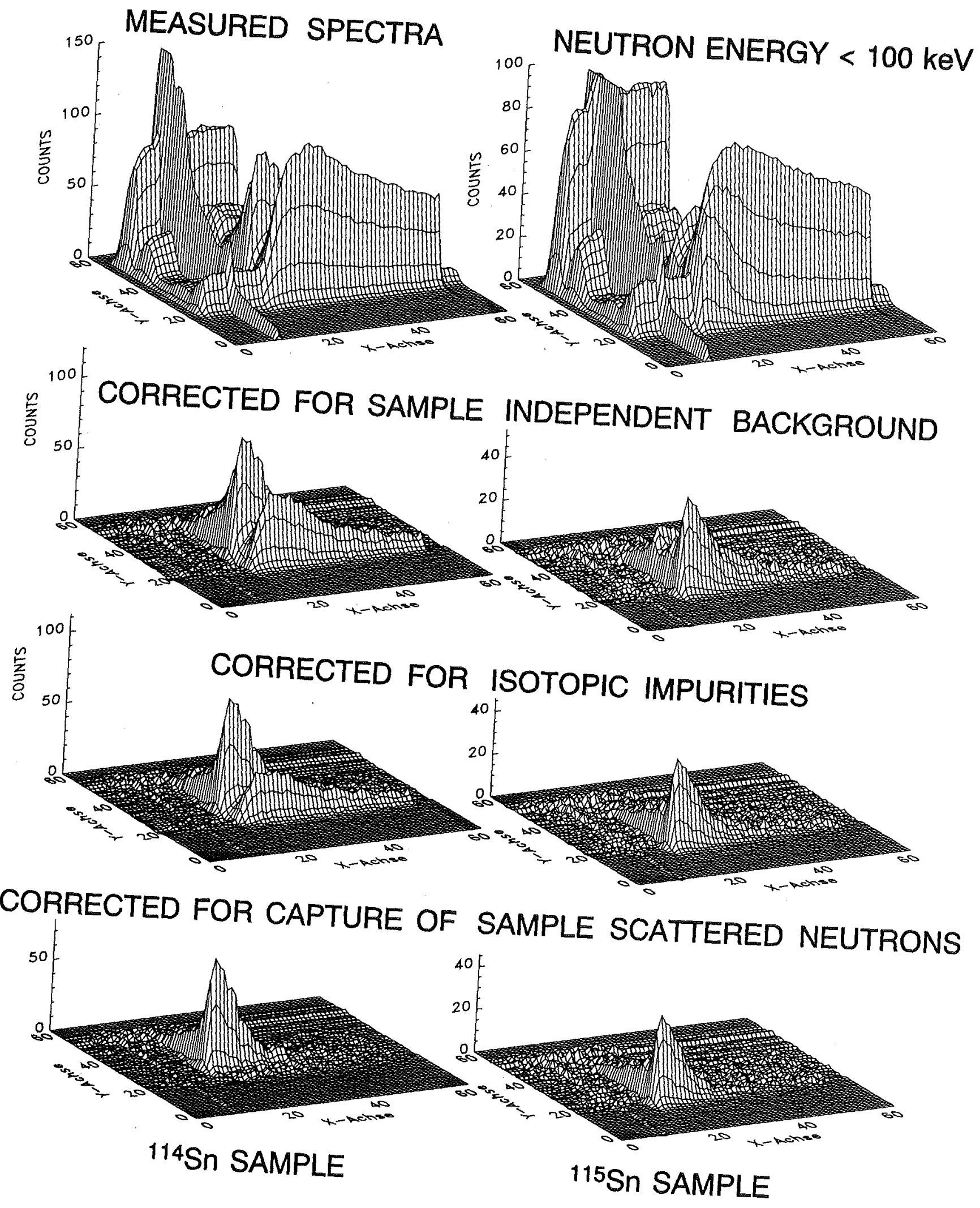



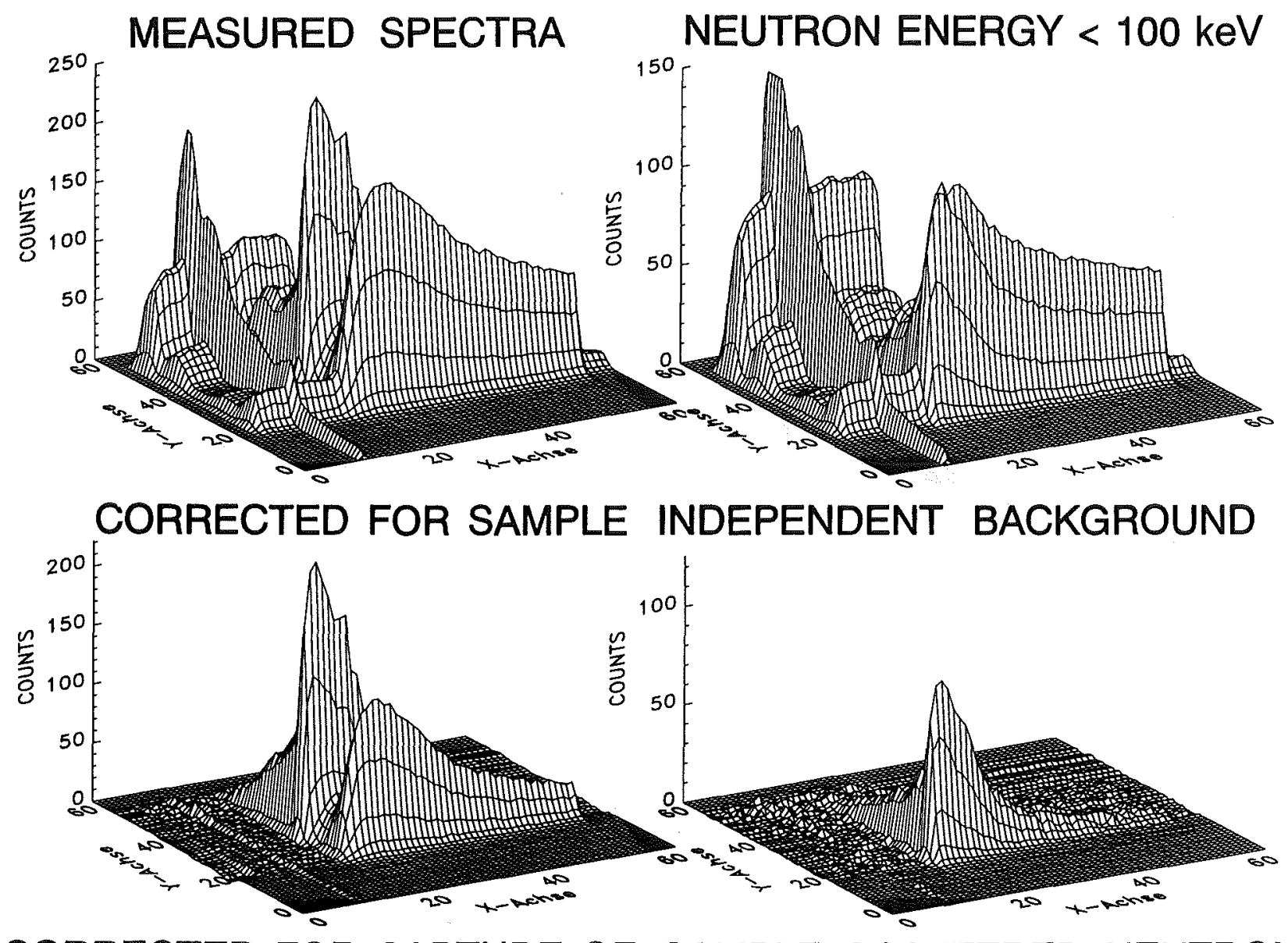

CORRECTED FOR CAPTURE OF SAMPLE SCATTERED NEUTRONS

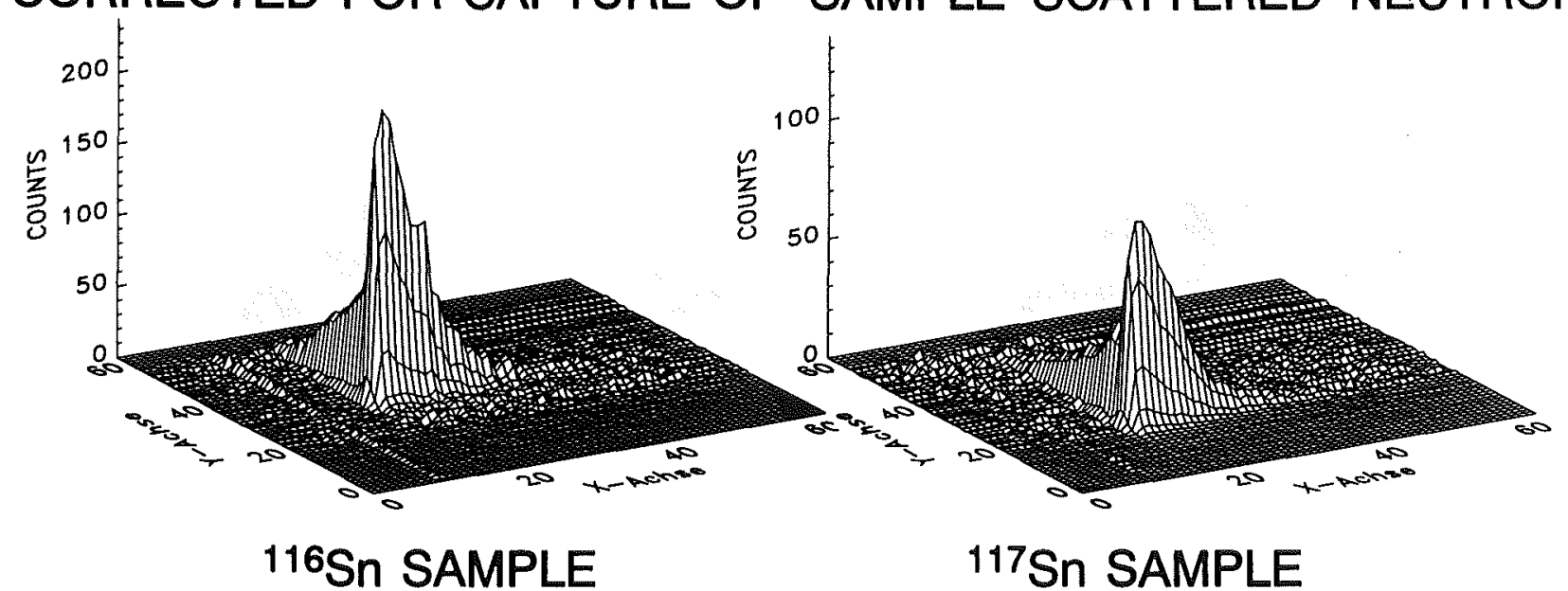

Figure 3: The same as Fig. 2 but for the ${ }^{116} \mathrm{Sn}$ and ${ }^{117} \mathrm{Sn}$ samples. The correction for isotopic impurities was omitted since the difference is not visible in these spectra. 


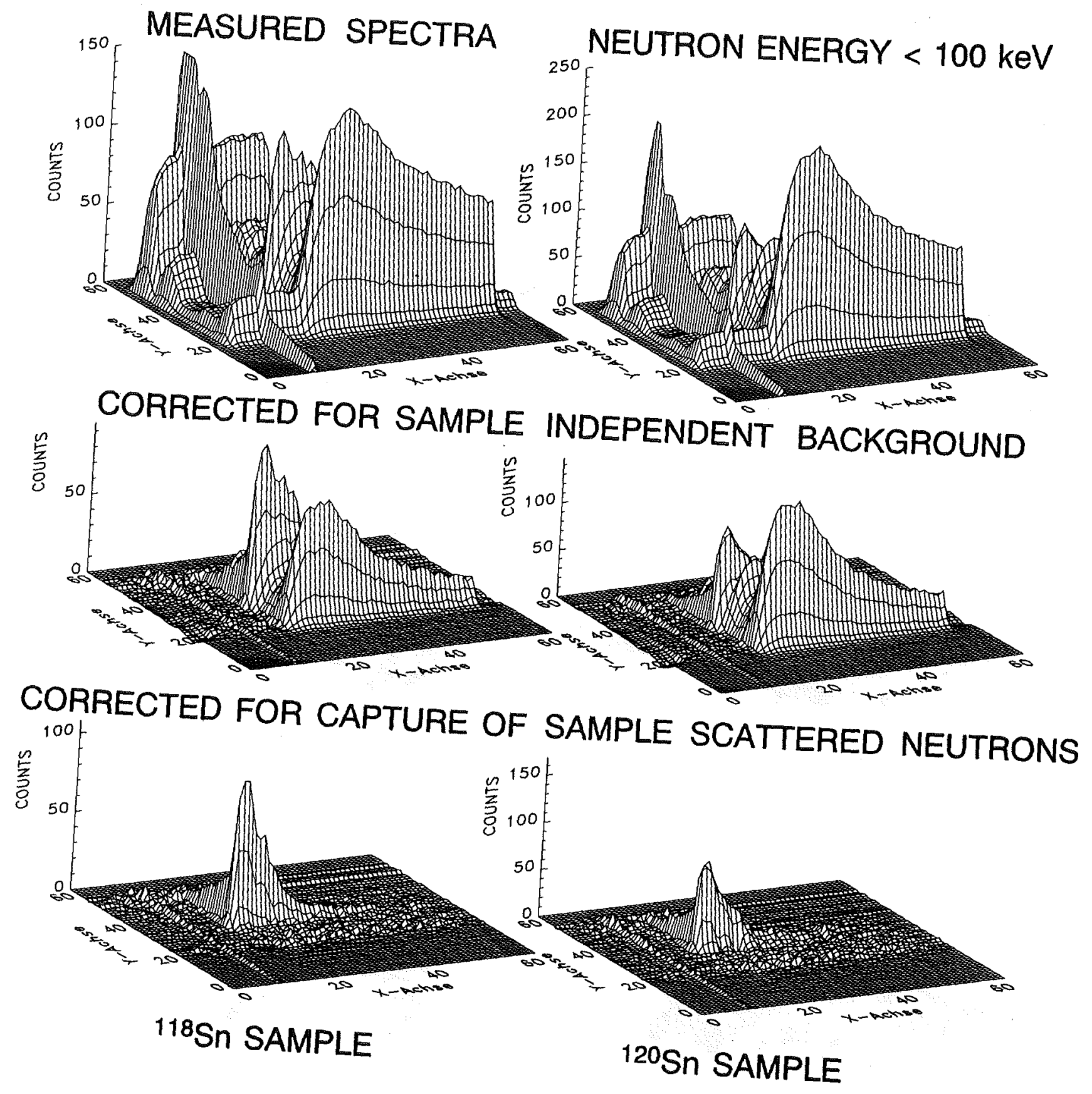

Figure 4: The same as Fig. 3 but for the ${ }^{118} \mathrm{Sn}$ and ${ }^{120} \mathrm{~S}$ samples. 


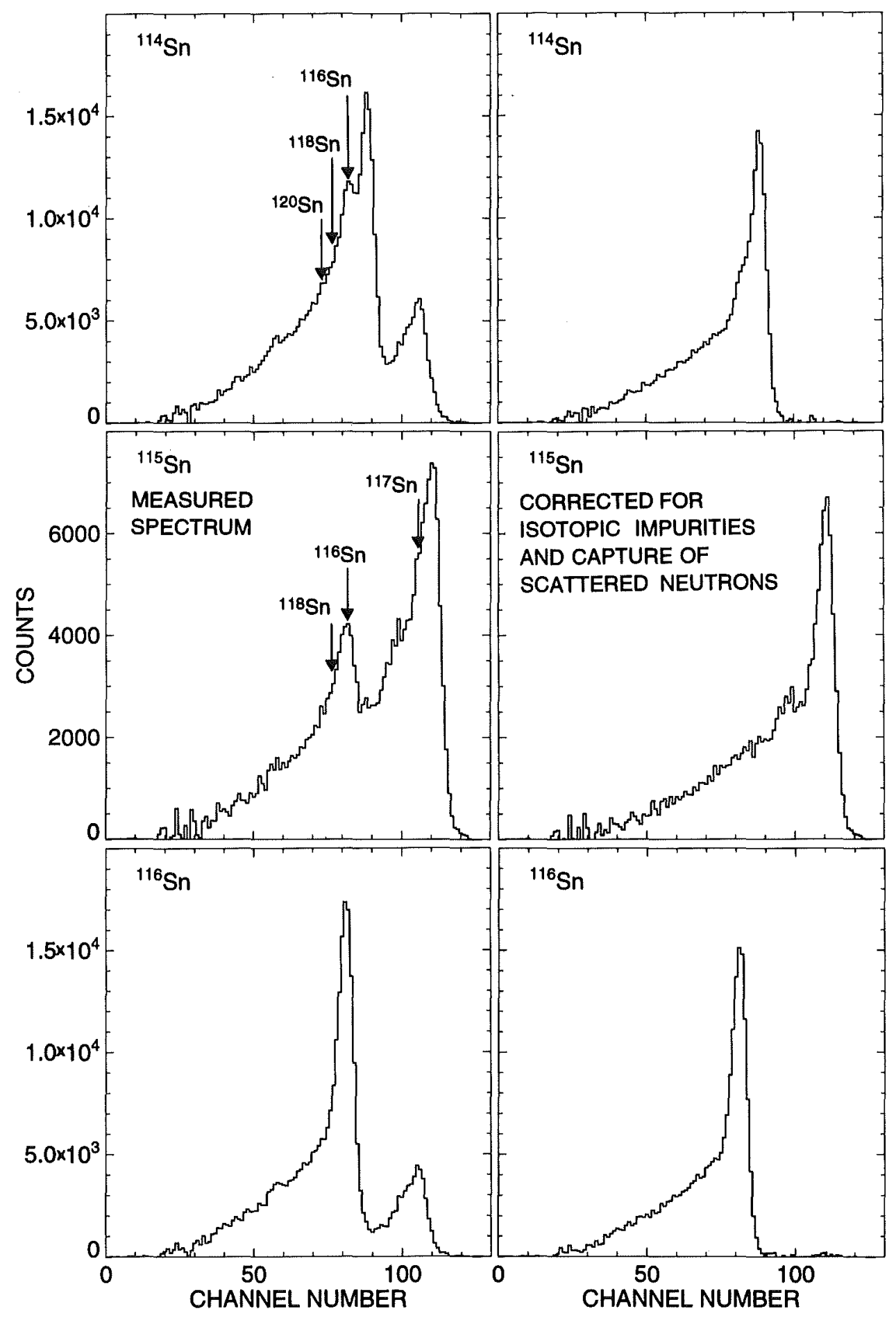

Figure 5: Sum energy spectra of the ${ }^{114} \mathrm{Sn},{ }^{115} \mathrm{Sn}$, and ${ }^{116} \mathrm{Sn}$ samples before and after correction for isotopic impurities and capture of scattered neutrons. 


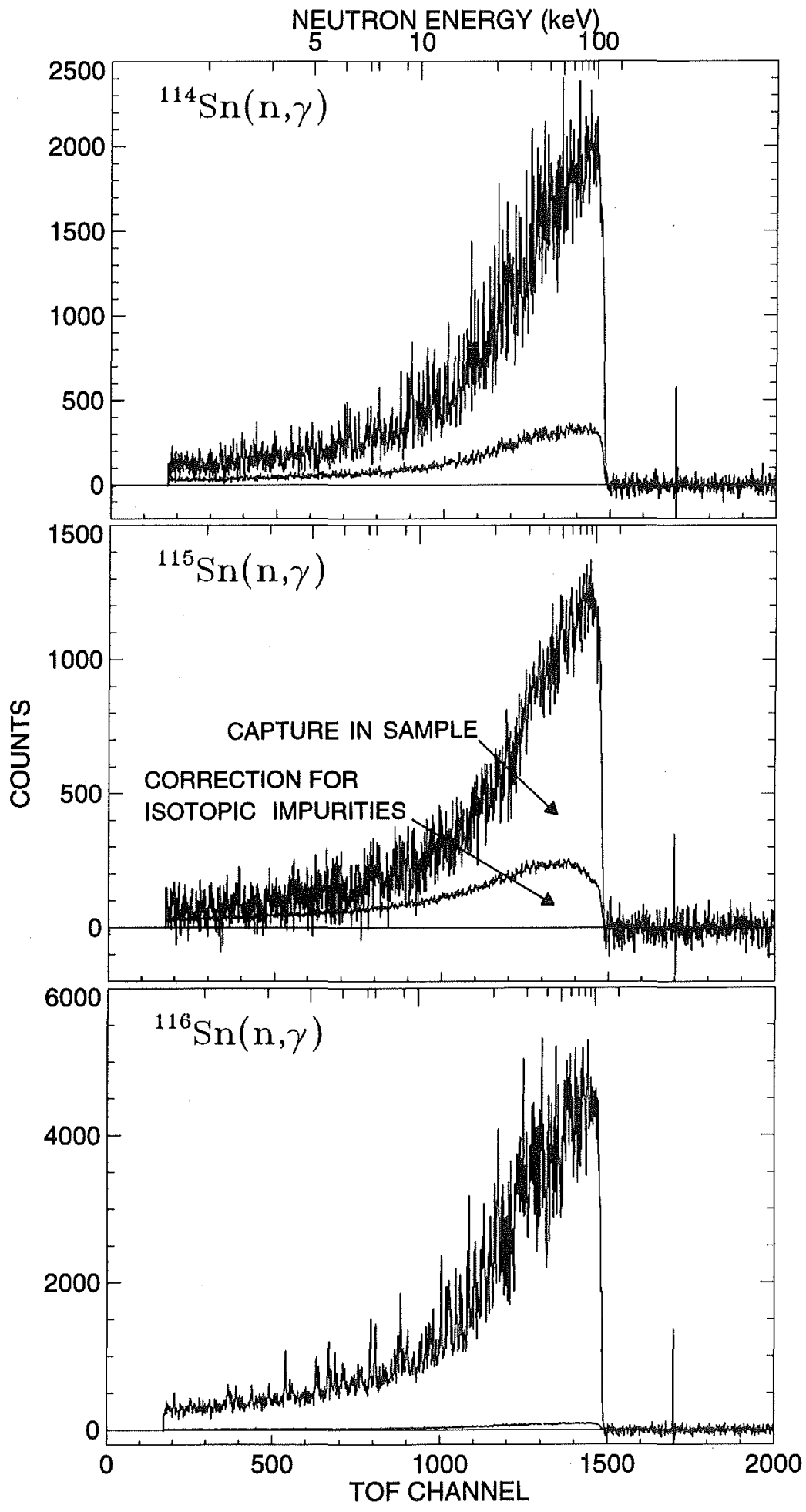

Figure 6: TOF spectra of the ${ }^{114} \mathrm{Sn},{ }^{115} \mathrm{Sn}$, and ${ }^{116} \mathrm{Sn}$ samples. The background due to isotopic impurities is shown separately. 
Table 7: SIGNAL/BACKGROUND RATIO FOR RUNS WITH DIFFERENT MAXIMUM NEUTRON ENERGY

\begin{tabular}{lccccc}
\hline Sample & $\begin{array}{c}\sigma_{t} / \sigma_{\gamma} \\
\text { at } 30 \mathrm{keV}\end{array}$ & $\begin{array}{c}\text { Maximum Neutron } \\
\text { Energy (keV) }\end{array}$ & \multicolumn{3}{c}{$\begin{array}{c}\text { Signal/Background ratio } \\
\text { neutron energy }\end{array}$} \\
& & & 30 & 20 & 10 \\
\hline${ }^{114} \mathrm{Sn}$ & 52.0 & 100 & 3.1 & 2.2 & 1.8 \\
${ }^{115} \mathrm{Sn}$ & 7.6 & & 4.1 & 2.6 & 1.7 \\
${ }^{116} \mathrm{Sn}$ & 58.5 & & 2.7 & 1.7 & 1.4 \\
${ }^{117} \mathrm{Sn}$ & 16.8 & & 4.5 & 2.6 & 1.6 \\
${ }^{118} \mathrm{Sn}$ & 86.2 & & 2.3 & 1.7 & 1.5 \\
${ }^{120} \mathrm{Sn}$ & 175. & & 1.9 & 1.5 & 1.5 \\
${ }^{197} \mathrm{Au}$ & 24.0 & & 10.1 & 4.4 & 3.1 \\
& & & & & \\
${ }^{114} \mathrm{Sn}$ & & 200 & 2.6 & 2.0 & 1.6 \\
${ }^{115} \mathrm{Sn}$ & & & 3.2 & 2.0 & 1.3 \\
${ }^{116} \mathrm{Sn}$ & & & 2.3 & 1.6 & 1.4 \\
${ }^{117} \mathrm{Sn}$ & & & 3.0 & 2.0 & 1.3 \\
${ }^{118} \mathrm{Sn}$ & & & 2.0 & 1.6 & 1.4 \\
${ }^{120} \mathrm{Sn}$ & & & 1.7 & 1.4 & 1.4 \\
${ }^{197} \mathrm{Au}$ & & & 8.2 & 3.8 & 3.0 \\
\hline
\end{tabular}

${ }^{1}$ the ratios are defined as (effect+background)/background

It is obvious from the spectra of Fig. 7 that individual resonances are resolved in the spectra of ${ }^{116} \mathrm{Sn},{ }^{118} \mathrm{Sn}$, and ${ }^{120} \mathrm{Sn}$ below $10 \mathrm{keV}$ neutron energy. Individual resonance parameters will be extracted from this part of the spectra by a shape analysis program as for ${ }^{136} \mathrm{Ba}$ [23]. However, since the stellar cross section of ${ }^{136} \mathrm{Ba}$ was practically independent of how it was determined, from the resonance parameters and simply by averaging the observed yield, this is likely to hold for the tin isotopes, as well.

After subtraction of the background from scattered neutrons, the TOF spectra of Fig.7 were used to determine the cross section shape. For normalization, the two-dimensional data were projected onto the sum energy axis using the TOF region of optimum signal to background ratio as indicated in Fig.7 by dashed boxes. The resulting pulse height spectra are shown in Fig. 8 for the events with multiplicity $>2$. Note, that the threshold in sum energy could be lowered to $1.6 \mathrm{MeV}$.

In Fig.9, the sum energy spectra of the tin isotopes are shown for different multiplicities. These multiplicities correspond to the number of detector modules contributing per event. The true multiplicities are slightly smaller, because of cross talking effects. In the even isotopes, 30 to $40 \%$ of the capture events are observed with multiplicities $\geq 5$, while the respective fraction in the odd isotopes is about 60\%. The arrows in Fig. 9 indicate the range of sum energy channels that were integrated to obtain the TOF spectra of Fig. 7, from which the cross section shapes were determined.

Following the spectra of the even isotopes in Fig. 9, there is a systematic trend towards lower multiplicities with increasing mass number due to the decreasing level density in 
the compound nucleus. Of all isotopes investigated so far with the $4 \pi \mathrm{BaF}_{2}$ detector, ${ }^{120} \mathrm{Sn}$ represents a remarkable extreme with $14 \%$ of the capture events being observed with multiplicity one.

The cross section ratio of isotope $X$ relative to the gold standard is given by

$$
\frac{\sigma_{i}(X)}{\sigma_{i}(A u)}=\frac{Z_{i}(X)}{Z_{i}(A u)} \cdot \frac{\Sigma Z(A u)}{\Sigma Z(X)} \cdot \frac{\Sigma E(X)}{\Sigma E(A u)} \cdot \frac{m(A u)}{m(X)} \cdot F_{1} \cdot F_{2}
$$

In this expression, $Z_{i}$ is the count rate in channel $i$ of the TOF spectrum, $\Sigma Z$ is the TOF rate integrated over the interval used for normalization (Fig.7), $\Sigma \mathrm{E}$ is the total count rate in the sum energy spectrum for all multiplicities summed over the normalization interval (Fig.8), and $m$ is the sample thickness in atoms/barn. The factor $F_{1}=(100-f(A u)) /(100-$ $f(X))$ corrects for the fraction of capture events $f$ below the experimental threshold in sum energy, where $X$ refers to the respective tin sample (Table 8), and $F_{2}$ is the ratio of the multiple scattering and self-shielding corrections .

The fraction of unobserved capture events, $f$, and the correction factor $F_{1}$ were calculated as described in detail in Ref.[20]. The required input for this calculation are the individual neutron capture cascades and their relative contributions to the total capture cross section as well as the detector efficiency for monoenergetic $\gamma$-rays in the energy range up to $10 \mathrm{MeV}$. Capture cascades and capture $\gamma$-ray spectra of the involved isotopes, were calculated according to the statistical and optical models [24] as in the previous measurements with the $4 \pi \mathrm{BaF}_{2}$ detector $[7,8,9]$, The calculations are based on the Hauser Feshbach approach. In Table 9, the cross sections are given as a function of cascade multiplicity together with the $\gamma$-ray energies of the 20 most probable cascades. The capture gamma-ray spectra are shown in Fig. 10. In contrast to the barium experiment [9] where the intensity of cascades with multiplicity 1 was well reproduced, the calculated values for the even tin isotopes are lower by a factor of two compared to the experimental results in Fig. 9. This indicates either a strong nuclear structure effect or a significant contribution from the direct capture channel.

According to Table 9, less than 40 cascades were required to cover $95 \%$ of the capture cross section of the even tin isotopes ${ }^{116,118,120} \mathrm{Sn}$ due to the low binding energies and level densities. The limited number of cascades did not allow to simulate the finite solid angle of the $4 \pi \mathrm{BaF}_{2}$ detector by randomly neglecting some gamma transitions. Instead, the spectrum fraction $\mathrm{f}$ was calculated for all isotopes assuming a solid angle of $\Omega=1.0$, without neglecting any transitions. This calculation was repeated as described in Ref. [9] with $\Omega=0.94$ for the three isotopes ${ }^{114,115,117} \mathrm{~S}$ n which exhibit a sufficient number of cascades. The difference $\Delta f=f(\Omega=0.94)-f(\Omega=1.00)$ is plotted versus the binding energy of the respective isotope (filled symbols) in the lower part of Fig. 11.

It was found in all previous experiments with the $4 \pi \mathrm{BaF}_{2}$ detector that both parameters, $f$ as well as the correction factor $F_{1}$, depend linearly on the binding energy of the captured neutron. Therefore, it is plausible that this feature holds also for $\Delta f$, so that these values could be determined for ${ }^{116,118,120} \mathrm{Sn}$ by linear extrapolation (open symbols in the lower part of Fig.11), yielding the $f$-values and the correction factors $F_{1}$ in Table 8. The upper part of Fig. 11 shows the final correction $F_{1}$ versus the binding energy, again confirming a linear dependence. 
Table 8: FRACTION OF UNDETECTED CAPTURE EVENTS, f (\%), AND THE RELATED CORRECTION FACTORS $\mathrm{F}_{1}{ }^{1}$

\begin{tabular}{lccc}
\hline & \multicolumn{3}{c}{ Threshold in Sum Energy $(\mathrm{MeV})$} \\
& 1.5 & 1.6 & 2.0 \\
& & & \\
\hline & & & 5.28 \\
$\mathrm{f}(\mathrm{Au})$ & 3.56 & & 3.28 \\
$\mathrm{f}\left({ }^{114} \mathrm{Sn}\right)$ & 2.06 & & 1.72 \\
$\mathrm{f}\left({ }^{115} \mathrm{Sn}\right)$ & 1.27 & & 4.16 \\
$\mathrm{f}\left({ }^{116} \mathrm{Sn}\right)$ & 2.52 & & 1.59 \\
$\mathrm{f}\left({ }^{117} \mathrm{Sn}\right)$ & 1.14 & & 6.22 \\
$\mathrm{f}\left({ }^{118} \mathrm{Sn}\right)$ & 3.56 & & 6.16 \\
$\mathrm{f}\left({ }^{120} \mathrm{Sn}\right)$ & 3.76 & & \\
& & & \\
\hline & & & \\
$\mathrm{F}_{1}\left({ }^{114} \mathrm{Sn} / \mathrm{Au}\right)$ & 0.985 & 0.984 & 0.979 \\
$\mathrm{~F}_{1}\left({ }^{115} \mathrm{Sn} / \mathrm{Au}\right)$ & 0.977 & 0.974 & 0.964 \\
$\mathrm{~F}_{1}\left({ }^{116} \mathrm{Sn} / \mathrm{Au}\right)$ & 0.989 & 0.989 & 0.988 \\
$\mathrm{~F}_{1}\left({ }^{117} \mathrm{Sn} / \mathrm{Au}\right)$ & 0.976 & 0.973 & 0.963 \\
$\mathrm{~F}_{1}\left({ }^{118} \mathrm{Sn} / \mathrm{Au}\right)$ & 1.000 & 1.002 & 1.010 \\
$\mathrm{~F}_{1}\left({ }^{120} \mathrm{Sn} / \mathrm{Au}\right)$ & 1.002 & 1.003 & 1.009 \\
& & & \\
\hline
\end{tabular}

${ }^{1}$ Solid angle $94 \%, \gamma$-ray threshold $50 \mathrm{keV}$

The efficiency of the $4 \pi \mathrm{BaF}_{2}$ detector was determined experimentally [25] by measuring the response for monoenergetic $\gamma$-rays, which were produced by $(p, \gamma)$-reactions on thin ${ }^{26} \mathrm{Mg},{ }^{30} \mathrm{Si}$, and ${ }^{34} \mathrm{~S}$ targets. In these reactions, certain proton resonances decay predominantly by cascades with only two transitions. Replacing one of the $\mathrm{BaF}_{2}$ modules by a Ge-detector, and looking for $\mathrm{BaF}_{2}-\mathrm{Ge}$-coincidences, two-dimensional spectra, $\mathrm{E}_{\gamma}(\mathrm{Ge})$ versus $\mathrm{E}_{\gamma}\left(\mathrm{BaF}_{2}\right)$, were recorded. The response of the $4 \pi \mathrm{BaF}_{2}$ detector for monoenergetic $\gamma$-rays was then obtained by selecting those events, where the full energy of the complementary $\gamma$-ray is registered in the germanium detector.

Using seven $(p, \gamma)$-resonances and an ${ }^{88} \mathrm{Y}$ source, the line shapes of $20 \gamma$-transitions in the energy range from 0.843 to $8.392 \mathrm{MeV}$ could be determined. These data were used in the calculation of the spectrum fractions, $f$, and of the correction factors, $F_{1}$, given in Table 8. The resulting sum energy spectra shown in Fig. 12 are in good agreement with the experimental spectra of Fig. 8, thus confirming the calculation of the correction factors $F_{1}$.

It is important to note that the lower threshold of $1.6 \mathrm{MeV}$, which became possible replacing the crystals with the highest radium impurities, resulted in a significantly improved detector efficiency. While the fraction of unobserved capture events in the previous measurements of the samarium and barium cross sections $[8,9]$ was $7 \%$ and $6 \%$ for the 


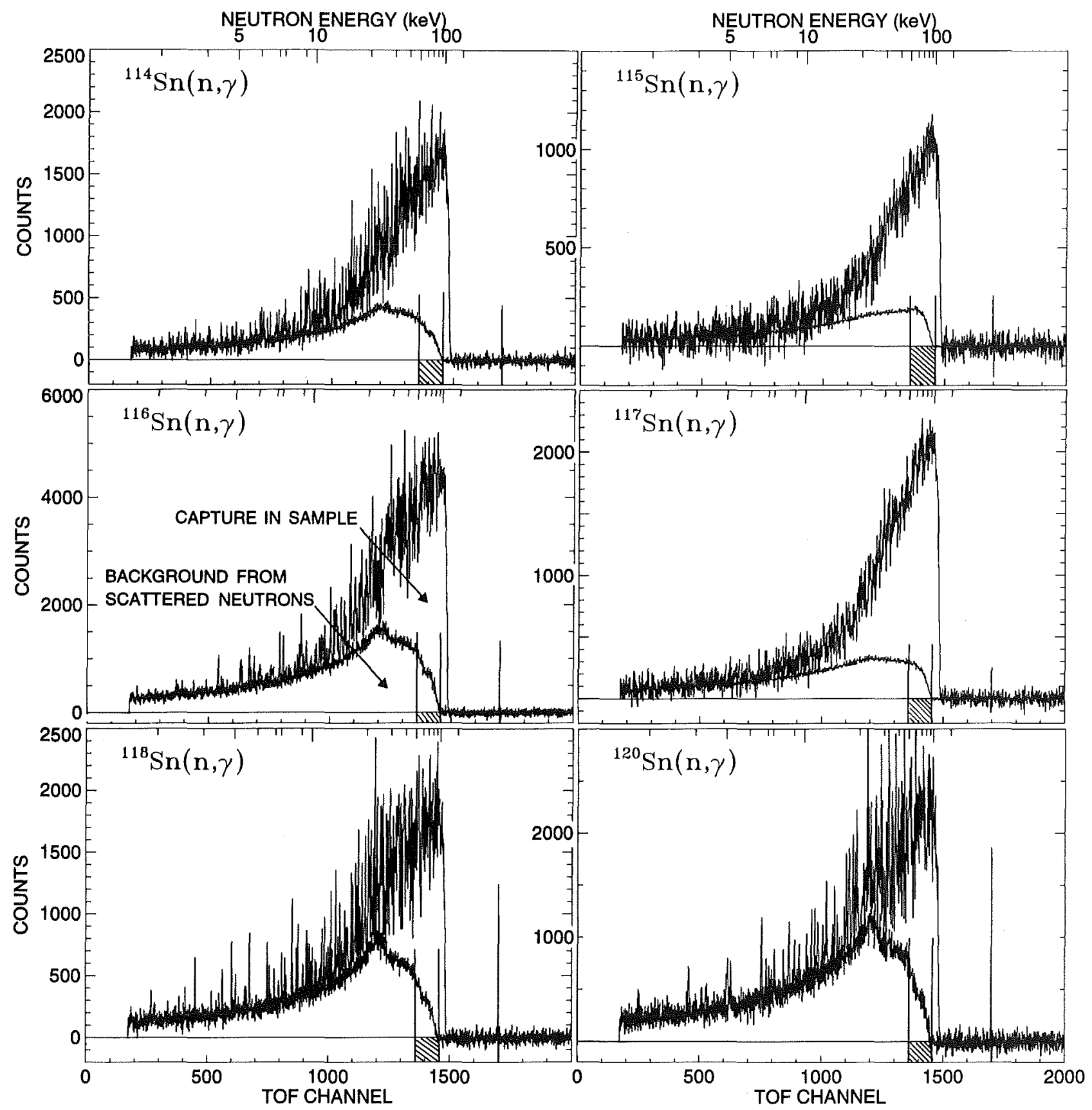

Figure 7: TOF spectra measured with the tin samples in run 3 with $100 \mathrm{keV}$ maximum neutron energy. The background due to sample scattered neutrons is shown separately. The region used for the absolute normalization of the cross section is indicated by hatched boxes. 


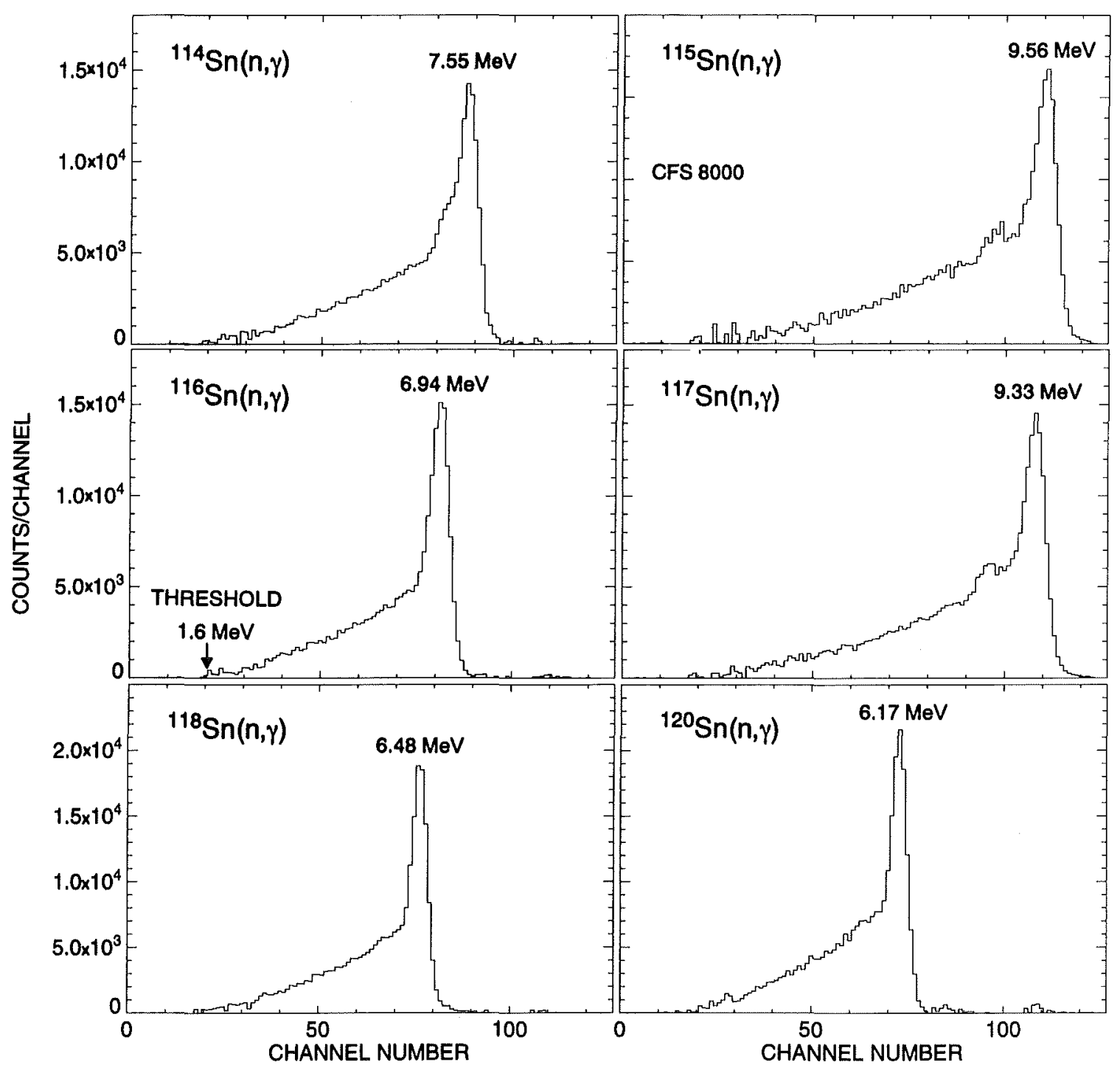

Figure 8: Sum energy spectra of all isotopes measured in run 2 containing events with multiplicity $>2$. These spectra were obtained by projection of the two-dimensional spectra in the TOF region below the maximum neutron energy as indicated by hatched boxes in Fig. 7 


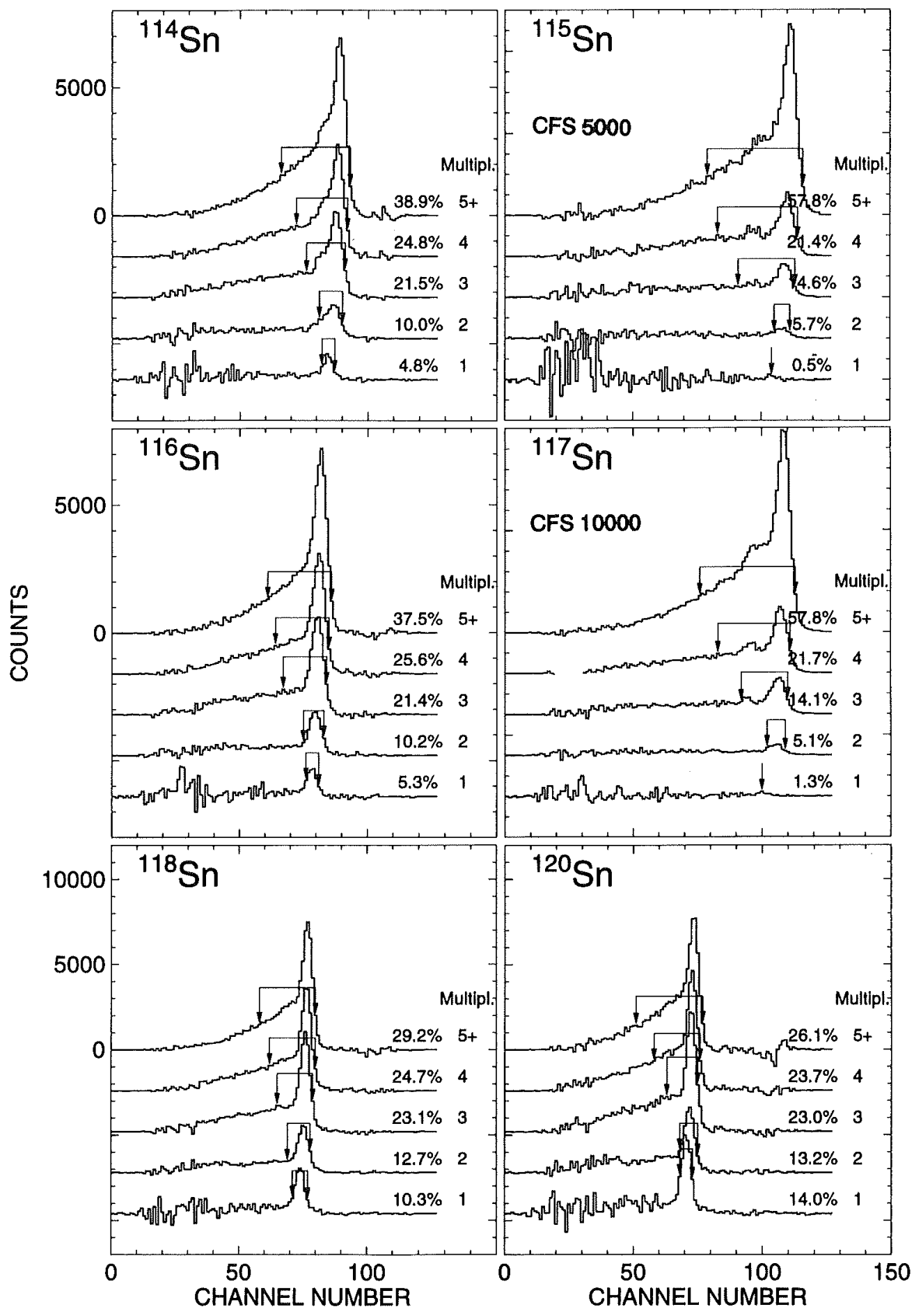

Figure 9: Sum energy spectra of all tin isotopes in dependence of the detector multiplicity. The regions used to determine the cross section shape are indicated by arrows. 
Table 9: CALCULATED CAPTURE $\gamma$-RAY CASCADES INCLUDING MULTIPLICITIES, PARTIAL CROSS SECTIONS, $\sigma_{p}$, AND $\gamma$-RAY ENERGIES OF THE 20 MOST SIGNIFICANT CASCADES

\begin{tabular}{|c|c|c|c|c|c|}
\hline \multicolumn{6}{|c|}{${ }^{114} \mathrm{Sn}$} \\
\hline \multicolumn{2}{|c|}{$\begin{array}{l}\sigma(30 \mathrm{keV})=125 \mathrm{mb} \\
\sigma(\mathrm{mul} \mathrm{1})=3.9 \mathrm{mb} \\
\sigma(\mathrm{mul} \mathrm{2})=34.6 \mathrm{mb} \\
\sigma(\mathrm{mul} \mathrm{3})=52.0 \mathrm{mb} \\
\sigma(\mathrm{mul} 4)=27.1 \mathrm{mb} \\
\sigma(\mathrm{mul} 5)=6.6 \mathrm{mb} \\
\sigma(\mathrm{mul} 6)=0.8 \mathrm{mb}\end{array}$} & \multicolumn{4}{|c|}{ average multiplicity $\langle\mathrm{m}\rangle=3.0$} \\
\hline \multicolumn{6}{|c|}{744 cascades covering $95 \%$ of the cross section } \\
\hline $\begin{array}{l}\sigma_{p} \\
(\mathrm{mb})\end{array}$ & $\begin{array}{c}\sigma_{p} / \sigma \\
(\%)\end{array}$ & $\mathrm{E}_{\gamma 1}$ & $\mathrm{E}_{\gamma 2}$ & $(\mathrm{MeV})^{\mathrm{E}_{\gamma 3}}$ & $\mathrm{E}_{\gamma 4}$ \\
\hline 6.17 & 4.9 & 4.848 & 2.728 & & \\
\hline 4.70 & 3.8 & 4.309 & 3.267 & & \\
\hline 4.00 & 3.2 & 4.848 & 2.231 & 0.497 & \\
\hline 3.71 & 3.0 & 7.576 & & & \\
\hline 3.46 & 2.8 & 4.309 & 2.770 & 0.497 & \\
\hline 3.43 & 2.7 & 3.770 & 3.806 & & \\
\hline 2.75 & 2.2 & 3.770 & 3.308 & 0.497 & \\
\hline 2.57 & 2.1 & 7.079 & 0.497 & & \\
\hline 2.42 & 1.9 & 3.232 & 4.344 & & \\
\hline 2.05 & 1.6 & 3.232 & 3.847 & 0.497 & \\
\hline 1.61 & 1.3 & 2.693 & 4.883 & & \\
\hline 1.42 & 1.1 & 2.693 & 4.386 & 0.497 & \\
\hline 1.39 & 1.1 & 2.693 & 2.155 & 2.728 & \\
\hline 1.39 & 1.1 & 3.232 & 1.616 & 2.728 & \\
\hline 1.21 & 0.97 & 6.296 & 1.280 & & \\
\hline 1.13 & 0.90 & 2.155 & 2.693 & 2.728 & \\
\hline 1.08 & 0.86 & 4.848 & 2.116 & & \\
\hline 1.07 & 0.86 & 3.770 & 1.077 & 2.728 & \\
\hline 1.00 & 0.80 & 2.693 & 2.155 & 2.231 & 0.497 \\
\hline 0.99 & $\Sigma=\underline{0.79}$ & 3.232 & 1.616 & 2.231 & 0.497 \\
\hline
\end{tabular}

${ }^{1}$ normalized to present experimental result 
TABLE 9 (continued)

${ }^{115} \mathrm{Sn}$

$$
\begin{aligned}
& \sigma(100 \mathrm{keV})=356 \mathrm{mb} \text { total capture cross section } \\
& \sigma(\text { mul 1 })=14.1 \mathrm{mb} \\
& \sigma(\text { mul 2) }=36.5 \mathrm{mb} \\
& \sigma(\text { mul } 3)=123.7 \mathrm{mb} \\
& \sigma(\mathrm{mul} 4)=131.7 \mathrm{mb} \quad \text { average multiplicity }<\mathrm{m}>=3.5 \\
& \sigma(\mathrm{mul} 5)=46.4 \mathrm{mb} \\
& \sigma(\mathrm{mul} 6)=3.6 \mathrm{mb}
\end{aligned}
$$

\begin{tabular}{|c|c|c|c|c|c|}
\hline $\begin{array}{l}\sigma_{p} \\
(\mathrm{mb})\end{array}$ & $\begin{array}{c}\sigma_{p} / \sigma \\
(\%)\end{array}$ & $\mathrm{E}_{\gamma 1}$ & $\mathrm{E}_{\gamma 2}$ & ${ }_{(\mathrm{MeV})^{\mathrm{E}_{\gamma 3}}}$ & $\mathrm{E}_{\gamma 4}$ \\
\hline 22.3 & 6.3 & 4.635 & 3.663 & 1.293 & \\
\hline 13.4 & 3.8 & 9.592 & & & \\
\hline 13.1 & 3.7 & 5.298 & 3.001 & 1.293 & \\
\hline 10.9 & 3.1 & 5.298 & 2.538 & 0.463 & 1.293 \\
\hline 8.5 & 2.4 & 8.299 & 1.293 & & \\
\hline 7.7 & 2.1 & 5.960 & 1.875 & 0.463 & 1.293 \\
\hline 6.4 & 1.8 & 5.960 & 1.520 & 2.112 & \\
\hline 6.2 & 1.8 & 3.973 & 4.325 & 1.293 & \\
\hline 5.8 & 1.6 & 5.960 & 2.339 & 1.293 & \\
\hline 5.0 & 1.4 & 3.973 & 5.619 & & \\
\hline 4.9 & 1.4 & 3.311 & 4.988 & 1.293 & \\
\hline 4.9 & 1.4 & 5.960 & 1.520 & 0.819 & 1.293 \\
\hline 4.0 & 1.1 & 3.311 & 6.281 & & \\
\hline 4.0 & 1.1 & 4.635 & 2.587 & 1.076 & 1.293 \\
\hline 4.0 & 1.1 & 5.298 & 2.182 & 2.112 & \\
\hline 3.5 & 0.98 & 2.649 & 5.650 & 1.293 & \\
\hline 3.5 & 0.98 & 2.649 & 1.987 & 3.663 & 1.293 \\
\hline 3.3 & 0.93 & 1.987 & 2.649 & 3.663 & 1.293 \\
\hline 3.2 & 0.90 & 2.649 & 2.649 & 3.001 & 1.293 \\
\hline 3.2 & $\frac{0.89}{-388 \%}$ & 7.835 & 0.463 & 1.293 & \\
\hline
\end{tabular}

341 cascades covering $95 \%$ of the cross section 
${ }^{116} \mathrm{Sn}$

$\sigma(30 \mathrm{keV})=93.5 \mathrm{mb}^{1} \quad$ total capture cross section

$\sigma(\mathrm{mul} \mathrm{1})=2.8 \mathrm{mb}$

$\sigma(\mathrm{mul} \mathrm{2})=20.9 \mathrm{mb}$

$\sigma(\mathrm{mul} \mathrm{3})=58.9 \mathrm{mb}$

average multiplicity $\langle\mathrm{m}\rangle=2.8$

$\sigma(\mathrm{mul} \mathrm{4})=10.9 \mathrm{mb}$

39 cascades covering $95 \%$ of the cross section

$\begin{array}{lccccc}\begin{array}{l}\sigma_{p} \\ (\mathrm{mb})\end{array} & \begin{array}{c}\sigma_{p} / \sigma \\ (\%)\end{array} & \mathrm{E}_{\gamma 1} & \mathrm{E}_{\gamma 2} & \begin{array}{c}\mathrm{E}_{\gamma 3} \\ (\mathrm{MeV})\end{array} & \mathrm{E}_{\gamma 4} \\ 11.7 & 12.5 & 3.650 & 3.165 & 0.158 & \\ 10.5 & 11.2 & 4.171 & 2.644 & 0.158 & \\ 9.2 & 9.8 & 4.693 & 0.977 & 0.990 & \\ 8.1 & 8.7 & 2.607 & 3.063 & 0.990 & \\ 7.6 & 8.1 & 3.128 & 3.845 & & \\ & & & & & \\ 7.3 & 7.8 & 2.086 & 4.888 & & \\ 5.1 & 5.5 & 3.128 & 3.687 & 0.158 & \\ 4.1 & 4.4 & 2.086 & 4.730 & 0.158 & \\ 2.7 & 2.9 & 2.607 & 1.043 & 3.324 & \\ 2.7 & 2.9 & 6.974 & & & \\ & & & & & \\ 2.4 & 2.6 & 6.815 & 0.158 & & \\ 1.8 & 1.9 & 2.607 & 1.043 & 3.166 & 0.158 \\ 1.7 & 1.8 & 1.564 & 3.128 & 0.977 & 0.990 \\ 1.6 & 1.7 & 1.564 & 2.607 & 2.644 & 0.158 \\ 1.3 & 1.4 & 1.564 & 2.086 & 3.165 & 0.158 \\ & & & & & \\ 1.0 & 1.1 & 5.969 & 1.004 & & \\ 0.78 & 0.83 & 1.043 & 3.128 & 2.644 & 0.158 \\ 0.76 & 0.81 & 1.043 & 3.650 & 0.977 & 0.990 \\ 0.75 & 0.80 & 1.043 & 2.607 & 3.165 & 0.158 \\ 0.63 & \underline{0.67} & 5.794 & 1.021 & 0.158 & \\ & \Sigma=87.4 \% & & & & \\ & & & & & \end{array}$

${ }^{1}$ normalized to experimental result 
TABLE 9 (continued)

${ }^{117} \mathrm{Sn}$

$\sigma(100 \mathrm{keV})=340 \mathrm{mb}$ total capture cross section

$\sigma(\mathrm{mul} \mathrm{1})=12.2 \mathrm{mb}$

$\sigma(\mathrm{mul} \mathrm{2})=52.6 \mathrm{mb}$

$\sigma(\mathrm{mul} \mathrm{3})=117.5 \mathrm{mb}$

$\sigma(\mathrm{mul} 4)=122.6 \mathrm{mb} \quad$ average multiplicity $<\mathrm{m}>=3.3$

$\sigma(\mathrm{mul} \mathrm{5})=34.6 \mathrm{mb}$

$\sigma(\mathrm{mul} \mathrm{6})=0.5 \mathrm{mb}$

968 cascades covering $95 \%$ of the cross section

\begin{tabular}{|c|c|c|c|c|c|}
\hline $\begin{array}{l}\sigma_{p} \\
(\mathrm{mb})\end{array}$ & $\begin{array}{l}\sigma_{p} / \sigma \\
(\%)\end{array}$ & $\mathrm{E}_{\gamma \mathbf{1}}$ & $\mathrm{E}_{\gamma^{\prime} 2}$ & $\frac{\mathrm{E}_{\gamma 3}}{(\mathrm{MeV})^{-}}$ & $\mathrm{E}_{\gamma 4}$ \\
\hline 10.1 & 3.0 & 9.356 & & & \\
\hline 8.8 & 2.6 & 5.927 & 2.199 & 1.229 & \\
\hline 7.8 & 2.3 & 5.269 & 2.858 & 1.229 & \\
\hline 7.5 & 2.2 & 5.927 & 3.428 & & \\
\hline 6.8 & 2.0 & 4.610 & 3.516 & 1.229 & \\
\hline 6.3 & 1.9 & 5.269 & 4.087 & & \\
\hline 5.8 & 1.7 & 8.126 & 1.229 & & \\
\hline 5.8 & 1.7 & 3.952 & 4.175 & 1.229 & \\
\hline 5.5 & 1.6 & 4.610 & 4.746 & & \\
\hline 4.7 & 1.4 & 3.952 & 5.404 & & \\
\hline 4.6 & 1.4 & 3.293 & 4.833 & 1.229 & \\
\hline 4.4 & 1.3 & 3.293 & 2.634 & 2.199 & 1.229 \\
\hline 3.9 & 1.1 & 2.634 & 3.293 & 2.199 & 1.229 \\
\hline 3.9 & 1.1 & 3.952 & 1.976 & 2.199 & 1.229 \\
\hline 3.9 & 1.1 & 3.293 & 6.063 & & \\
\hline 3.2 & 0.94 & 2.634 & 5.492 & 1.229 & \\
\hline 3.2 & 0.94 & 3.293 & 2.634 & 3.428 & \\
\hline 3.0 & 0.88 & 3.952 & 1.976 & 3.428 & \\
\hline 2.9 & 0.85 & 2.634 & 6.721 & & \\
\hline 2.7 & $\Sigma=\frac{0.79}{308 \%}$ & 2.634 & 3.293 & 3.428 & \\
\hline
\end{tabular}


TABLE 9 (continued)

${ }^{118} \mathrm{Sn}$

$\sigma(30 \mathrm{keV})=58.3 \mathrm{mb}^{1} \quad$ total capture cross section

$\sigma($ mul 1$)=4.8 \mathrm{mb}$

$\sigma(\mathrm{mul} \mathrm{2})=37.9 \mathrm{mb}$

$\sigma($ mul 3) $=15.2 \mathrm{mb} \quad$ average multiplicity $\langle\mathrm{m}\rangle=2.2$

$\sigma(\mathrm{mul} \mathrm{4})=0.4 \mathrm{mb}$

25 cascades covering $95 \%$ of the cross section)

\begin{tabular}{|c|c|c|c|c|c|}
\hline $\begin{array}{l}\sigma_{p} \\
(\mathrm{mb})\end{array}$ & $\begin{array}{l}\sigma_{p} / \sigma \\
(\%)\end{array}$ & $\mathrm{E}_{\gamma 1}$ & $\mathrm{E}_{\gamma 2}$ & $\frac{\mathrm{E}_{\gamma 3}}{(\mathrm{MeV})}$ & $\mathrm{E}_{\gamma 4}$ \\
\hline 7.0 & 12.0 & 3.594 & 2.896 & 0.024 & \\
\hline 6.2 & 10.6 & 4.621 & 1.869 & 0.024 & \\
\hline 6.2 & 10.6 & 4.108 & 1.317 & 1.066 & 0.024 \\
\hline 6.0 & 10.3 & 2.054 & 4.437 & 0.024 & \\
\hline 5.6 & 9.6 & 3.081 & 2.184 & 1.250 & \\
\hline 3.5 & 6.0 & 2.567 & 3.947 & & \\
\hline 3.4 & 5.8 & 2.567 & 3.923 & 0.024 & \\
\hline 3.3 & 5.7 & 1.540 & 4.950 & 0.024 & \\
\hline 2.3 & 3.9 & 6.514 & & & \\
\hline 2.3 & 3.9 & 6.490 & 0.024 & & \\
\hline 1.6 & 2.7 & 3.081 & 2.184 & 1.226 & 0.024 \\
\hline 1.0 & 1.7 & 1.540 & 4.974 & & \\
\hline 0.98 & 1.7 & 5.454 & 1.060 & & \\
\hline 0.86 & 1.5 & 5.304 & 1.210 & & \\
\hline 0.84 & 1.4 & 5.594 & 0.920 & & \\
\hline 0.74 & 1.3 & 5.326 & 1.164 & 0.024 & \\
\hline 0.64 & 1.1 & 5.265 & 1.250 & & \\
\hline 0.55 & 0.94 & 5.425 & 1.066 & 0.024 & \\
\hline 0.50 & 0.86 & 5.593 & 0.897 & 0.024 & \\
\hline 0.39 & $\underline{\Sigma}=\frac{0.67}{92.3 \%}$ & 4.108 & 1.317 & 1.089 & \\
\hline
\end{tabular}

${ }^{1}$ normalized to experimental result 
${ }^{120} \mathrm{Sn}$

$\sigma(100 \mathrm{keV})=31.1 \mathrm{mb}$ total capture cross section

$\sigma(\mathrm{mul} \mathrm{1})=1.8 \mathrm{mb}$

$\sigma(\mathrm{mul} \mathrm{2})=17.9 \mathrm{mb}$

$\sigma(\mathrm{mul} \mathrm{3})=9.1 \mathrm{mb}$

$\sigma(\mathrm{mul} 4)=2.3 \mathrm{mb} \quad$ average multiplicity $<\mathrm{m}>=2.4$

17 cascades covering $95 \%$ of the cross section)

\begin{tabular}{lccccc}
$\begin{array}{l}\sigma_{p} \\
(\mathrm{mb})\end{array}$ & $\begin{array}{c}\sigma_{p} / \sigma \\
(\%)\end{array}$ & $\mathrm{E}_{\gamma 1}$ & $\mathrm{E}_{\gamma 2}$ & $\begin{array}{c}\mathrm{E}_{\gamma 3} \\
(\mathrm{MeV})\end{array}$ & $\mathrm{E}_{\gamma 4}$ \\
3.6 & 11.6 & 3.543 & 1.709 & 0.943 & \\
3.6 & 11.4 & 2.531 & 3.664 & & \\
3.4 & 10.9 & 4.049 & 2.146 & & \\
3.3 & 10.5 & 3.037 & 2.239 & 0.925 & \\
2.2 & 7.2 & 2.024 & 4.170 & & \\
& & & & & \\
2.2 & 7.1 & 1.518 & 2.530 & 1.203 & 0.943 \\
1.7 & 5.5 & 6.201 & & & \\
1.7 & 5.4 & 4.555 & 1.646 & & \\
1.6 & 5.1 & 6.141 & 0.060 & & \\
1.5 & 4.9 & 4.555 & 1.640 & & \\
& & & & & \\
0.99 & 3.2 & 1.012 & 4.240 & 0.943 & \\
0.83 & 2.6 & 2.024 & 3.513 & 0.657 & \\
0.81 & 2.6 & 5.292 & 0.909 & & \\
0.72 & 2.3 & 5.179 & 1.022 & \\
0.68 & 2.2 & 5.332 & 0.869 & & \\
& & & & \\
0.43 & 1.4 & 5.100 & 1.101 & \\
0.37 & 1.2 & 5.081 & 1.120 & \\
& $\Sigma=95.1 \%$ & & & \\
\hline
\end{tabular}




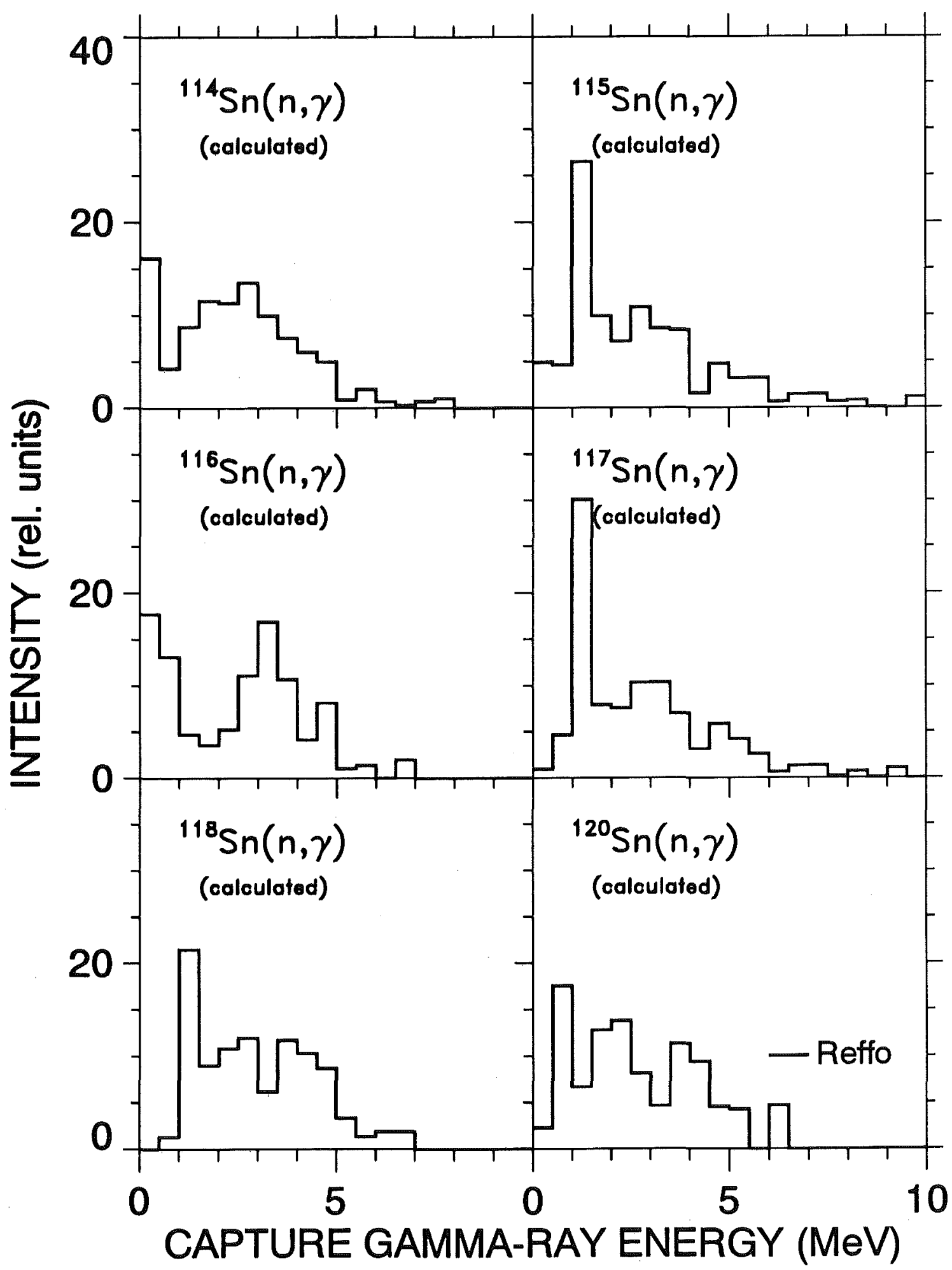

Figure 10: Calculated capture $\gamma$-ray spectra for the tin isotopes. 


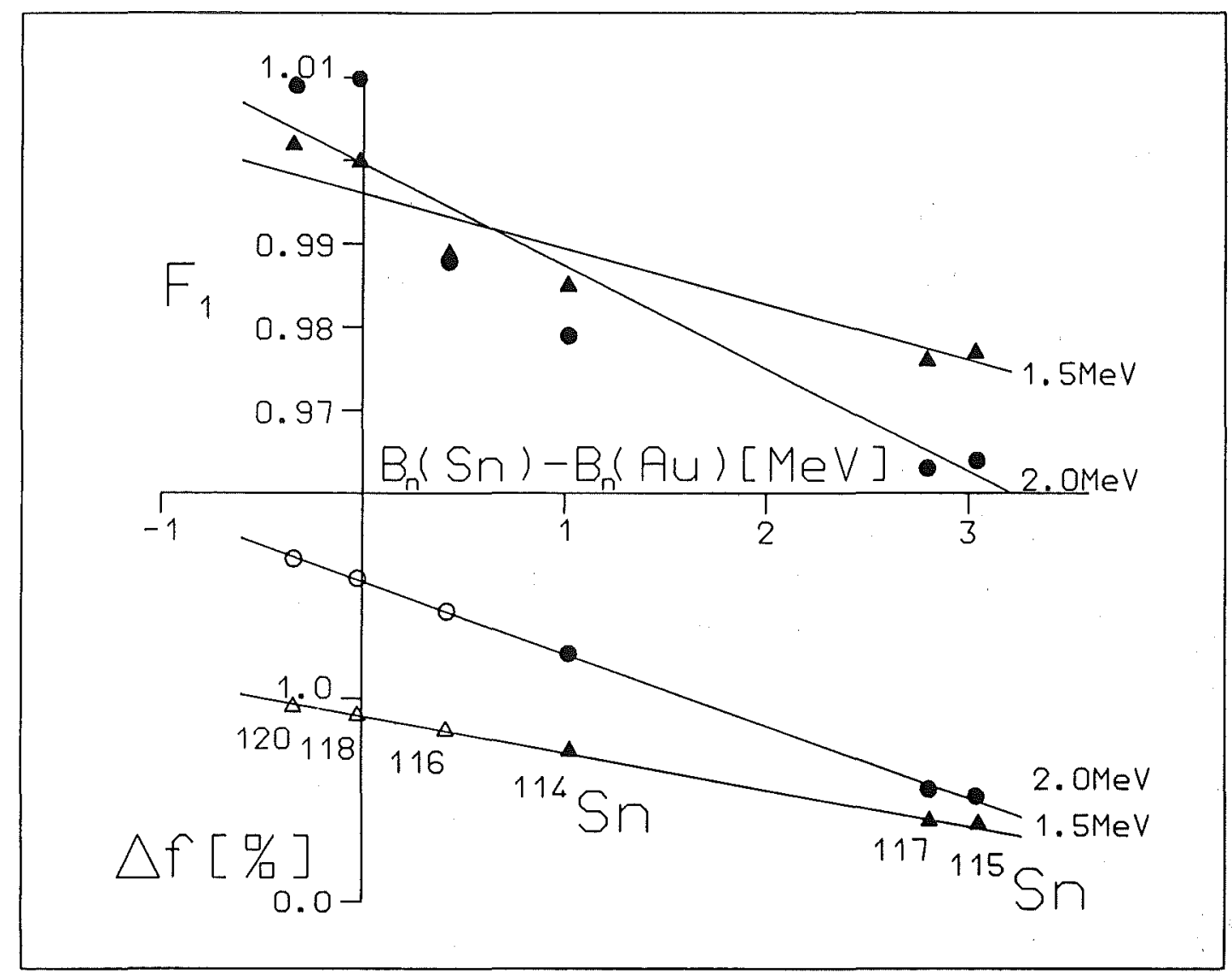

Figure 11: The correction $\mathrm{F}_{1}$ for unobserved capture events, plotted versus the difference in binding energy between the investigated tin isotopes and the gold standard for two different sum energy thresholds (top), and the difference $\Delta f=f(\Omega=0.94)-f(\Omega=1.00)$ (bottom). Calculated values are indicated by closed symbols, open symbols denote extrapolated values.

even isotopes, respectively, values of $2-4 \%$ could now be reached.

The correction for neutron multiple scattering and self-shielding was calculated with the SESH code [21]. Apart from the pairing energies [26], most of the input parameters were adopted from the work of Timokhov et al. [11], who determined these data sets by fitting their measured capture and total cross sections. The good agreement of these cross sections and the present results justifies the choice of these parameters, which are listed in Table 10 together with the calculated total cross sections. The resulting correction factors, $\mathrm{MS}(\mathrm{X})$ and $\mathrm{F}_{2}$, are compiled in Tables 11 and 12 .

For the ${ }^{114} \mathrm{~S} n$ and ${ }^{115} \mathrm{~S} n$ samples, however, these corrections required special considerations because of the low isotopic enrichments of $70.2 \%$ and $45.3 \%$, respectively. They could be calculated either for the true composition of the sample or for that part which remains after the correction for isotopic impurities. Since most samples of the present experiment are very similar in weight and in size, it could be assumed, that subtraction of the isotopic impurities via the spectra of the other samples accounts for the respective contributions to the multiple scattering corrections as well. Therefore, these corrections were calculated as if the two samples consisted of the main isotopes, ${ }^{114} \mathrm{Sn}$ or ${ }^{115} \mathrm{Sn}$, only. 
In general, these corrections are small, e.g. below $2 \%$ for ${ }^{114,115,117} \mathrm{Sn}$, the thin ${ }^{116} \mathrm{Sn}$ sample, and for the gold sample, but can be sizable for the other samples as well as at energies below $10 \mathrm{keV}$. The calculations can be checked via the results obtained for the two ${ }^{116} \mathrm{Sn}$ samples, in particular below $20 \mathrm{keV}$, where the differences are large enough to produce a significant effect on the observed count rates.

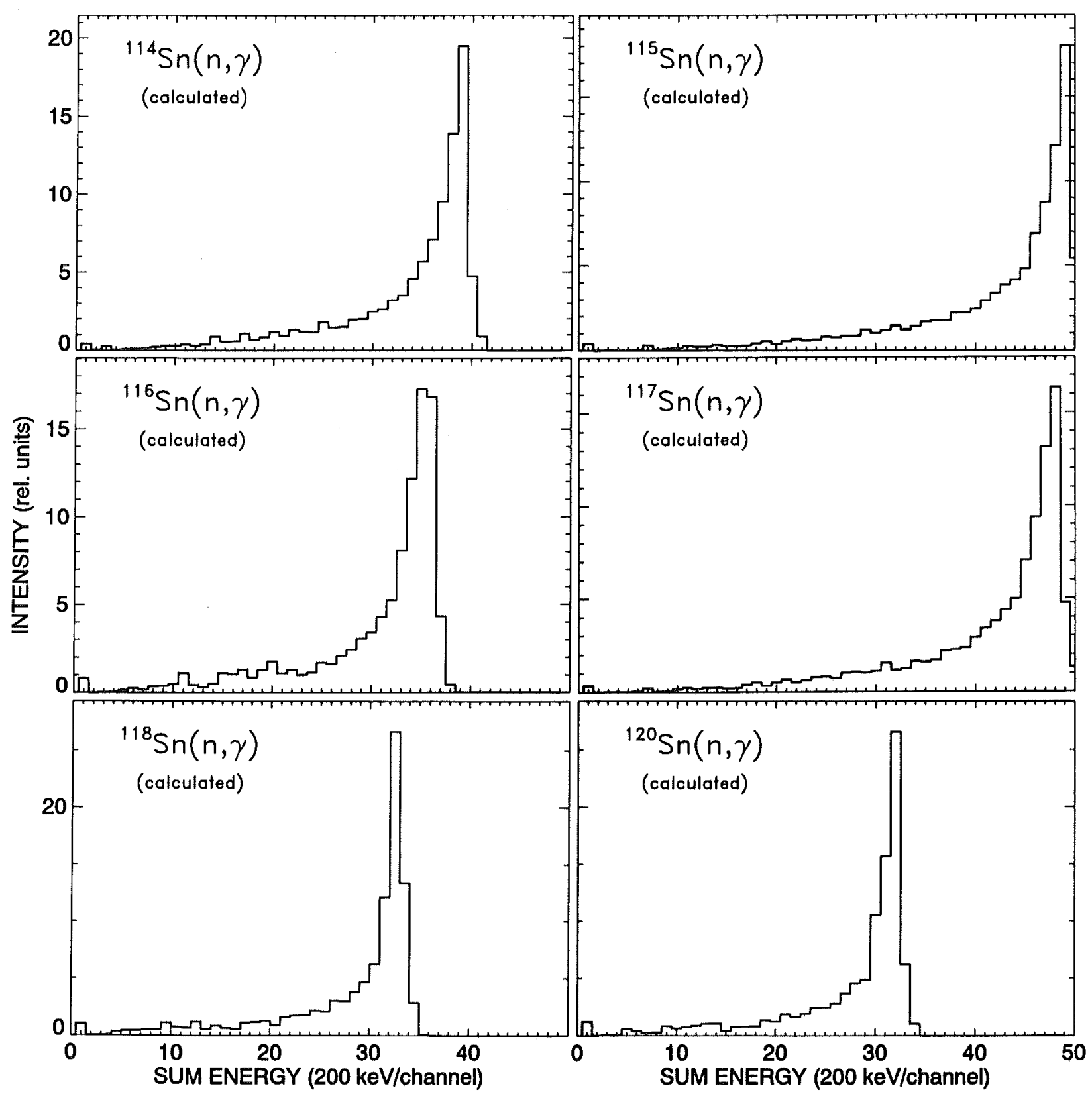

Figure 12: Calculated sum energy spectra of the $4 \pi \mathrm{BaF}_{2}$ detector based on the measured lineshapes. These spectra were used to derive the correction $F_{1}$ for unobserved capture events. 
Table 10: PARAMETERS FOR THE CALCULATION OF NEUTRON SELFSHIELDING AND MULTIPLE SCATTERING CORRECTIONS

\begin{tabular}{|c|c|c|c|c|c|c|c|}
\hline Parameter & & ${ }^{114} \mathrm{Sn}$ & ${ }^{115} \mathrm{Sn}$ & ${ }^{116} \mathrm{Sn}$ & ${ }^{117} \mathrm{Sn}$ & ${ }^{118} \mathrm{Sn}$ & ${ }^{120} \mathrm{Sn}$ \\
\hline Nucleon Number & & 114 & 115 & 116 & 117 & 118 & 120 \\
\hline Binding Energy (MeV) & & 7.546 & 9.562 & 6.944 & 9.326 & 6.484 & 6.172 \\
\hline Pairing Energy (MeV) & & 1.19 & 2.51 & 1.19 & 2.34 & 1.19 & 1.19 \\
\hline Effective Temperature (K) & & 293 & 293 & 293 & 293 & 293 & 293 \\
\hline Nuclear Spin & & 0 & 0.5 & 0 & 0.5 & 0 & 0 \\
\hline Average Radiation & $\mathrm{s}$ & 0.09 & 0.09 & 0.09 & 0.09 & 0.09 & 0.09 \\
\hline Width $(\mathrm{eV})$ & $\mathrm{p}$ & 0.08 & 0.08 & 0.08 & 0.08 & 0.08 & 0.08 \\
\hline Average Level & s & 345. & 46. & 540. & 58. & 800 & 1610 \\
\hline Spacing $(e V)$ & $\mathrm{p}^{1}$ & 115 & 20.4 & 180. & 25.8 & 267 & 537 \\
\hline Strength Function & $\mathrm{S}_{0}$ & 0.2 & 0.3 & 0.18 & 0.21 & 0.16 & 0.14 \\
\hline$\left(10^{-4}\right)$ & $\mathrm{S}_{1}$ & 2.8 & 3.8 & 2.3 & 2.6 & 2.1 & 1.6 \\
\hline Nuclear Radius & $\mathrm{s}$ & 5.9 & 5.7 & 5.8 & 5.9 & 5.6 & 6.1 \\
\hline$(\mathrm{fm})$ & $\mathrm{p}$ & 7.8 & 7.9 & 8.2 & 8.5 & 8.5 & 8.7 \\
\hline Neutron Energy (keV) & & \multicolumn{6}{|c|}{ Calculated total cross sections (b) } \\
\hline 3 & & 6.29 & 6.90 & 5.92 & 6.34 & 5.46 & 5.97 \\
\hline 5 & & 6.05 & 6.54 & 5.70 & 6.08 & 5.27 & 5.79 \\
\hline 10 & & 5.90 & 6.29 & 5.55 & 5.90 & 5.14 & 5.65 \\
\hline 20 & & 5.91 & 6.28 & 5.54 & 5.88 & 5.14 & 5.62 \\
\hline 100 & & 6.36 & 6.91 & 5.88 & 6.26 & 5.48 & 5.76 \\
\hline 200 & & 6.56 & 7.23 & 6.04 & 6.43 & 5.66 & 5.82 \\
\hline 300 & & 6.59 & 7.29 & 6.08 & 6.45 & 5.72 & 5.80 \\
\hline
\end{tabular}

${ }^{1}$ Calculated with the SESH code [21]

Table 11: CORRECTION FACTORS FOR NEUTRON SELF-SHIELDING AND MULTIPLE SCATTERING, MS

\begin{tabular}{ccccccccc}
\hline $\begin{array}{c}\text { Neutron Energy Range } \\
(\mathrm{keV})\end{array}$ & ${ }^{197} \mathrm{Au}$ & ${ }^{114} \mathrm{Sn}$ & ${ }^{115} \mathrm{Sn}$ & ${ }^{116} \mathrm{Sn}^{1}$ & ${ }^{117} \mathrm{Sn}$ & ${ }^{118} \mathrm{Sn}$ & ${ }^{120} \mathrm{Sn}$ \\
\hline $3-5$ & 1.004 & 0.950 & 0.998 & 0.819 & 0.927 & 0.998 & 0.855 & 0.710 \\
$5-7.5$ & 1.014 & 0.972 & 1.000 & 0.874 & 0.953 & 1.002 & 0.898 & 0.770 \\
$7.5-10$ & 1.019 & 0.984 & 1.002 & 0.907 & 0.969 & 1.004 & 0.923 & 0.809 \\
$10-12.5$ & 1.023 & 0.992 & 1.003 & 0.927 & 0.978 & 1.005 & 0.939 & 0.835 \\
$12.5-15$ & 1.023 & 0.996 & 1.004 & 0.941 & 0.984 & 1.006 & 0.950 & 0.855 \\
$15-20$ & 1.022 & 1.000 & 1.005 & 0.955 & 0.991 & 1.008 & 0.962 & 0.876 \\
$20-25$ & 1.021 & 1.004 & 1.006 & 0.968 & 0.996 & 1.009 & 0.972 & 0.897 \\
$25-30$ & 1.020 & 1.006 & 1.006 & 0.976 & 0.999 & 1.010 & 0.978 & 0.912 \\
$30-40$ & 1.018 & 1.007 & 1.007 & 0.984 & 1.003 & 1.010 & 0.985 & 0.929 \\
\hline
\end{tabular}


Table 11 continued

\begin{tabular}{ccccccccc}
\hline $40-50$ & 1.017 & 1.008 & 1.007 & 0.991 & 1.005 & 1.011 & 0.991 & 0.945 \\
$50-60$ & 1.015 & 1.009 & 1.007 & 0.996 & 1.007 & 1.011 & 0.995 & 0.956 \\
$60-80$ & 1.013 & 1.009 & 1.007 & 1.001 & 1.008 & 1.011 & 0.999 & 0.969 \\
$80-100$ & 1.012 & 1.010 & 1.007 & 1.006 & 1.010 & 1.011 & 1.003 & 0.981 \\
$100-120$ & 1.011 & 1.010 & 1.007 & 1.010 & 1.011 & 1.011 & 1.006 & 0.990 \\
$120-150$ & 1.010 & 1.010 & 1.007 & 1.013 & 1.012 & 1.011 & 1.009 & 0.998 \\
$150-175$ & 1.009 & 1.011 & 1.006 & 1.017 & 1.013 & 1.011 & 1.012 & 1.005 \\
$175-200$ & 1.008 & 1.012 & 1.006 & 1.020 & 1.014 & 1.010 & 1.014 & 1.011 \\
$200-225$ & 1.007 & 1.013 & 1.005 & 1.023 & 1.015 & 1.010 & 1.016 & 1.015 \\
\hline Uncertainty (\%) & 0.2 & 0.3 & 0.2 & 0.4 & 0.3 & 0.2 & 0.4 & 0.6 \\
\hline
\end{tabular}

${ }^{1}$ Thick sample left column, thin sample right column

Table 12: CORRECTION FACTORS FOR THE CROSS SECTION RATIOS, $\mathrm{F}_{2}=$ $\operatorname{MS}(\mathrm{Au}) / \mathrm{MS}(\mathrm{X})$

\begin{tabular}{cccccccc}
\hline $\begin{array}{c}\text { Neutron Energy Range } \\
(\mathrm{keV})\end{array}$ & ${ }^{114} \mathrm{Sn} / \mathrm{Au}$ & ${ }^{115} \mathrm{Sn} / \mathrm{Au}$ & ${ }^{116} \mathrm{Sn} / \mathrm{Au}^{1}$ & ${ }^{117} \mathrm{Sn} / \mathrm{Au}$ & ${ }^{118} \mathrm{Sn} / \mathrm{Au}$ & ${ }^{120} \mathrm{Sn} / \mathrm{Au}$ \\
\hline $3-5$ & 1.057 & 1.006 & 1.226 & 1.083 & 1.006 & 1.174 & 1.414 \\
$5-7.5$ & 1.043 & 1.014 & 1.160 & 1.064 & 1.012 & 1.129 & 1.317 \\
$7.5-10$ & 1.036 & 1.017 & 1.123 & 1.052 & 1.015 & 1.104 & 1.260 \\
$10-12.5$ & 1.031 & 1.020 & 1.104 & 1.046 & 1.018 & 1.089 & 1.225 \\
$12.5-15$ & 1.027 & 1.019 & 1.087 & 1.040 & 1.017 & 1.077 & 1.196 \\
$15-20$ & 1.022 & 1.017 & 1.070 & 1.031 & 1.014 & 1.062 & 1.167 \\
$20-25$ & 1.017 & 1.015 & 1.055 & 1.025 & 1.012 & 1.050 & 1.138 \\
$25-30$ & 1.014 & 1.014 & 1.045 & 1.021 & 1.010 & 1.043 & 1.118 \\
$30-40$ & 1.011 & 1.011 & 1.035 & 1.015 & 1.008 & 1.034 & 1.096 \\
$40-50$ & 1.009 & 1.010 & 1.026 & 1.012 & 1.006 & 1.026 & 1.076 \\
$50-60$ & 1.006 & 1.008 & 1.019 & 1.008 & 1.004 & 1.020 & 1.062 \\
$60-80$ & 1.004 & 1.006 & 1.012 & 1.005 & 1.002 & 1.014 & 1.045 \\
$80-100$ & 1.002 & 1.005 & 1.006 & 1.002 & 1.001 & 1.009 & 1.032 \\
$100-120$ & 1.001 & 1.004 & 1.001 & 1.000 & 1.000 & 1.005 & 1.021 \\
$120-150$ & 1.000 & 1.003 & 0.997 & 0.998 & 0.999 & 1.001 & 1.012 \\
$150-175$ & 0.998 & 1.003 & 0.992 & 0.996 & 0.998 & 0.997 & 1.004 \\
$175-200$ & 0.996 & 1.002 & 0.988 & 0.994 & 0.998 & 0.994 & 0.997 \\
$200-225$ & 0.994 & 1.002 & 0.984 & 0.992 & 0.997 & 0.991 & 0.992 \\
\hline Uncertainty (\%) & 0.4 & 0.3 & 0.4 & 0.4 & 0.3 & 0.4 & 0.6 \\
\hline
\end{tabular}

${ }^{1}$ Thick sample left column, thin sample right column 


\section{RESULTS FOR THE NEUTRON CAPTURE CROSS SECTIONS}

The ratios of the neutron capture cross sections of the tin isotopes and of ${ }^{197} \mathrm{Au}$ are listed in Tables 13 to 18 together with the respective statistical uncertainties. The data are given for the three experimental runs and for the two evaluations discussed in Sec.3. The last column in each table contains the weighted average, the weight being determined by the inverse of the squared statistical uncertainties. Since the cross section ratios depend weakly on energy, the averages for the energy interval from 30 to $80 \mathrm{keV}$ are also included to allow for a better comparison of the individual results. The data are free of systematic differences with respect to the different runs or evaluations. This is particularly important for the comparison of runs 1 and 3, which were made with different data acquisition modes. The only exception may occur for ${ }^{117} \mathrm{Sn}$, where a systematic difference of $\pm 1.2 \%$ is found between evaluations 1 and 2. Though this difference is still within the $2 \sigma$ limit of the individual statistical uncertainties, it is observed for all three runs and may be due to the problems with the background from sample scattered neutrons as discussed above.

As in the previous measurements with the $4 \pi \mathrm{BaF}_{2}$ detector $[7,8,9]$, the final cross section ratios were adopted from evaluation 2 . The respective mean values are compiled for all runs in Table 19 together with the statistical, systematic, and total uncertainties. The energy bins are sufficiently fine to avoid systematic uncertainties in the calculation of the Maxwellian averaged cross sections (Sec.6). The final uncertainties of the cross section ratios are $\sim 1 \%$ for the even, and $\sim 2 \%$ for the odd isotopes, which represents a significant improvement compared to previous data $[11,12,13,15]$.

The experimental ratios were converted into cross sections using the gold cross section of Macklin [27] after normalization by a factor of 0.989 to the absolute value of Ratynski and Käppeler [28] (Table 20). The uncertainties of these data can be obtained by adding the $1.5 \%$ uncertainty of the reference cross section to the uncertainties of the respective cross section ratios.

The present results are compared to the data of Timokhov et al. [11] in Figures 13 to 15. For these data, accuracies of 5-10\% are quoted for $114,115,116,117 \mathrm{Sn}$ and of $10-20 \%$ for ${ }^{118,120} \mathrm{Sn}$. On average, the present results are systematically lower by $12 \%$, the individual ratios ranging from 0.80 to 1.00 . Most of this systematic difference is due to a $\sim 10 \%$ smaller gold cross section used by Timokhov et al. for converting the experimental cross section ratios to absolute values. Apart from this problem, all remaining differences are well within the quoted uncertainties [29]. A general comparison with all other data will be discussed in Sec. 6 in connection with the stellar cross sections. 
Table 13: $\sigma\left({ }^{114} \mathrm{Sn}\right) / \sigma\left({ }^{197} \mathrm{Au}\right)$ AND STATISTICAL UNCERTAINTIES (in \%)

\begin{tabular}{|c|c|c|c|c|c|c|c|c|}
\hline \multirow{2}{*}{$\begin{array}{c}\text { Neutron Energy Range } \\
(\mathrm{keV})\end{array}$} & \multicolumn{2}{|c|}{ Run I } & \multicolumn{2}{|c|}{ Run II } & \multicolumn{2}{|c|}{ Run III } & \multicolumn{2}{|c|}{ Average } \\
\hline & & & & & & & & \\
\hline $3-5$ & 0.1335 & 26.4 & 0.1913 & 28.9 & 0.1238 & 32.7 & 0.1504 & 17.1 \\
\hline $5-7.5$ & 0.1066 & 18.5 & 0.1772 & 15.2 & 0.1938 & 13.1 & 0.1689 & 8.9 \\
\hline $7.5-10$ & 0.2447 & 7.9 & 0.2673 & 9.9 & 0.2297 & 10.1 & 0.2470 & 5.3 \\
\hline $10-12.5$ & 0.2746 & 5.4 & 0.2869 & 7.0 & 0.2504 & 6.5 & 0.2703 & 3.6 \\
\hline $12.5-15$ & 0.2208 & 5.9 & 0.1985 & 8.5 & 0.1789 & 7.6 & 0.2037 & 4.1 \\
\hline $15-20$ & 0.2882 & 2.8 & 0.2660 & 3.8 & 0.2924 & 3.1 & 0.2845 & 1.8 \\
\hline $20-25$ & 0.2955 & 2.4 & 0.3136 & 2.7 & 0.2974 & 2.6 & 0.3016 & 1.5 \\
\hline $25-30$ & 0.2010 & 2.5 & 0.2204 & 2.7 & 0.2075 & 2.7 & 0.2091 & 1.5 \\
\hline $30-40$ & 0.2546 & 1.6 & 0.2612 & 1.7 & 0.2564 & 1.8 & 0.2574 & 1.0 \\
\hline $40-50$ & 0.2445 & 1.6 & 0.2428 & 1.8 & 0.2492 & 1.8 & 0.2454 & 1.0 \\
\hline $50-60$ & 0.2306 & 1.6 & 0.2295 & 1.8 & 0.2347 & 1.7 & 0.2316 & 1.0 \\
\hline $60-80$ & 0.2218 & 1.4 & 0.2237 & 1.5 & 0.2253 & 1.5 & 0.2235 & 0.8 \\
\hline $80-100$ & 0.2177 & 1.4 & 0.2236 & 1.4 & 0.2275 & 1.6 & 0.2225 & 0.8 \\
\hline $100-120$ & 0.2101 & 1.5 & 0.2160 & 1.4 & 0.2168 & 1.9 & 0.2141 & 0.9 \\
\hline $120-150$ & - & - & 0.2144 & 1.3 & - & - & 0.2144 & 1.3 \\
\hline $150-175$ & - & - & 0.2150 & 1.4 & - & - & 0.2150 & 1.4 \\
\hline $175-200$ & - & - & 0.2242 & 1.5 & - & - & 0.2242 & 1.5 \\
\hline $200-225$ & - & - & 0.2271 & 2.1 & - & - & 0.2271 & 2.1 \\
\hline $30-80$ & 0.2379 & 1.2 & 0.2393 & 1.0 & 0.2414 & 1.3 & 0.2394 & 0.7 \\
\hline Evaluation 2 & & & & & & & & \\
\hline $3-5$ & 0.1370 & 19.8 & 0.2133 & 19.1 & 0.1225 & 23.6 & 0.1629 & 12.2 \\
\hline $5-7.5$ & 0.1376 & 11.2 & 0.2031 & 10.4 & 0.1598 & 11.8 & 0.1690 & 6.5 \\
\hline $7.5-10$ & 0.2486 & 5.9 & 0.2676 & 7.4 & 0.2642 & 6.4 & 0.2588 & 3.7 \\
\hline $10-12.5$ & 0.2601 & 4.5 & 0.2563 & 5.9 & 0.2490 & 4.9 & 0.2553 & 2.9 \\
\hline $12.5-15$ & 0.2128 & 4.8 & 0.2004 & 6.6 & 0.1862 & 5.8 & 0.2016 & 3.2 \\
\hline $15-20$ & 0.2771 & 2.3 & 0.2630 & 3.0 & 0.2835 & 2.5 & 0.2760 & 1.5 \\
\hline $20-25$ & 0.2998 & 1.9 & 0.3032 & 2.2 & 0.2948 & 2.0 & 0.2991 & 1.2 \\
\hline $25-30$ & 0.2091 & 1.9 & 0.2199 & 2.2 & 0.2124 & 2.1 & 0.2134 & 1.2 \\
\hline $30-40$ & 0.2563 & 1.3 & 0.2607 & 1.4 & 0.2533 & 1.4 & 0.2568 & 0.8 \\
\hline $40-50$ & 0.2464 & 1.3 & 0.2421 & 1.4 & 0.2458 & 1.4 & 0.2449 & 0.8 \\
\hline $50-60$ & 0.2320 & 1.2 & 0.2282 & 1.5 & 0.2305 & 1.4 & 0.2305 & 0.8 \\
\hline $60-80$ & 0.2183 & 1.0 & 0.2165 & 1.2 & 0.2183 & 1.1 & 0.2178 & 0.7 \\
\hline $80-100$ & 0.2180 & 1.0 & 0.2187 & 1.2 & 0.2216 & 1.2 & 0.2193 & 0.7 \\
\hline $100-120$ & 0.2095 & 1.2 & 0.2126 & 1.2 & 0.2132 & 1.6 & 0.2115 & 0.8 \\
\hline $120-150$ & - & - & 0.2134 & 1.1 & - & - & 0.2134 & 1.1 \\
\hline $150-175$ & - & - & $0: 2131$ & 1.2 & - & - & 0.2131 & 1.2 \\
\hline $175-200$ & - & - & 0.2247 & 1.2 & - & - & 0.2247 & 1.2 \\
\hline $200-225$ & - & - & 0.2254 & 1.8 & - & - & 0.2254 & 1.8 \\
\hline $30-80$ & 0.2383 & 0.8 & 0.2369 & 0.7 & 0.2370 & 0.9 & 0.2374 & 0.5 \\
\hline
\end{tabular}


Table 14: $\sigma\left({ }^{115} \mathrm{Sn}\right) / \sigma\left({ }^{197} \mathrm{Au}\right)$ AND STATISTICAL UNCERTAINTIES (in \%)

\begin{tabular}{|c|c|c|c|c|c|c|c|c|}
\hline \multirow{2}{*}{$\begin{array}{c}\text { Nentron Energy Range } \\
(\mathrm{keV})\end{array}$} & \multicolumn{2}{|c|}{ Run I } & \multicolumn{2}{|c|}{ Run II } & \multicolumn{2}{|c|}{ Run III } & \multicolumn{2}{|c|}{ Average } \\
\hline & & & & & & & & \\
\hline $3-5$ & - & $\ldots$ & - & - & 0.6531 & 34.0 & 0.6531 & 34.0 \\
\hline $5-7.5$ & 0.2781 & 39.2 & - & - & 0.3657 & 37.5 & 0.3238 & 27.4 \\
\hline $7.5-10$ & 0.4155 & 25.1 & - & - & 0.5518 & 22.4 & 0.4911 & 16.9 \\
\hline $10-12.5$ & 0.6120 & 12.9 & 0.1189 & 88.4 & 0.5574 & 15.1 & 0.5833 & 9.8 \\
\hline $12.5-15$ & 0.4780 & 14.4 & 0.4600 & 19.7 & 0.5925 & 12.3 & 0.5288 & 8.5 \\
\hline $15-20$ & 0.6591 & 6.3 & 0.5845 & 8.9 & 0.6140 & 7.0 & 0.6272 & 4.1 \\
\hline $20-25$ & 0.7043 & 5.1 & 0.6904 & 6.1 & 0.7546 & 4.8 & 0.7208 & 3.0 \\
\hline $25-30$ & 0.6674 & 4.2 & 0.5868 & 5.2 & 0.7061 & 3.9 & 0.6643 & 2.5 \\
\hline $30-40$ & 0.7243 & 3.1 & 0.6823 & 3.1 & 0.7566 & 2.7 & 0.7245 & 1.7 \\
\hline $40-50$ & 0.7222 & 3.1 & 0.6803 & 3.1 & 0.7076 & 2.8 & 0.7037 & 1.7 \\
\hline $50-60$ & 0.6879 & 3.0 & 0.6343 & 3.2 & 0.6617 & 2.7 & 0.6624 & 1.7 \\
\hline $60-80$ & 0.6259 & 2.7 & 0.6162 & 2.6 & 0.5860 & 2.3 & 0.6072 & 1.4 \\
\hline $80-100$ & 0.6493 & 2.6 & 0.5961 & 2.5 & 0.6423 & 2.3 & 0.6295 & 1.4 \\
\hline $100-120$ & 0.6132 & 2.9 & 0.5935 & 2.5 & 0.6160 & 3.0 & 0.6059 & 1.6 \\
\hline $120-150$ & - & - & 0.5623 & 2.3 & - & - & 0.5623 & 2.3 \\
\hline $150-175$ & - & - & 0.5741 & 2.4 & - & - & 0.5741 & 2.4 \\
\hline $175-200$ & - & - & 0.5806 & 2.6 & - & - & 0.5806 & 2.6 \\
\hline $200-225$ & - & - & 0.5926 & 3.8 & - & - & 0.5926 & 3.8 \\
\hline $30-80$ & 0.6901 & 2.4 & 0.6533 & 1.7 & 0.6780 & 1.8 & 0.6702 & 1.1 \\
\hline \multicolumn{9}{|l|}{ Evaluation 2} \\
\hline $3-5$ & - & - & - & - & 0.2332 & 69.4 & 0.2332 & 69.4 \\
\hline $5-7.5$ & 0.2735 & 32.0 & - & - & 0.2443 & 43.2 & 0.2631 & 25.8 \\
\hline $7.5-10$ & 0.3954 & 20.4 & 0.2540 & 42.0 & 0.3511 & 25.7 & 0.3626 & 15.0 \\
\hline $10-12.5$ & 0.5456 & 11.4 & 0.3032 & 26.8 & 0.4156 & 15.4 & 0.4787 & 8.8 \\
\hline $12.5-15$ & 0.4930 & 11.2 & 0.5781 & 12.5 & 0.4597 & 12.6 & 0.5094 & 7.0 \\
\hline $15-20$ & 0.6295 & 5.1 & 0.6390 & 6.5 & 0.5500 & 6.2 & 0.6083 & 3.4 \\
\hline $20-25$ & 0.6778 & 4.0 & 0.7149 & 4.7 & 0.6980 & 4.1 & 0.6952 & 2.4 \\
\hline $25-30$ & 0.6342 & 3.3 & 0.6113 & 4.0 & 0.6257 & 3.4 & 0.6253 & 2.0 \\
\hline $30-40$ & 0.7027 & 2.2 & 0.7101 & 2.5 & 0.7186 & 2.3 & 0.7102 & 1.3 \\
\hline $40-50$ & 0.7092 & 2.1 & 0.6944 & 2.5 & 0.6980 & 2.3 & 0.7013 & 1.3 \\
\hline $50-60$ & 0.6625 & 2.1 & 0.6409 & 2.6 & 0.6516 & 2.2 & 0.6533 & 1.3 \\
\hline $60-80$ & 0.6185 & 1.7 & 0.6217 & 2.1 & 0.5859 & 1.9 & 0.6089 & 1.1 \\
\hline $80-100$ & 0.6424 & 1.7 & 0.6016 & 2.1 & 0.6311. & 1.9 & 0.6281 & 1.1 \\
\hline $100-120$ & 0.6060 & 1.9 & 0.5949 & 2.1 & 0.6274 & 2.4 & 0.6075 & 1.2 \\
\hline $120-150$ & - & - & 0.5557 & 1.9 & - & - & 0.5557 & 1.9 \\
\hline $150-175$ & - & - & 0.5632 & 2.0 & - & - & 0.5632 & 2.0 \\
\hline $175-200$ & - & - & 0.5833 & 2.1 & - & - & 0.5833 & 2.1 \\
\hline $200-225$ & - & - & 0.5752 & 3.2 & - & - & 0.5752 & 3.2 \\
\hline $30-80$ & 0.6732 & 1.4 & 0.6668 & 1.4 & 0.6635 & 1.5 & 0.6680 & 0.8 \\
\hline
\end{tabular}


Table 15: $\sigma\left({ }^{116} \mathrm{Sn}\right) / \sigma\left({ }^{197} \mathrm{Au}\right)$ AND STATISTICAL UNCERTAINTIES (in \%)

\begin{tabular}{|c|c|c|c|c|c|c|c|c|}
\hline \multirow{2}{*}{$\begin{array}{c}\text { Neutron Energy Range } \\
\text { (keV) }\end{array}$} & \multicolumn{2}{|c|}{ Run I } & \multicolumn{2}{|c|}{ Run II } & \multicolumn{2}{|c|}{ Run III } & \multicolumn{2}{|c|}{ Average } \\
\hline & & & & & & & & \\
\hline $3-5$ & 0.1107 & 12.0 & 0.1205 & 32.3 & 0.0839 & 17.9 & 0.1040 & 9.6 \\
\hline $5-7.5$ & 0.1692 & 4.8 & 0.1458 & 13.1 & 0.1648 & 6.2 & 0.1659 & 3.6 \\
\hline $7.5-10$ & 0.1344 & 5.4 & 0.1445 & 12.7 & 0.1395 & 6.4 & 0.1372 & 3.9 \\
\hline $10-12.5$ & 0.1465 & 3.9 & 0.1559 & 8.9 & 0.1431 & 4.4 & 0.1461 & 2.8 \\
\hline $12.5-15$ & 0.1797 & 3.0 & 0.1903 & 6.4 & 0.1715 & 3.4 & 0.1777 & 2.1 \\
\hline $15-20$ & 0.1892 & 1.8 & 0.2065 & 3.5 & 0.1947 & 2.0 & 0.1935 & 1.3 \\
\hline $20-25$ & 0.1691 & 1.7 & 0.1813 & 3.2 & 0.1743 & 1.9 & 0.1728 & 1.2 \\
\hline $25-30$ & 0.1812 & 1.4 & 0.1856 & 2.4 & 0.1795 & 1.5 & 0.1812 & 0.9 \\
\hline $30-40$ & 0.1646 & 1.1 & 0.1722 & 1.8 & 0.1673 & 1.2 & 0.1669 & 0.8 \\
\hline $40-50$ & 0.1470 & 1.1 & 0.1508 & 2.0 & 0.1486 & 1.3 & 0.1482 & 0.8 \\
\hline $50-60$ & 0.1594 & 1.1 & 0.1591 & 1.9 & 0.1577 & 1.2 & 0.1587 & 0.7 \\
\hline $60-80$ & 0.1488 & 0.9 & 0.1543 & 1.6 & 0.1509 & 1.1 & 0.1505 & 0.6 \\
\hline $80-100$ & 0.1472 & 1.0 & 0.1513 & 1.5 & 0.1499 & 1.1 & 0.1489 & 0.7 \\
\hline $100-120$ & 0.1478 & 1.0 & 0.1495 & 1.6 & 0.1500 & 1.3 & 0.1488 & 0.7 \\
\hline $120-150$ & - & - & 0.1519 & 1.4 & - & - & 0.1519 & 1.4 \\
\hline $150-175$ & - & - & 0.1571 & 1.5 & - & - & 0.1571 & 1.5 \\
\hline $175-200$ & - & - & 0.1578 & 1.6 & - & - & 0.1578 & 1.6 \\
\hline $200-225$ & - & - & 0.1666 & 2.1 & - & - & 0.1666 & 2.1 \\
\hline $30-80$ & 0.1550 & 0.8 & 0.1591 & 1.1 & 0.1561 & 0.9 & 0.1563 & 0.5 \\
\hline \multicolumn{9}{|l|}{ Evaluation 2} \\
\hline $3-5$ & 0.0945 & 11.4 & 0.1109 & 25.8 & 0.0801 & 14.2 & 0.0912 & 8.4 \\
\hline $5-7.5$ & 0.1755 & 3.8 & 0.1796 & 8.4 & 0.1572 & 5.1 & 0.1701 & 2.9 \\
\hline $7.5-10$ & 0.1397 & 4.2 & 0.1314 & 10.4 & 0.1369 & 4.9 & 0.1379 & 3.0 \\
\hline $10-12.5$ & 0.1488 & 3.1 & 0.1565 & 6.8 & 0.1388 & 3.6 & 0.1458 & 2.2 \\
\hline $12.5-15$ & 0.1800 & 2.5 & 0.1910 & 5.0 & 0.1672 & 2.9 & 0.1766 & 1.8 \\
\hline $15-20$ & 0.1837 & 1.5 & 0.1896 & 3.0 & 0.1839 & 1.7 & 0.1845 & 1.1 \\
\hline $20-25$ & 0.1780 & 1.4 & 0.1838 & 2.5 & 0.1777 & 1.5 & 0.1787 & 1.0 \\
\hline $25-30$ & 0.1882 & 1.1 & 0.1904 & 1.9 & 0.1828 & 1.3 & 0.1866 & 0.8 \\
\hline $30-40$ & 0.1653 & 0.9 & 0.1676 & 1.4 & 0.1651 & 1.0 & 0.1657 & 0.6 \\
\hline $40-50$ & 0.1521 & 0.9 & 0.1529 & 1.5 & 0.1512 & 1.1 & 0.1519 & 0.6 \\
\hline $50-60$ & 0.1618 & 0.9 & 0.1579 & 1.5 & 0.1581 & 1.0 & 0.1598 & 0.6 \\
\hline $60-80$ & 0.1506 & 0.8 & 0.1519 & 1.2 & 0.1516 & 0.9 & 0.1512 & 0.5 \\
\hline $80-100$ & 0.1492 & 0.8 & 0.1505 & 1.2 & 0.1498 & 0.9 & 0.1497 & 0.5 \\
\hline $100-120$ & 0.1506 & 0.8 & 0.1480 & 1.2 & 0.1509 & 1.1 & 0.1501 & 0.6 \\
\hline $120-150$ & - & - & 0.1510 & 1.1 & - & - & 0.1510 & 1.1 \\
\hline $150-175$ & - & - & 0.1566 & 1.1 & - & - & 0.1566 & 1.1 \\
\hline $175-200$ & - & - & 0.1580 & 1.2 & - & - & 0.1580 & 1.2 \\
\hline $200-225$ & - & - & 0.1683 & 1.7 & - & - & 0.1683 & 1.7 \\
\hline $30-80$ & 0.1575 & 0.6 & 0.1576 & 0.8 & 0.1565 & 0.7 & 0.1572 & 0.4 \\
\hline
\end{tabular}


Table 16: $\sigma\left({ }^{117} \mathrm{Sn}\right) / \sigma\left({ }^{197} \mathrm{Au}\right)$ AND STATISTICAL UNCERTAINTIES (in \%)

\begin{tabular}{|c|c|c|c|c|c|c|c|c|}
\hline \multirow{2}{*}{$\begin{array}{c}\text { Neutron Energy Range } \\
(\mathrm{keV})\end{array}$} & \multicolumn{2}{|c|}{ Run I } & \multicolumn{2}{|c|}{ Run II } & \multicolumn{2}{|c|}{ Run III } & \multicolumn{2}{|c|}{ Average } \\
\hline & & & & & & & & \\
\hline $3-5$ & 0.4261 & 19.4 & - & - & 0.4048 & 23.5 & 0.0669 & 14.9 \\
\hline $5-7.5$ & 0.3811 & 12.2 & 0.0692 & 86.7 & 0.2607 & 22.3 & 0.3489 & 10.8 \\
\hline $7.5-10$ & 0.5944 & 7.8 & 0.3575 & 16.4 & 0.4462 & 12.0 & 0.5246 & 6.1 \\
\hline $10-12.5$ & 0.6103 & 5.7 & 0.3724 & 11.9 & 0.4289 & 8.5 & 0.5296 & 4.5 \\
\hline $12.5-15$ & 0.6328 & 4.9 & 0.5329 & 7.3 & 0.4826 & 6.6 & 0.5695 & 3.5 \\
\hline $15-20$ & 0.6403 & 2.8 & 0.5516 & 4.1 & 0.5561 & 3.5 & 0.5951 & 1.9 \\
\hline $20-25$ & 0.7501 & 2.1 & 0.7171 & 2.7 & 0.7171 & 2.5 & 0.7309 & 1.4 \\
\hline $25-30$ & 0.6969 & 1.7 & 0.6621 & 2.1 & 0.6801 & 2.1 & 0.6822 & 1.1 \\
\hline $30-40$ & 0.6512 & 1.3 & 0.6405 & 1.5 & 0.6479 & 1.6 & 0.6469 & 0.9 \\
\hline $40-50$ & 0.6169 & 1.3 & 0.6071 & 1.6 & 0.6127 & 1.7 & 0.6127 & 0.9 \\
\hline $50-60$ & 0.6028 & 1.2 & 0.6186 & 1.5 & 0.6025 & 1.6 & 0.6073 & 0.8 \\
\hline $60-80$ & 0.5458 & 1.0 & 0.5608 & 1.3 & 0.5330 & 1.4 & 0.5472 & 0.7 \\
\hline $80-100$ & 0.5528 & 1.0 & 0.5539 & 1.3 & 0.5458 & 1.5 & 0.5516 & 0.7 \\
\hline $100-120$ & 0.5215 & 1.2 & 0.5178 & 1.3 & 0.5348 & 1.8 & 0.5227 & 0.8 \\
\hline $120-150$ & - & - & 0.5130 & 1.1 & - & - & 0.5130 & 1.1 \\
\hline $150-175$ & - & - & 0.4831 & 1.3 & - & - & 0.4831 & 1.3 \\
\hline $175-200$ & - & - & 0.4125 & 1.5 & - & - & 0.4125 & 1.5 \\
\hline $200-225$ & - & - & 0.3872 & 2.4 & - & - & 0.3872 & 2.4 \\
\hline $30-80$ & 0.6042 & 0.8 & 0.6068 & 0.8 & 0.5990 & 1.2 & 0.6043 & 0.5 \\
\hline \multicolumn{9}{|l|}{ Evaluation 2} \\
\hline $3-5$ & 0.3545 & 17.9 & - & - & 0.3582 & 18.7 & 0.3563 & 12.9 \\
\hline $5-7.5$ & 0.3697 & 10.0 & - & - & 0.2876 & 15.1 & 0.3447 & 8.4 \\
\hline $7.5-10$ & 0.5782 & 6.1 & 0.2690 & 16.5 & 0.4504 & 8.4 & 0.5129 & 4.8 \\
\hline $10-12.5$ & 0.5707 & 4.8 & 0.3168 & 10.8 & 0.4309 & 6.3 & 0.4973 & 3.6 \\
\hline $12.5-15$ & 0.5948 & 4.1 & 0.4506 & 6.8 & 0.5093 & 4.9 & 0.5402 & 2.9 \\
\hline $15-20$ & 0.6169 & 2.4 & 0.4969 & 3.6 & 0.5719 & 2.6 & 0.5774 & 1.6 \\
\hline $20-25$ & 0.7213 & 1.8 & 0.6538 & 2.3 & 0.6912 & 1.9 & 0.6941 & 1.1 \\
\hline $25-30$ & 0.6634 & 1.5 & 0.6172 & 1.8 & 0.6394 & 1.6 & 0.6430 & 0.9 \\
\hline $30-40$ & 0.6347 & 1.1 & 0.6151 & 1.3 & 0.6265 & 1.2 & 0.6263 & 0.7 \\
\hline $40-50$ & 0.6069 & 1.1 & 0.5849 & 1.3 & 0.5938 & 1.2 & 0.5965 & 0.7 \\
\hline $50-60$ & 0.5992 & 1.1 & 0.6019 & 1.3 & 0.5942 & 1.2 & 0.5983 & 0.7 \\
\hline $60-80$ & 0.5430 & 0.9 & 0.5489 & 1.1 & 0.5285 & 1.0 & 0.5401 & 0.6 \\
\hline $80-100$ & 0.5405 & 0.9 & 0.5440 & 1.1 & 0.5314 & 1.1 & 0.5389 & 0.6 \\
\hline $100-120$ & 0.5134 & 1.1 & 0.5141 & 1.1 & 0.5134 & 1.4 & 0.5137 & 0.7 \\
\hline $120-150$ & - & - & 0.5037 & 1.0 & - & - & 0.5037 & 1.0 \\
\hline $150-175$ & - & - & 0.4825 & 1.1 & - & - & 0.4825 & 1.1 \\
\hline $175-200$ & - & - & 0.4096 & 1.3 & - & - & 0.4096 & 1.3 \\
\hline $200-225$ & - & - & 0.3866 & 2.0 & - & - & 0.3866 & 2.0 . \\
\hline $30-80$ & 0.5960 & 0.7 & 0.5877 & 0.7 & 0.5858 & 0.8 & 0.5902 & 0.4 \\
\hline
\end{tabular}


Table 17: $\sigma\left({ }^{118} \mathrm{Sn}\right) / \sigma\left({ }^{197} \mathrm{Au}\right)$ AND STATISTICAL UN(ERTAINTIES (in \%)

\begin{tabular}{|c|c|c|c|c|c|c|c|c|}
\hline \multirow{2}{*}{$\begin{array}{l}\text { Neutron Energy Range } \\
(\mathrm{keV})\end{array}$} & \multicolumn{2}{|c|}{ Run I } & \multicolumn{2}{|c|}{ Run II } & \multicolumn{2}{|c|}{ Run III } & \multicolumn{2}{|c|}{ Average } \\
\hline & & & & & & & & \\
\hline $3-5$ & 0.1157 & 12.4 & 0.0947 & 23.1 & 0.0795 & 21.2 & 0.1044 & 9.8 \\
\hline $5-7.5$ & 0.0884 & 9.0 & 0.0969 & 11.1 & 0.0857 & 12.2 & 0.0903 & 6.1 \\
\hline $7.5-10$ & 0.1365 & 5.7 & 0.1476 & 7.1 & 0.1375 & 7.1 & 0.1399 & 3.8 \\
\hline $10-12.5$ & 0.1226 & 4.8 & 0.1178 & 6.7 & 0.1140 & 5.9 & 0.1189 & 3.3 \\
\hline $12.5-15$ & 0.1167 & 4.5 & 0.1107 & 6.2 & 0.1058 & 5.6 & 0.1120 & 3.0 \\
\hline $15-20$ & 0.1248 & 2.6 & 0.1271 & 3.2 & 0.1239 & 3.2 & 0.1252 & 1.7 \\
\hline $20-25$ & 0.1188 & 2.5 & 0.1222 & 2.8 & 0.1232 & 2.8 & 0.1211 & 1.5 \\
\hline $25-30$ & 0.1007 & 2.2 & 0.0975 & 2.5 & 0.1008 & 2.6 & 0.0997 & 1.4 \\
\hline $30-40$ & 0.1098 & 1.6 & 0.1100 & 1.6 & 0.1095 & 2.0 & 0.1098 & 1.0 \\
\hline $40-50$ & 0.0926 & 1.7 & 0.0919 & 1.8 & 0.0943 & 2.1 & 0.0928 & 1.1 \\
\hline $50-60$ & 0.1013 & 1.5 & 0.1060 & 1.7 & 0.1036 & 1.9 & 0.1035 & 1.0 \\
\hline $60-80$ & 0.0988 & 1.4 & 0.1027 & 1.4 & 0.1005 & 1.8 & 0.1007 & 0.9 \\
\hline $80-100$ & 0.1011 & 1.4 & 0.1001 & 1.4 & 0.1008 & 1.8 & 0.1006 & 0.9 \\
\hline $100-120$ & 0.0967 & 1.5 & 0.0992 & 1.4 & 0.0991 & 2.0 & 0.0983 & 0.9 \\
\hline $120-150$ & - & - & 0.1019 & 1.2 & - & - & 0.1019 & 1.2 \\
\hline $150-175$ & - & - & 0.1022 & 1.3 & - & - & 0.1022 & 1.3 \\
\hline $175-200$ & - & - & 0.1098 & 1.3 & - & - & 0.1098 & 1.3 \\
\hline $200-225$ & - & - & 0.1099 & 1.8 & - & - & 0.1099 & 1.8 \\
\hline $30-80$ & 0.1006 & 1.3 & 0.1027 & 1.0 & 0.1020 & 1.6 & 0.1019 & 0.7 \\
\hline \multicolumn{9}{|l|}{ Evaluation 2} \\
\hline $3-5$ & 0.1064 & 12.1 & 0.0918 & 19.2 & 0.0812 & 16.9 & 0.0966 & 8.8 \\
\hline $5-7.5$ & 0.0950 & 7.6 & 0.0906 & 10.1 & 0.0842 & 10.5 & 0.0911 & 5.3 \\
\hline $7.5-10$ & 0.1395 & 4.8 & 0.1496 & 5.8 & 0.1433 & 5.5 & 0.1435 & 3.1 \\
\hline $10-12.5$ & 0.1171 & 4.4 & 0.1071 & 6.1 & 0.1082 & 5.2 & 0.1119 & 2.9 \\
\hline $12.5-15$ & 0.1120 & 4.2 & 0.1079 & 5.4 & 0.1065 & 4.9 & 0.1092 & 2.7 \\
\hline $15-20$ & 0.1168 & 2.5 & 0.1161 & 3.0 & 0.1135 & 2.9 & 0.1156 & 1.6 \\
\hline $20-25$ & 0.1243 & 2.1 & 0.1268 & 2.3 & 0.1239 & 2.3 & 0.1250 & 1.3 \\
\hline $25-30$ & 0.1099 & 1.8 & 0.1058 & 2.0 & 0.1063 & 2.1 & 0.1075 & 1.1 \\
\hline $30-40$ & 0.1109 & 1.4 & 0.1104 & 1.3 & 0.1092 & 1.6 & 0.1102 & 0.8 \\
\hline $40-50$ & 0.0986 & 1.4 & 0.0952 & 1.5 & 0.0966 & 1.6 & 0.0969 & 0.9 \\
\hline $50-60$ & 0.1056 & 1.3 & 0.1048 & 1.4 & 0.1034 & 1.5 & 0.1047 & 0.8 \\
\hline $60-80$ & 0.1016 & 1.1 & 0.1020 & 1.4 & 0.1010 & 1.3 & 0.1016 & 0.7 \\
\hline $80-100$ & 0.1036 & 1.2 & 0.1002 & 1.1 & 0.1003 & 1.4 & 0.1014 & 0.7 \\
\hline $100-120$ & 0.1020 & 1.3 & 0.1014 & 1.1 & 0.1013 & 1.6 & 0.1016 & 0.8 \\
\hline $120-150$ & - & - & 0.1042 & 1.1 & - & - & 0.1042 & 1.0 \\
\hline $150-175$ & - & - & 0.1054 & 1.0 & - & - & 0.1054 & 1.0 \\
\hline $175-200$ & - & - & 0.1143 & 1.0 & - & - & 0.1143 & 1.1 \\
\hline $200-225$ & - & - & 0.1135 & 1.1 & - & - & 0.1135 & 1.6 \\
\hline $30-80$ & 0.1042 & 1.0 & 0.1031 & 0.7 & 0.1026 & 1.1 & 0.1033 & 0.5 \\
\hline
\end{tabular}


Table 18: $\sigma\left({ }^{120} \mathrm{Sn}\right) / \sigma\left({ }^{197} \mathrm{Au}\right)$ AND STATISTICAL UNCERTAINTIES (in \%)

\begin{tabular}{|c|c|c|c|c|c|c|c|c|}
\hline \multirow{2}{*}{$\begin{array}{l}\text { Neutron Energy Range } \\
(\mathrm{keV})\end{array}$} & \multicolumn{2}{|c|}{ Run I } & \multicolumn{2}{|c|}{ Run II } & \multicolumn{2}{|c|}{ Run III } & \multicolumn{2}{|c|}{ Average } \\
\hline & & & & & & & & \\
\hline $3-5$ & 0.0528 & 23.7 & 0.0675 & 25.8 & 0.0503 & 29.1 & 0.0571 & 15.1 \\
\hline $5-7.5$ & 0.0726 & 9.3 & 0.0754 & 11.0 & 0.0848 & 10.4 & 0.0773 & 5.9 \\
\hline $7.5-10$ & 0.0478 & 12.6 & 0.0709 & 10.8 & 0.0728 & 10.5 & 0.0655 & 6.6 \\
\hline $10-12.5$ & 0.0744 & 6.2 & 0.0793 & 7.4 & 0.0882 & 6.1 & 0.0809 & 3.8 \\
\hline $12.5-15$ & 0.0698 & 5.8 & 0.0696 & 7.1 & 0.0781 & 5.9 & 0.0728 & 3.6 \\
\hline $15-20$ & 0.0829 & 3.2 & 0.0894 & 3.5 & 0.0906 & 3.4 & 0.0874 & 1.9 \\
\hline $20-25$ & 0.0650 & 3.3 & 0.0710 & 3.5 & 0.0745 & 3.4 & 0.0701 & 2.0 \\
\hline $25-30$ & 0.0618 & 2.8 & 0.0581 & 3.1 & 0.0619 & 3.1 & 0.0607 & 1.7 \\
\hline $30-40$ & 0.0560 & 2.3 & 0.0548 & 2.3 & 0.0573 & 2.4 & 0.0560 & 1.4 \\
\hline $40-50$ & 0.0549 & 2.2 & 0.0543 & 2.3 & 0.0570 & 2.4 & 0.0554 & 1.3 \\
\hline $50-60$ & 0.0643 & 2.0 & 0.0669 & 2.1 & 0.0638 & 2.2 & 0.0650 & 1.2 \\
\hline $60-80$ & 0.0608 & 1.9 & 0.0621 & 1.9 & 0.0626 & 2.0 & 0.0618 & 1.1 \\
\hline $80-100$ & 0.0596 & 1.9 & 0.0600 & 1.9 & 0.0603 & 2.1 & 0.0599 & 1.1 \\
\hline $100-120$ & 0.0577 & 2.0 & 0.0611 & 1.9 & 0.0605 & 2.3 & 0.0597 & 1.2 \\
\hline $120-150$ & - & - & 0.0589 & 1.8 & - & - & 0.0589 & 1.8 \\
\hline $150-175$ & - & - & 0.0647 & 1.7 & - & - & 0.0647 & 1.7 \\
\hline $175-200$ & - & - & 0.0635 & 1.8 & - & - & 0.0635 & 1.8 \\
\hline $200-225$ & - & - & 0.0586 & 2.3 & - & - & 0.0586 & 2.3 \\
\hline $30-80$ & 0.0590 & 1.7 & 0.0595 & 1.5 & 0.0602 & 1.8 & 0.0595 & 1.0 \\
\hline \multicolumn{9}{|l|}{ Evaluation 2} \\
\hline $3-5$ & 0.0436 & 26.7 & 0.0554 & 26.0 & 0.0512 & 23.8 & 0.0503 & 14.7 \\
\hline $5-7.5$ & 0.0751 & 8.4 & 0.0836 & 8.7 & 0.0774 & 9.8 & 0.0787 & 5.2 \\
\hline $7.5-10$ & 0.0514 & 10.6 & 0.0589 & 10.9 & 0.0684 & 9.1 & 0.0605 & 5.9 \\
\hline $10-12.5$ & 0.0721 & 5.8 & 0.0718 & 6.8 & 0.0790 & 5.7 & 0.0746 & 3.5 \\
\hline $12.5-15$ & 0.0632 & 5.8 & 0.0588 & 7.3 & 0.0697 & 5.8 & 0.0646 & 3.6 \\
\hline $15-20$ & 0.0769 & 3.0 & 0.0804 & 3.2 & 0.0810 & 3.2 & 0.0793 & 1.8 \\
\hline $20-25$ & 0.0655 & 2.9 & 0.0728 & 2.9 & 0.0702 & 3.0 & 0.0695 & 1.7 \\
\hline $25-30$ & 0.0619 & 2.4 & 0.0576 & 2.7 & 0.0609 & 2.7 & 0.0602 & 1.5 \\
\hline $30-40$ & 0.0569 & 1.9 & 0.0539 & 2.0 & 0.0550 & 2.1 & 0.0553 & 1.2 \\
\hline $40-50$ & 0.0568 & 1.9 & 0.0543 & 2.0 & 0.0569 & 2.1 & 0.0560 & 1.1 \\
\hline $50-60$ & 0.0662 & 1.7 & 0.0648 & 1.8 & 0.0631 & 1.9 & 0.0648 & 1.0 \\
\hline $60-80$ & 0.0618 & 1.5 & 0.0597 & 1.5 & 0.0618 & 1.7 & 0.0611 & 0.9 \\
\hline $80-100$ & 0.0624 & 1.5 & 0.0599 & 1.5 & 0.0602 & 1.7 & 0.0609 & 0.9 \\
\hline $100-120$ & 0.0604 & 1.6 & 0.0605 & 1.5 & 0.0617 & 1.9 & 0.0608 & 1.0 \\
\hline $120-150$ & - & - & 0.0594 & 1.4 & - & - & 0.0594 & 1.4 \\
\hline $150-175$ & - & - & 0.0660 & 1.4 & - & - & 0.0660 & 1.4 \\
\hline $175-200$ & - & - & 0.0645 & 1.4 & - & - & 0.0645 & 1.4 \\
\hline $200-225$ & - & - & 0.0606 & 2.0 & - & - & 0.0606 & 2.0 \\
\hline $30-80$ & 0.0604 & 1.4 & 0.0582 & 1.1 & 0.0592 & 1.5 & 0.0591 & 0.7 \\
\hline
\end{tabular}


Table 19: FINAL NEUTRON CAPTURE CROSS SECTION RATIOS OF ${ }^{114} \mathrm{Sn},{ }^{115} \mathrm{Sn}$, ${ }^{116} \mathrm{Sn},{ }^{117} \mathrm{Sn}{ }^{118} \mathrm{Sn}$, AND ${ }^{120} \mathrm{Sn}$ RELATIVE TO ${ }^{197} \mathrm{Au}$

\begin{tabular}{|c|c|c|c|c|c|c|c|c|c|c|c|c|}
\hline \multirow{2}{*}{$\begin{array}{c}\text { Energy }{ }^{1} \\
(\mathrm{keV})\end{array}$} & \multirow[t]{2}{*}{$\frac{\sigma\left({ }^{14} \mathrm{Sn}\right)}{\sigma\left({ }^{197} \mathrm{Au}\right)}$} & \multicolumn{3}{|c|}{ Uncertainty (\%) } & \multirow[t]{2}{*}{$\frac{\sigma\left({ }^{115} \mathrm{Sn}\right)}{\sigma\left(^{197} \mathrm{Au}\right)}$} & \multicolumn{3}{|c|}{ Uncertainty (\%) } & \multirow[t]{2}{*}{$\frac{\sigma\left({ }^{116} \mathrm{Sn}\right)}{\sigma\left({ }^{197} \mathrm{Au}\right)}$} & \multicolumn{3}{|c|}{ Uncertainty (\%) } \\
\hline & & stat & sys & tot & & stat & sys & tot & & stat & sys & tot \\
\hline $3-5$ & 0.1629 & 12.2 & 0.9 & 12.2 & 0.2332 & - & & & 0.0912 & 8.4 & 0.7 & 8.4 \\
\hline $5-7.5$ & 0.1690 & 6.5 & 0.9 & 6.6 & 0.2631 & - & & & 0.1701 & 2.9 & 0.7 & 3.0 \\
\hline $7.5-10$ & 0.2588 & 3.7 & 0.9 & 3.8 & 0.3626 & - & & & 0.1379 & 3.0 & 0.7 & 3.1 \\
\hline $10-12.5$ & 0.2553 & 2.9 & 0.9 & 3.0 & 0.4787 & 8.8 & 1.5 & 8.9 & 0.1458 & 2.2 & 0.7 & 2.3 \\
\hline $12.5-15$ & 0.2016 & 3.2 & 0.9 & 3.3 & 0.5094 & 7.0 & 1.5 & 7.2 & 0.1766 & 1.8 & 0.7 & 1.9 \\
\hline $15-20$ & 0.2760 & 1.5 & 0.9 & 1.7 & 0.6083 & 3.4 & 1.5 & 3.7 & 0.1845 & 1.1 & 0.7 & 1.3 \\
\hline $20-25$ & 0.2991 & 1.2 & 0.9 & 1.5 & 0.6952 & 2.4 & 1.5 & 2.8 & 0.1787 & 1.0 & 0.7 & 1.2 \\
\hline $25-30$ & 0.2134 & 1.2 & 0.9 & 1.5 & 0.6253 & 2.0 & 1.5 & 2.5 & 0.1866 & 0.8 & 0.7 & 1.1 \\
\hline $30-40$ & 0.2568 & 0.8 & 0.9 & 1.2 & 0.7102 & 1.3 & 1.5 & 2.0 & 0.1657 & 0.6 & 0.7 & 0.9 \\
\hline $40-50$ & 0.2449 & 0.8 & 0.9 & 1.2 & 0.7013 & 1.3 & 1.5 & 2.0 & 0.1519 & 0.6 & 0.7 & 0.9 \\
\hline $50-60$ & 0.2305 & 0.8 & 0.9 & 1.2 & 0.6533 & 1.3 & 1.5 & 2.0 & 0.1598 & 0.6 & 0.7 & 0.9 \\
\hline $60-80$ & 0.2178 & 0.7 & 0.9 & 1.1 & 0,6089 & 1.1 & 1.5 & 1.9 & 0.1512 & 0.5 & 0.7 & 0.9 \\
\hline $80-100$ & 0.2193 & 0.7 & 0.9 & 1.1 & 0.6281 & 1.1 & 1.5 & 1.9 & 0.1497 & 0.5 & 0.7 & 0.9 \\
\hline $100-120$ & 0.2115 & 0.8 & 0.9 & 1.2 & 0.6075 & 1.2 & 1.5 & 2.0 & 0.1501 & 0.6 & 0.7 & 0.9 \\
\hline $120-150$ & 0.2134 & 1.1 & 0.9 & 1.4 & 0.5557 & 1.9 & 1.5 & 2.4 & 0.1510 & 1.1 & 0.7 & 1.3 \\
\hline $150-175$ & 0.2131 & 1.2 & 0.9 & 1.5 & 0.5632 & 2.0 & 1.5 & 2.5 & 0.1566 & 1.1 & 0.7 & 1.3 \\
\hline $175-200$ & 0.2247 & 1.2 & 0.9 & 1.5 & 0.5833 & 2.1 & 1.5 & 2.6 & 0.1580 & 1.2 & 0.7 & 1.4 \\
\hline $200-225$ & 0.2254 & 1.8 & 0.9 & 2.0 & 0.5752 & 3.2 & 1.5 & 3.5 & 0.1683 & 1.7 & 0.7 & 1.8 \\
\hline
\end{tabular}

Energy $^{1} \quad \frac{\sigma\left({ }^{117} \mathrm{Sn}\right)}{\sigma\left({ }^{197} \mathrm{Au}\right)} \quad$ Uncertainty (\%) $\quad \frac{\sigma\left({ }^{118} \mathrm{Sn}\right)}{\sigma\left({ }^{197} \mathrm{Au}\right)} \quad$ Uncertainty (\%) $\quad \frac{\sigma\left({ }^{120} \mathrm{Sn}\right)}{\sigma\left({ }^{197} \mathrm{Au}\right)} \quad$ Uncertainty (\%)

\begin{tabular}{|c|c|c|c|c|c|c|c|c|c|c|c|c|}
\hline$(\mathrm{keV})$ & & stat & sys & tot & & stat & sys & tot & & stat & sys & tot \\
\hline $3-5$ & 0.3563 & 12.9 & 1.4 & 13.0 & 0.0966 & 8.8 & 0.7 & 8.8 & 0.0503 & 14.7 & 0.8 & 14.7 \\
\hline $5-7.5$ & 0.3447 & 8.4 & 1.4 & 8.5 & 0.0911 & 5.3 & 0.7 & 5.3 & 0.0787 & 5.2 & 0.8 & 5.3 \\
\hline $7.5-10$ & 0.5129 & 4.8 & 1.4 & 5.0 & 0.1435 & 3.1 & 0.7 & 3.2 & 0.0605 & 5.9 & 0.8 & 6.0 \\
\hline $10-12.5$ & 0.4973 & 3.6 & 1.4 & 3.9 & 0.1119 & 2.9 & 0.7 & 3.0 & 0.0746 & 3.5 & 0.8 & 3.6 \\
\hline $12.5-15$ & 0.5402 & 2.9 & 1.4 & 3.2 & 0.1092 & 2.7 & 0.7 & 2.8 & 0.0646 & 3.6 & 0.8 & 3.7 \\
\hline $15-20$ & 0.5774 & 1.6 & 1.4 & 2.1 & 0.1156 & 1.6 & 0.7 & 1.7 & 0.0793 & 1.8 & 0.8 & 2.0 \\
\hline $20-25$ & 0.6941 & 1.1 & 1.4 & 1.8 & 0.1250 & 1.3 & 0.7 & 1.5 & .0695 & 1.7 & 0.8 & 1.9 \\
\hline $25-30$ & 0.6430 & 0.9 & 1.4 & 1.7 & 0.1075 & 1.1 & 0.7 & 1.3 & 0.0602 & 1.5 & 0.8 & 1.7 \\
\hline $30-40$ & 0.6263 & 0.7 & 1.4 & 1.6 & 0.1102 & 0.8 & 0.7 & 1.1 & 0.0553 & 1.2 & 0.8 & 1.4 \\
\hline $40-50$ & 5965 & 0.7 & 1.4 & 1.6 & 0.0969 & 0.9 & 0.7 & 1.1 & 0.0560 & 1.1 & 0.8 & 1.4 \\
\hline $50-60$ & 983 & 0.7 & 1.4 & 1.6 & 0.1 & 0.8 & 0.7 & 1.1 & 48 & 1.0 & 0.8 & 1.3 \\
\hline $60-80$ & 401 & 0.6 & 1.4 & 1.5 & 0.1016 & 0.7 & 0.7 & 1.0 & 11 & 0.9 & 0.8 & 1.2 \\
\hline $80-100$ & 0.5389 & 0.6 & 1.4 & 1.5 & 0.1014 & 0.7 & 0.7 & 1.0 & 0.0609 & 0.9 & 0.8 & 1.2 \\
\hline $100-120$ & 5137 & 0.7 & 1.4 & 1.6 & 0.1016 & 0.8 & 0.7 & 1.1 & 0.0608 & 1.0 & 0.8 & 1.3 \\
\hline $120-150$ & 0.5037 & 1.0 & 1.4 & 1.7 & 0.1042 & 1.0 & 0.7 & 1.2 & 0.0594 & 1.4 & 0.8 & 1.6 \\
\hline $150-175$ & 0.4825 & 1.1 & 1.4 & 1.8 & 0.1054 & 1.0 & 0.7 & 1.2 & 0.0660 & 1.4 & 0.8 & 1.6 \\
\hline $175-200$ & 4096 & 1.3 & 1.4 & 1.9 & 0.1143 & 1.1 & 0.7 & 1.3 & 0.0645 & 1.4 & 0.8 & 1.6 \\
\hline $200-225$ & 0.3866 & 2.0 & 1.4 & 2.4 & 0.1135 & 1.6 & 0.7 & 1.7 & 0.0606 & 2.0 & 0.8 & 2.2 \\
\hline
\end{tabular}

${ }^{1}$ Neutron energy intervals as used for calculating the Maxwellian averaged cross sections 

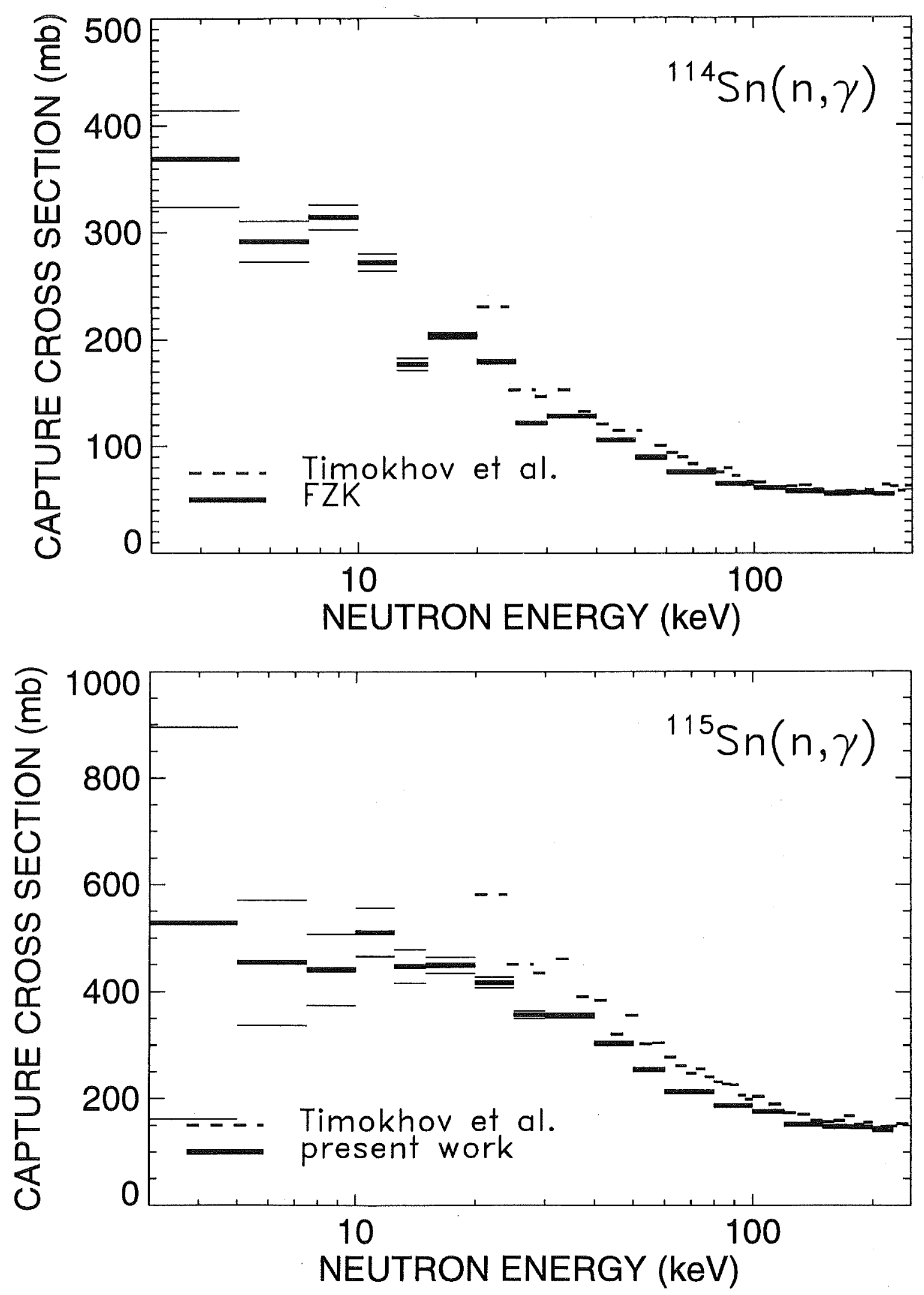

Figure 13: The neutron capture cross sections of ${ }^{114} \mathrm{Sn}$ and ${ }^{115} \mathrm{Sn}$ compared to the data of Timokhov et al. [11]. 

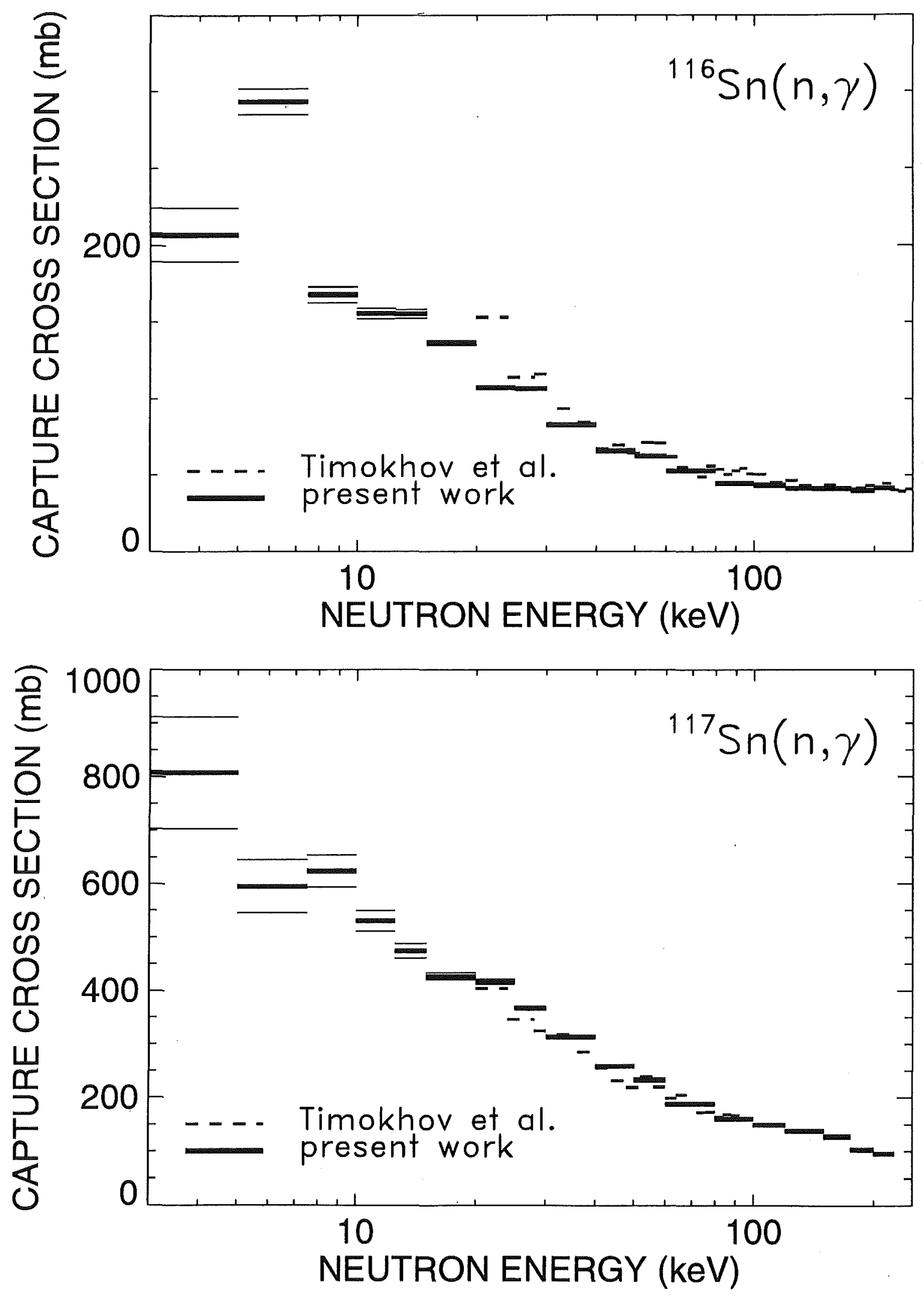

Figure 14: The neutron capture cross sections of ${ }^{116} \mathrm{Sn}$ and ${ }^{117} \mathrm{Sn}$ compared to the data of Timokhov et al. [11]. 

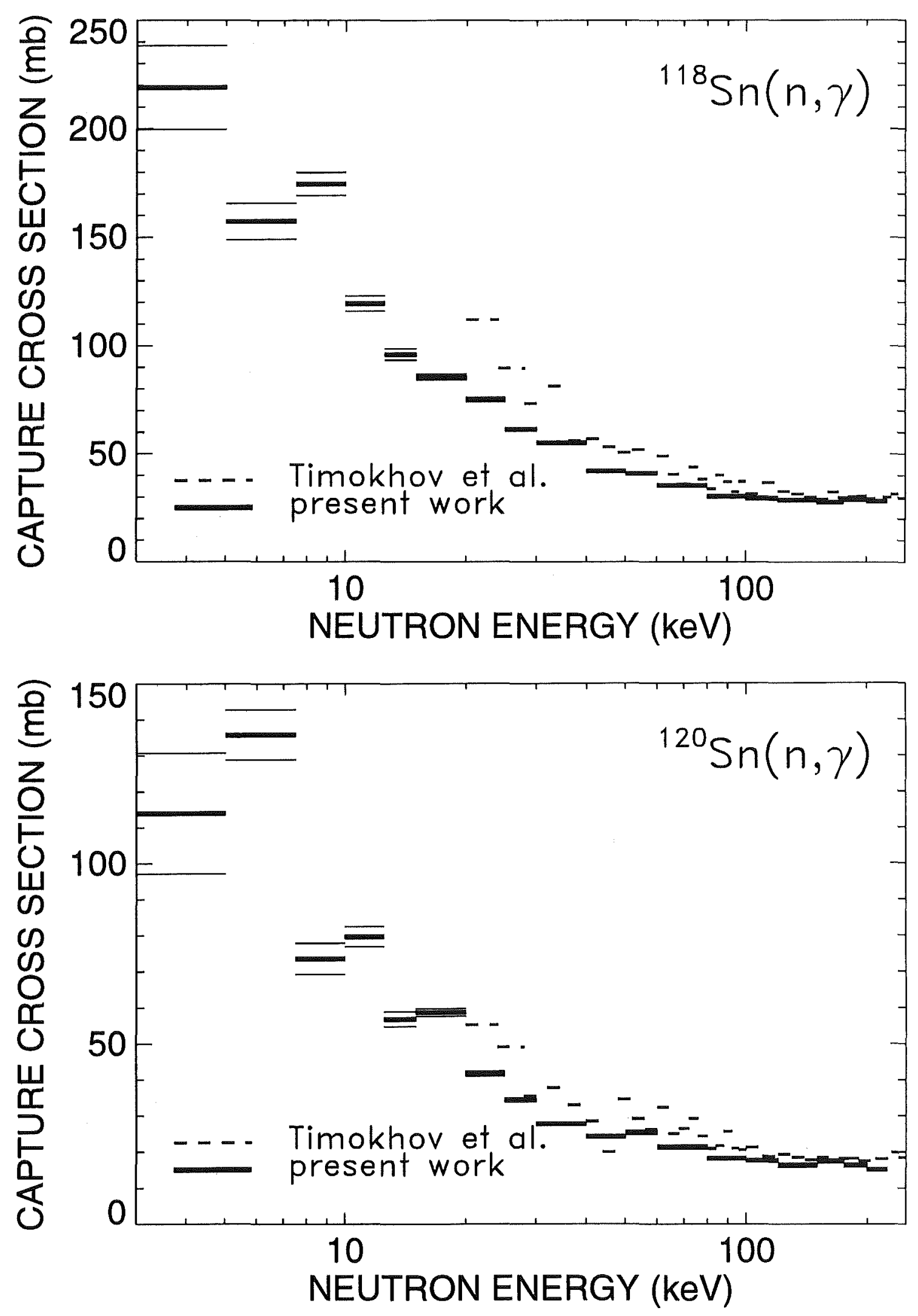

Figure 15: The neutron capture cross sections of ${ }^{118} \mathrm{Sn}$ and ${ }^{120} \mathrm{Sn}$ compared to the data Timokhov et al. [11]. 
Table 20: NEUTRON CAPTURE CROSS SECTIONS OF ${ }^{114} \mathrm{Sn},{ }^{115} \mathrm{Sn},{ }^{116} \mathrm{Sn},{ }^{117} \mathrm{Sn}$, ${ }^{118} \mathrm{Sn}, \mathrm{AND}{ }^{120} \mathrm{Sn}$ (in mb)

\begin{tabular}{cccccccc}
\hline $\begin{array}{c}\text { Energy Interval } \\
(\mathrm{keV})\end{array}$ & $\sigma\left({ }^{197} \mathrm{Au}\right)^{2}$ & $\sigma\left({ }^{114} \mathrm{Sn}\right)$ & $\sigma\left({ }^{115} \mathrm{Sn}\right)$ & $\sigma\left({ }^{116} \mathrm{Sn}\right)$ & $\sigma\left({ }^{117} \mathrm{Sn}\right)$ & $\sigma\left({ }^{18} \mathrm{Sn}\right)$ & $\sigma\left({ }^{120} \mathrm{Sn}\right)$ \\
\hline $3-5$ & 2266.7 & 369.2 & - & 206.8 & 807.6 & 219.0 & 114.0 \\
$5-7.5$ & 1726.7 & 291.8 & - & 293.8 & 595.2 & 157.4 & 135.9 \\
$7.5-10$ & 1215.7 & 314.6 & - & 167.7 & 623.5 & 174.5 & 73.6 \\
$10-12.5$ & 1066.7 & 272.4 & 510.7 & 155.5 & 530.4 & 119.3 & 79.6 \\
$12.5-15$ & 878.0 & 177.0 & 447.2 & 155.0 & 474.3 & 95.9 & 56.8 \\
$15-20$ & 738.8 & 203.9 & 449.4 & 136.3 & 426.6 & 85.4 & 58.6 \\
$20-25$ & 600.0 & 179.5 & 417.2 & 107.2 & 416.5 & 75.0 & 41.7 \\
$25-30$ & 570.8 & 121.8 & 356.9 & 106.5 & 367.0 & 61.4 & 34.4 \\
$30-40$ & 500.4 & 128.5 & 355.4 & 82.9 & 313.4 & 55.2 & 27.7 \\
$40-50$ & 433.3 & 106.1 & 303.9 & 65.8 & 258.5 & 42.0 & 24.3 \\
$50-60$ & 389.6 & 89.8 & 254.5 & 62.3 & 233.1 & 40.8 & 25.3 \\
$60-80$ & 349.4 & 76.1 & 212.7 & 52.8 & 188.7 & 35.5 & 21.3 \\
$80-100$ & 298.3 & 65.4 & 187.4 & 44.6 & 160.7 & 30.3 & 18.2 \\
$100-120$ & 290.1 & 61.4 & 176.3 & 43.6 & 149.0 & 29.5 & 17.6 \\
$120-150$ & 274.1 & 58.5 & 152.3 & 41.4 & 138.1 & 28.6 & 16.3 \\
$150-175$ & 263.7 & 56.2 & 148.5 & 41.3 & 127.2 & 27.8 & 17.4 \\
$175-200$ & 252.6 & 56.8 & 147.3 & 39.9 & 103.5 & 28.9 & 16.3 \\
$200-225$ & 248.5 & 56.0 & 142.9 & 41.8 & 96.1 & 28.2 & 15.1 \\
\hline
\end{tabular}

${ }^{1}$ as used for calculating the Maxwellian averaged cross sections

${ }^{2}$ based on the ${ }^{197} \mathrm{Au}$ data from literature $[27,28]$

\section{DISCUSSION OF UNCERTAINTIES}

The determination of statistical and systematic uncertainties in measurements with the $4 \pi$ $\mathrm{BaF}_{2}$ detector has been described in Refs. $[7,8,20]$. The uncertainties of the present tin measurements are somewhere in between those achieved for the samarium [8] and barium [9] isotopes, the two experiments with the $4 \pi \mathrm{BaF}_{2}$ detector, which were characterized by the lowest and highest backgrounds. The following discussion concentrates on the particular aspects of the present experiment. The various uncertainties are compiled in Table 21.

As for the even tin isotopes, no systematic differences outside the statistical uncertainties were observed in the data, neither in the different runs nor with the different acquisition modes and evaluation methods (see Tables 13,15,17,18). In these cases, the 
systematic uncertainty for background subtraction was negligible as for the samarium isotopes. For the odd isotopes, the difficulties of proper background subtraction were described in Sec. 3, and lead to the following consequence for the ${ }^{115} \mathrm{Sn}$ results: As is obvious from Fig. 13, the cross section exhibits very large uncertainties below $10 \mathrm{keV}$. Since it is impossible to estimate a realistic systematic uncertainty in this region, these data have been withdrawn from the final results presented in Tables 19 and 20. Despite of the fact that they appear in Table 14 and in Fig. 13 for demonstrating the problem, these data should not be used in any further application. In case of ${ }^{117} \mathrm{~S} \mathrm{~S}$, an average systematic difference of $\pm 1.2 \%$ is found between the results of evaluation 1 and 2 . This difference can be attributed to background uncertainties in the reference interval used for normalization of the cross section. Since part of this difference is due to counting statistics, a systematic uncertainty of $1 \%$ was assumed for this normalization (see Table 21). In view of the similar background situation, this uncertainty was considered for both odd isotopes, although no such differences were found for ${ }^{115} \mathrm{Sn}$.

As discussed in Sec 3.1 the measured total cross sections provided an independent check, which confirmed the $0.2 \%$ uncertainty of the neutron flux normalization for the different samples.

The isotopic composition was specified by the supplier with an absolute uncertainty of $\pm 0.2 \%$. Though it seems to be a conservative estimate according to the very good agreement obtained in the independent measurements of the isotopic composition of the samarium samples [8], this value was adopted as an absolute uncertainty for all isotopes in each sample. Consequently, a relative uncertainty of $0.2 \%$ could be assigned to the abundances of the main isotopes in the highly enriched samples, but corresponding uncertainties of $0.3 \%$ and $0.4 \%$ had to be allowed for ${ }^{114} \mathrm{Sn}$ and ${ }^{115} \mathrm{Sn}$, respectively (Table21).

With the adopted $0.2 \%$ abundance uncertainty, the even $(25.2 \%)$ and odd $(4.8 \%)$ impurity isotopes in the ${ }^{114} \mathrm{Sn}$ sample (Table 2) yield relative uncertainties of $2.0 \%$ and $7.2 \%$, respectively. These uncertainties are comparably large, since, for example, the uncertainties of the six even isotopes have to be added in quadrature. The measured count rate between threshold and neutron binding energy (channels 16 to 93) in the sum energy spectrum of ${ }^{114} \mathrm{~S}$ (Fig. 5) is composed in the following way: $72 \%$ are true captures in ${ }^{114} \mathrm{Sn}$, but $5 \%$ are due to the odd, and $13 \%$ due to the even impurity isotopes. The resulting systematic uncertainties for the ${ }^{114} \mathrm{Sn}$ and ${ }^{115} \mathrm{Sn}$ samples were $0.6 \%$, while the specified uncertainty of $0.2 \%$ could be adopted for all other isotopes.

The samples with low enrichment are also problematic with respect to the correction for multiple scattering and self-shielding. The multiple scattering effect may either not be completely considered or even overcompensated by subtracting the normalized spectra of the impurity isotopes. This holds certainly if the individual sample masses are significantly different. Therefore, the calculation of the correction factors MS were performed for the total sample as well as for the isotope remaining after the isotopic correction. The respective differences (Table 12 ) were $0.5 \%$ and $0.4 \%$ for the ${ }^{114} \mathrm{Sn}$ and ${ }^{115} \mathrm{Sn}$ samples, nearly independent of the neutron energy. Therefore, $25 \%$ of this difference was adopted as an additional systematic uncertainty for these isotopes, analoguously to the procedure used in the gadolinium experiment [10]. For the other isotopes, only the uncertainties provided by the SESH program [21] were considered. This was justified by the reliable set of input data, by which the total and capture cross sections could be reproduced. 
Table 21: SYSTEMATIC UNCERTAINTIES (\%)

\begin{tabular}{ll} 
Background subtraction in normalization interval & \\
cross section ratio ${ }^{115,117} \mathrm{Sn} / \mathrm{Au}$ & 1.0 \\
Flight path & 0.1 \\
Neutron flux normalization & 0.2 \\
Sample mass (elemental impurities) & 0.2 \\
Isotopic composition $\left({ }^{114} \mathrm{Sn} /{ }^{115} \mathrm{Sn} /{ }^{i} \mathrm{Sn}^{1}\right.$ samples) & $0.3 / 0.4 / 0.2$ \\
Isotopic correction $\left({ }^{114} \mathrm{Sn} /{ }^{115} \mathrm{Sn} /{ }^{i} \mathrm{Sn}^{1}\right.$ samples) & $0.6 / 0.6 / 0.2$ \\
Multiple scattering and self-shielding: $\mathrm{F}_{2}$ & \\
cross section ratio ${ }^{114,116,118} \mathrm{Sn} / \mathrm{Au}$ & 0.4 \\
cross section ratio ${ }^{115,117} \mathrm{Sn} / \mathrm{Au}$ & 0.3 \\
cross section ratio ${ }^{120} \mathrm{Sn} / \mathrm{Au}$ & 0.6 \\
Undetected events: F & \\
cross section ratio ${ }^{114,116,118,120} \mathrm{Sn} / \mathrm{Au}$ & 0.4 \\
cross section ratio ${ }^{115,117} \mathrm{Sn} / \mathrm{Au}$ & 0.8 \\
\hline
\end{tabular}

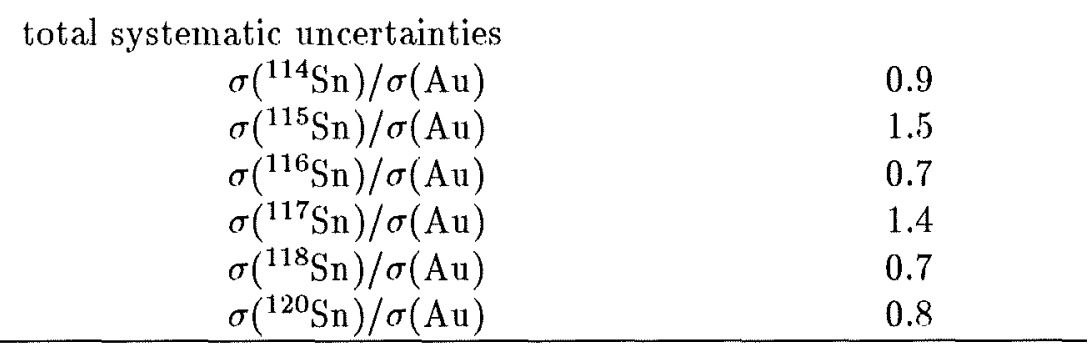

${ }^{1} \mathrm{i}$ stands for mass numbers $116,117,118$, and 120.

Comparison of the results obtained with the thick and thin ${ }^{116} \mathrm{Sn}$ samples shows no indication for significant systematic differences. For example, the cross section difference in the energy interval from 30 to $80 \mathrm{keV}$ is $\pm 0.2 \%$, while the respective correction factors $\mathrm{F}_{2}$ differ by $1.3 \%$. As noted before, the interval from 5 to $10 \mathrm{keV}$ is most sensitive, since $\mathrm{F}_{2}$ differs by $8.4 \%$ for the two samples (see Table 12 ), but again the cross sections agree to $\pm 1 \%$. This means that all differences are fully accounted for by the statistical uncertainties, thus confirming the reliability of the calculated corrections.

The systematic uncertainties due to undetected events were discussed in detail for the gadolinium experiment [10], where uncertainties of $0.3 \%$ for the even and $0.8 \%$ for the odd isotopes were estimated for $\mathrm{F}_{1}$ on the basis of two independent sets of calculated capture cascades, in good agreement with the uncertainties quoted in previous measurements with the $4 \pi \mathrm{BaF}_{2}$ detector $[7,8,9]$. Accordingly, the same uncertainties were adopted in the present case, too. An additional uncertainty of $0.3 \%$ was considered for the extrapolation of the $f$ values from $\Omega=1$ to $\Omega=0.94$, which is plausible from the lower part of Fig. 11 . 


\section{MAXWELLIAN AVERAGED CROSS SECTIONS}

Maxwellian averaged cross sections were calculated in the same way as described in Refs. $[7,20]$. The neutron energy range from 0 to $700 \mathrm{keV}$ was divided into three intervals according to the origin of the adopted cross sections. The respective contributions $\mathrm{I}_{x}$ are given in Table 22 . The main contributions from the interval $I_{2}$ are provided by this experiment (Table 20). These data are presented with sufficient resolution to avoid systematic uncertainties that may result from a coarse energy grid.

The contributions $I_{1}$ from the energy range from 0 to $3 \mathrm{keV}$ were determined in two different ways. First, the cross section shapes from statistical model calculations were fitted to the present results and at lower energies to the data that were calculated from resonance parameters [30]. In a second calculation, the cross sections of the Joint Evaluated File [22] were normalized to the present data between 5 to $20 \mathrm{keV}$, the respective normalization factors ranging from 0.5 to 1.7 . In case of ${ }^{115} \mathrm{Sn}$, the extrapolation was made for the interval 0 to $10 \mathrm{keV}$ since no data could be obtained below $10 \mathrm{keV}$ in the present experiment. The quoted uncertainties of 10-15\% correspond to the observed differences from the mean, and include the respective systematic uncertainties. For ${ }^{115} \mathrm{Sn}$, larger uncertainties of $20 \%$ had to be admitted.

The energy interval from 225 to $700 \mathrm{keV}$ contributes very little to the Maxwellian average at typical s-process temperatures. Here, the data of Timokhov et al. [11] were used, normalized to the present results in the interval of overlap. Since these data range up to $460 \mathrm{keV}$, the remaining gap was filled by data from the JEF evaluation. The uncertainties were calculated under the assumption that the uncertainties of the normalized cross sections increase from $2 \%$ at $225 \mathrm{keV}$ to $10 \%$ at $700 \mathrm{keV}$ neutron energy.

The systematic uncertainties of the Maxwellian averaged cross sections in Table 22 correspond to the uncertainties of the cross section ratios (Table 19) and consider the contributions of the summed intensities, $\mathrm{I}_{2}+\mathrm{I}_{3}$. The $1.5 \%$ uncertainty of the gold standard was not included since it cancels out in most applications of relevance for s-process studies. In most cases, systematic and statistical uncertainties are of the same order. At low thermal energies, however, the statistical uncertainties dominate for all isotopes.

The present results at $\mathrm{kT}=30 \mathrm{keV}$ are eventually compared in Table 23 with previous experiments and with the compilations of Bao and Käppeler [31] and Beer, Voss, and Winters [32]. The individual results are in fair agreement, with typical differences of $\sim 10 \%$. A somewhat larger discrepancies of $14 \%$ was found for ${ }^{120} \mathrm{Sn}$. In all cases, the uncertainties have been reduced significantly by the present experimental technique. 
Table 22: MAXWELLIAN AVERAGED NEUTRON CAPTURE CROSS SECTIONS OF THE TIN ISOTOPES. THE CONTRIBUTIONS $\mathrm{I}_{x}$ FROM DIFFERENT ENERGY INTERVALS, $\triangle E$, ARE QUOTED SEPARATELY WITH THEIR STATISTICAL UNCERTAINTIES

\begin{tabular}{|c|c|c|c|c|c|c|c|}
\hline \multicolumn{8}{|c|}{${ }^{114} \mathrm{Sn}$} \\
\hline$\Delta \mathrm{E}$ & $0-3 \mathrm{keV}$ & $3-225 \mathrm{keV}$ & $225-700 \mathrm{keV}$ & \multicolumn{4}{|c|}{ Thermal Spectrum } \\
\hline & & & & \multirow{2}{*}{\multicolumn{4}{|c|}{$<\sigma \mathrm{v}>/ \mathrm{v}_{T}(\mathrm{mbarn})$}} \\
\hline $\mathrm{kT}$ & $\mathrm{I}_{1}$ & $\mathrm{I}_{2}$ & $\mathrm{I}_{3}$ & & & & \\
\hline$(\mathrm{keV})$ & $(\mathrm{mb})$ & $(\mathrm{mb})$ & $(\mathrm{mb})$ & & stat & sys $^{2}$ & tot \\
\hline 10 & $24.1 \pm 7.2$ & $223.6 \pm 3.8$ & 0.0 & 247.7 & 8.1 & 2.0 & 8.3 \\
\hline 12 & $17.2 \pm 5.1$ & $207.4 \pm 3.0$ & 0.0 & 224.6 & 5.9 & 1.9 & 6.2 \\
\hline 20 & $6.6 \pm 2.0$ & $161.7 \pm 1.5$ & 0.0 & 168.3 & 2.5 & 1.5 & 2.9 \\
\hline 25 & $4.3 \pm 1.3$ & $143.3 \pm 1.1$ & 0.1 & 147.7 & 1.7 & 1.3 & 2.1 \\
\hline 30 & $3.0 \pm 0.9$ & $129.6 \pm 0.9$ & 0.3 & 132.9 & 1.3 & 1.2 & 1.8 \\
\hline 40 & $1.7 \pm 0.5$ & $109.9 \pm 0.7$ & 1.6 & 113.2 & 0.9 & 1.0 & 1.3 \\
\hline 50 & $1.1 \pm 0.3$ & $95.9 \pm 0.5$ & $4.1 \pm 0.1$ & 101.1 & 0.6 & 0.9 & 1.1 \\
\hline 52 & $1.0 \pm 0.3$ & $93.5 \pm 0.5$ & $4.7 \pm 0.1$ & 99.2 & 0.6 & 0.9 & 1.1 \\
\hline 60 & $0.8 \pm 0.2$ & $84.9 \pm 0.5$ & $7.4 \pm 0.2$ & 93.1 & 0.6 & 0.8 & 1.0 \\
\hline 70 & $0.6 \pm 0.2$ & $75.6 \pm 0.4$ & $11.2 \pm 0.4$ & 87.4 & 0.6 & 0.8 & 1.0 \\
\hline 80 & $0.5 \pm 0.1$ & $67.8 \pm 0.4$ & $15.2 \pm 0.6$ & 83.5 & 0.7 & 0.7 & 1.0 \\
\hline 90 & $0.3 \pm 0.1$ & $61.0 \pm 0.3$ & $19.0 \pm 0.7$ & 80.3 & 0.8 & 0.7 & 1.1 \\
\hline 100 & $0.3 \pm 0.1$ & $55.1 \pm 0.3$ & $22.5 \pm 0.9$ & 77.9 & 1.0 & 0.7 & 1.2 \\
\hline \multicolumn{8}{|c|}{${ }^{115} \mathrm{Sn}$} \\
\hline $\begin{array}{c}\Delta \mathrm{E} \\
\text { Data: }\end{array}$ & $\begin{array}{l}0-10 \mathrm{keV} \\
\text { see text }\end{array}$ & $\begin{array}{c}10-225 \mathrm{keV} \\
\text { this work }\end{array}$ & $\begin{array}{c}225-700 \mathrm{keV} \\
\text { from Refs.[11, 22] }\end{array}$ & \multicolumn{4}{|c|}{ Thermal Spectrum } \\
\hline $\mathrm{kT}$ & $\mathrm{I}_{1}$ & $\mathrm{I}_{2}$ & $\mathrm{I}_{3}$ & \multicolumn{4}{|c|}{$\left\langle\sigma \mathrm{v}>/ \mathrm{v}_{T}(\mathrm{mb})\right.$} \\
\hline$(\mathrm{keV})$ & $(\mathrm{mb})$ & $(\mathrm{mb})$ & $(\mathrm{mb})$ & & stat & sys $^{2}$ & tot \\
\hline 10 & $212.7 \pm 42$ & $334.4 \pm 6.9$ & 0.0 & 547.1 & 42. & 5.0 & 42. \\
\hline 12 & $161.3 \pm 32$ & $347.2 \pm 6.2$ & 0.0 & 508.5 & 33. & 5.2 & 33. \\
\hline 20 & $69.7 \pm 14$ & $339.2 \pm 4.3$ & 0.0 & 408.9 & 15. & 5.1 & 16. \\
\hline 25 & $47.2 \pm 9.4$ & $321.5 \pm 3.7$ & 0.2 & 368.9 & 10. & 4.8 & 11. \\
\hline 30 & $34.1 \pm 6.8$ & $303.5 \pm 3.2$ & 0.7 & 338.3 & 7.5 & 4.5 & 8.7 \\
\hline 40 & $20.1 \pm 4.0$ & $270.7 \pm 2.6$ & $3.8 \pm 0.1$ & 294.6 & 4.8 & 4.1 & 6.3 \\
\hline 50 & $13.3 \pm 2.7$ & $242.4 \pm 2.3$ & $9.6 \pm 0.3$ & 265.3 & 3.5 & 3.8 & 5.2 \\
\hline 52 & $12.3 \pm 2.5$ & $237.2 \pm 2.2$ & $11.0 \pm 0.3$ & 260.5 & 3.3 & 3.7 & 5.0 \\
\hline 60 & $9.4 \pm 1.9$ & $217.6 \pm 2.0$ & $17.2 \pm 0.5$ & 244.2 & 2.8 & 3.5 & 4.5 \\
\hline 70 & $7.0 \pm 1.4$ & $195.7 \pm 1.8$ & $25.8 \pm 0.8$ & 228.5 & 2.3 & 3.3 & 4.0 \\
\hline 80 & $5.4 \pm 1.1$ & $176.4 \pm 1.7$ & $34.2 \pm 1.2$ & 216.0 & 2.0 & 3.2 & 3.8 \\
\hline 90 & $4.3 \pm 0.9$ & $159.3 \pm 1.5$ & $42.1 \pm 1.5$ & 205.7 & 1.7 & 3.0 & 3.4 \\
\hline 100 & $3.5 \pm 0.7$ & $144.3 \pm 1.4$ & $49.0 \pm 1.9$ & 196.8 & 1.6 & 2.9 & 3.3 \\
\hline
\end{tabular}


TABLE 22 (continued)

\begin{tabular}{|c|c|c|c|c|c|c|c|}
\hline \multicolumn{8}{|c|}{${ }^{116} \mathrm{Sn}$} \\
\hline$\Delta \mathrm{E}$ & $0-3 \mathrm{keV}$ & $3-225 \mathrm{keV}$ & $225-700 \mathrm{keV}$ & \multicolumn{4}{|c|}{ Thermal Spectrum } \\
\hline & & & & \multirow{2}{*}{\multicolumn{4}{|c|}{$<\sigma \mathrm{v}>/ \mathrm{v}_{T}(\mathrm{mb})$}} \\
\hline$\overline{k T}$ & $\mathrm{I}_{1}$ & $\mathrm{I}_{2}$ & $\mathrm{I}_{3}$ & & & & \\
\hline$(\mathrm{keV})$ & $(\mathrm{mb})$ & $(\mathrm{mb})$ & $(\mathrm{mb})$ & & stat & sys $^{2}$ & tot \\
\hline 10 & $17.2 \pm 1.7$ & $153.1 \pm 1.6$ & 0.0 & 197.0 & 2.3 & 1.1 & 2.5 \\
\hline 12 & $12.3 \pm 1.2$ & $141.7 \pm 1.3$ & 0.0 & 154.0 & 1.8 & 1.0 & 2.1 \\
\hline 20 & $4.7 \pm 0.5$ & $110.0 \pm 0.7$ & 0.0 & 114.7 & 0.9 & 0.8 & 1.2 \\
\hline 25 & $3.1 \pm 0.3$ & $97.5 \pm 0.6$ & 0.1 & 100.7 & 0.7 & 0.7 & 1.0 \\
\hline 30 & $2.2 \pm 0.2$ & $88.3 \pm 0.5$ & 0.2 & 90.7 & 0.5 & 0.6 & 0.8 \\
\hline 40 & $1.2 \pm 0.1$ & $75.2 \pm 0.4$ & 1.1 & 77.5 & 0.4 & 0.5 & 0.6 \\
\hline 50 & $0.8 \pm 0.1$ & $65.9 \pm 0.3$ & $2.8 \pm 0.1$ & 69.5 & 0.3 & 0.5 & 0.6 \\
\hline 52 & $0.7 \pm 0.1$ & $64.3 \pm 0.3$ & $3.2 \pm 0.1$ & 68.2 & 0.3 & 0.5 & 0.6 \\
\hline 60 & $0.6 \pm 0.1$ & $58.6 \pm 0.3$ & $5.1 \pm 0.2$ & 64.3 & 0.4 & 0.4 & 0.6 \\
\hline 70 & $0.4 \pm 0.0$ & $52.4 \pm 0.2$ & $7.7 \pm 0.3$ & 60.5 & 0.4 & 0.4 & 0.6 \\
\hline 80 & $0.3 \pm 0.0$ & $47.1 \pm 0.2$ & $10.4 \pm 0.4$ & 57.8 & 0.4 & 0.4 & 0.6 \\
\hline 90 & $0.3 \pm 0.0$ & $42.5 \pm 0.2$ & $13.1 \pm 0.5$ & 55.9 & 0.5 & 0.4 & 0.6 \\
\hline 100 & $0.2 \pm 0.0$ & $38.4 \pm 0.2$ & $15.5 \pm 0.6$ & 54.1 & 0.6 & 0.4 & 0.7 \\
\hline \multicolumn{8}{|c|}{${ }^{117} \mathrm{Sn}$} \\
\hline$\Delta \mathrm{E}$ & $0-3 \mathrm{keV}$ & $3-225 \mathrm{keV}$ & $225-700 \mathrm{keV}$ & \multirow{2}{*}{\multicolumn{4}{|c|}{ Thermal Spectrum }} \\
\hline Data: & see text & this work & from Refs.[11, 22] $]^{1}$ & & & & \\
\hline $\mathrm{kT}$ & $\mathrm{I}_{1}$ & $\mathrm{I}_{2}$ & $\mathrm{I}_{3}$ & \multicolumn{4}{|c|}{$<\sigma \mathrm{v}>/ \mathrm{v}_{T}(\mathrm{mb})$} \\
\hline$(\mathrm{keV})$ & $(\mathrm{mb})$ & $(\mathrm{mb})$ & $(\mathrm{mb})$ & & stat & sys $^{2}$ & tot \\
\hline 10 & $49.5 \pm 5.0$ & $496.7 \pm 9.2$ & 0.0 & 546.2 & 11. & 6.9 & 13. \\
\hline 12 & $35.4 \pm 3.5$ & $467.7 \pm 7.1$ & 0.0 & 503.1 & 7.9 & 6.5 & 10. \\
\hline 20 & $13.5 \pm 1.4$ & $378.1 \pm 3.5$ & 0.0 & 391.6 & 3.8 & 5.3 & 6.5 \\
\hline 25 & $8.8 \pm 0.9$ & $339.1 \pm 2.6$ & 0.1 & 348.0 & 2.8 & 4.7 & 5.5 \\
\hline 30 & $6.2 \pm 0.6$ & $308.4 \pm 2.1$ & 0.5 & 315.1 & 2.2 & 4.3 & 4.8 \\
\hline 40 & $3.5 \pm 0.4$ & $262.4 \pm 1.5$ & $2.2 \pm 0.1$ & 268.1 & 1.6 & 3.7 & 4.0 \\
\hline .50 & $2.3 \pm 0.2$ & $228.0 \pm 1.2$ & $5.7 \pm 0.2$ & 236.0 & 1.2 & 3.3 & 3.5 \\
\hline 52 & $2.1 \pm 0.2$ & $222.1 \pm 1.1$ & $6.5 \pm 0.2$ & 230.7 & 1.1 & 3.2 & 3.4 \\
\hline 60 & $1.6 \pm 0.2$ & $200.5 \pm 1.0$ & $10.2 \pm 0.3$ & 212.3 & 1.1 & 2.9 & 3.1 \\
\hline 70 & $1.2 \pm 0.1$ & $177.6 \pm 0.8$ & $15.2 \pm 0.5$ & 194.0 & 0.9 & 2.7 & 2.8 \\
\hline 80 & $0.9 \pm 0.1$ & $158.1 \pm 0.8$ & $20.3 \pm 0.7$ & 179.3 & 1.1 & 2.5 & 2.7 \\
\hline 90 & $0.7 \pm 0.1$ & $141.5 \pm 0.7$ & $25.1 \pm 0.9$ & 167.3 & 1.1 & 2.3 & 2.5 \\
\hline 100 & $0.6 \pm 0.1$ & $127.2 \pm 0.6$ & $29.5 \pm 1.2$ & 157.3 & 1.3 & 2.2 & 2.6 \\
\hline
\end{tabular}


TABLE 22 (continued)

\begin{tabular}{|c|c|c|c|c|c|c|c|}
\hline \multicolumn{8}{|c|}{${ }^{118} \mathrm{Sn}$} \\
\hline$\Delta \mathrm{E}$ & $0-3 \mathrm{keV}$ & $3-225 \mathrm{keV}$ & $225-700 \mathrm{keV}$ & \multicolumn{4}{|c|}{ Thermal Spectrum } \\
\hline & see text & this work & Rets. $[11,2 Z]^{*}$ & & & & \\
\hline $\mathrm{kT}$ & $\mathrm{I}_{1}$ & $\mathrm{I}_{2}$ & $I_{3}$ & \multicolumn{4}{|c|}{$<\sigma \mathrm{v}>/ \mathrm{v}_{T}(\mathrm{mb})$} \\
\hline$(\mathrm{keV})$ & $(\mathrm{mb})$ & $(\mathrm{mb})$ & $(\mathrm{mb})$ & & stat & sys $^{2}$ & tot \\
\hline 10 & $16.8 \pm 2.5$ & $109.1 \pm 1.7$ & 0.0 & 125.9 & 3.0 & 0.8 & 3.1 \\
\hline 12 & $12.0 \pm 1.8$ & $99.6 \pm 1.3$ & 0.0 & 111.6 & 2.2 & 0.7 & 2.3 \\
\hline 20 & $4.5 \pm 0.7$ & $75.0 \pm 0.7$ & 0.0 & 79.5 & 1.0 & 0.5 & 1.1 \\
\hline 25 & $2.9 \pm 0.4$ & $66.0 \pm 0.5$ & 0.0 & 68.9 & 0.6 & 0.5 & 0.8 \\
\hline 30 & $2.1 \pm 0.3$ & $59.5 \pm 0.4$ & 0.2 & 61.8 & 0.5 & 0.4 & 0.6 \\
\hline 40 & $1.2 \pm 0.2$ & $50.6 \pm 0.3$ & 0.8 & 52.6 & 0.4 & 0.4 & 0.6 \\
\hline 50 & $0.8 \pm 0.1$ & $44.4 \pm 0.3$ & $2.0 \pm 0.1$ & 47.2 & 0.3 & 0.3 & 0.4 \\
\hline 52 & $0.7 \pm 0.1$ & $43.3 \pm 0.3$ & $2.3 \pm 0.1$ & 46.3 & 0.3 & 0.3 & 0.4 \\
\hline 60 & $0.5 \pm 0.1$ & $39.5 \pm 0.2$ & $3.6 \pm 0.1$ & 43.6 & 0.2 & 0.3 & 0.4 \\
\hline 70 & $0.4 \pm 0.1$ & $35.4 \pm 0.2$ & $5.5 \pm 0.2$ & 41.3 & 0.3 & 0.3 & 0.4 \\
\hline 80 & $0.3 \pm 0.0$ & $31.8 \pm 0.2$ & $7.4 \pm 0.3$ & 39.5 & 0.4 & 0.3 & 0.5 \\
\hline 90 & $0.2 \pm 0.0$ & $28.7 \pm 0.2$ & $9.2 \pm 0.4$ & 38.1 & 0.4 & 0.3 & 0.5 \\
\hline 100 & $0.2 \pm 0.0$ & $26.0 \pm 0.1$ & $11.0 \pm 0.4$ & 37.2 & 0.4 & 0.3 & 0.5 \\
\hline \multicolumn{8}{|c|}{${ }^{120} \mathrm{Sn}$} \\
\hline $\begin{array}{c}\Delta \mathrm{E} \\
\text { Data: }\end{array}$ & $\begin{array}{l}0-3 \mathrm{keV} \\
\text { see text }\end{array}$ & $\begin{array}{c}3-225 \mathrm{keV} \\
\text { this work }\end{array}$ & $\begin{array}{c}225-700 \mathrm{keV} \\
\text { from Refs.[11, 22] }\end{array}$ & \multicolumn{4}{|c|}{ Thermal Spectrum } \\
\hline $\mathrm{kT}$ & $\mathrm{I}_{1}$ & $\mathrm{I}_{2}$ & $\mathrm{I}_{3}$ & \multicolumn{4}{|c|}{$<\sigma \mathrm{v}>/ \mathrm{v}_{T}(\mathrm{mb})$} \\
\hline$(\mathrm{keV})$ & $(\mathrm{mb})$ & $(\mathrm{mb})$ & $(\mathrm{mb})$ & & stat & sys $^{2}$ & tot \\
\hline 10 & $7.0 \pm 0.7$ & $65.8 \pm 1.4$ & 0.0 & 72.8 & 1.6 & 0.6 & 1.7 \\
\hline 12 & $5.0 \pm 0.5$ & $59.6 \pm 1.1$ & 0.0 & 64.6 & 1.2 & 0.5 & 1.3 \\
\hline 20 & $1.9 \pm 0.2$ & $44.3 \pm 0.6$ & 0.0 & 46.2 & 0.6 & 0.4 & 0.7 \\
\hline 25 & $1.2 \pm 0.1$ & $38.9 \pm 0.4$ & 0.0 & 40.1 & 0.4 & 0.3 & 0.5 \\
\hline 30 & $0.9 \pm 0.1$ & $35.0 \pm 0.4$ & 0.1 & 36.0 & 0.4 & 0.3 & 0.5 \\
\hline 40 & $0.5 \pm 0.1$ & $29.7 \pm 0.3$ & 0.5 & 30.7 & 0.3 & 0.2 & 0.4 \\
\hline 50 & $0.3 \pm 0.0$ & $26.1 \pm 0.2$ & 1.2 & 27.6 & 0.2 & 0.2 & 0.3 \\
\hline 52 & $0.3 \pm 0.0$ & $25.4 \pm 0.2$ & 1.4 & 27.1 & 0.2 & 0.2 & 0.3 \\
\hline 60 & $0.2 \pm 0.0$ & $23.2 \pm 0.2$ & $2.2 \pm 0.1$ & 25.6 & 0.2 & 0.2 & 0.3 \\
\hline 70 & $0.2 \pm 0.0$ & $20.7 \pm 0.2$ & $3.3 \pm 0.1$ & 24.2 & 0.2 & 0.2 & 0.3 \\
\hline 80 & $0.1 \pm 0.0$ & $18.6 \pm 0.2$ & $4.4 \pm 0.2$ & 23.1 & 0.3 & 0.2 & 0.4 \\
\hline 90 & $0.1 \pm 0.0$ & $16.8 \pm 0.1$ & $5.5 \pm 0.2$ & 22.4 & 0.2 & 0.2 & 0.3 \\
\hline 100 & $0.1 \pm 0.0$ & $15.2 \pm 0.1$ & $6.5 \pm 0.3$ & 21.8 & 0.3 & 0.2 & 0.4 \\
\hline
\end{tabular}

${ }^{1}$ normalized to present data

${ }^{2}$ The $1.5 \%$ uncertainty of the gold standard is not included, since it cancels out in most applications of relevance for nuclear astrophysics 
Table 23: MAXWELLIAN AVERAGED CROSS SECTIONS AT kT=30 keV COMPARED TO PREVIOUS EXPERIMENTS AND EVALUATIONS

\begin{tabular}{|c|c|c|c|c|}
\hline \multirow[t]{2}{*}{ Isotope } & \multicolumn{2}{|r|}{ Experiment } & \multicolumn{2}{|c|}{ Evaluation } \\
\hline & $\begin{array}{c}\text { Cross section } \\
(\mathrm{mb})\end{array}$ & Reference & $\begin{array}{l}\text { Bao and Käppeler } \\
{[31]}\end{array}$ & $\begin{array}{c}\text { Beer, Voss, Winters } \\
{[32]}\end{array}$ \\
\hline${ }^{114} \mathrm{Sn}$ & $\begin{array}{c}132.9 \pm 1.8 \\
133 \pm 7\end{array}$ & $\begin{array}{c}\text { present work }^{1} \\
\text { Timokhov et al. [11 }]^{2}\end{array}$ & 184 & - \\
\hline${ }^{115} \mathrm{Sn}$ & $\begin{array}{c}338.3 \pm 8.7 \\
382 \pm 18\end{array}$ & $\begin{array}{c}\text { present work }^{1} \\
\text { Timokhov et al. }[11]^{2}\end{array}$ & 430 & - \\
\hline${ }^{116} \mathrm{Sn}$ & $\begin{aligned} 90.7 & \pm 0.8 \\
90 & \pm 4 \\
92 & \pm 5 \\
104 & \pm 21\end{aligned}$ & $\begin{array}{c}\text { present work }{ }^{1} \\
\text { Timokhov et al. }[11]^{2} \\
\text { Beer et al. }[13] \\
\text { Macklin and Gibbons [12] }\end{array}$ & $100 \pm 19$ & $92 \pm 5$ \\
\hline${ }^{117} \mathrm{Sn}$ & $\begin{array}{l}315.1 \pm 4.8 \\
285 \pm 14 \\
418 \pm 99\end{array}$ & $\begin{array}{c}\text { present work }{ }^{1} \\
\text { Timokhov et al. }[11]^{2} \\
\text { Macklin and Gibbons [12] }\end{array}$ & $402 \pm 77$ & $402 \pm 77$ \\
\hline${ }^{118} \mathrm{Sn}$ & $\begin{aligned} 61.8 & \pm 0.6 \\
68 & \pm 4 \\
65 & \pm 13\end{aligned}$ & $\begin{array}{c}\text { present work }{ }^{1} \\
\text { Timokhov et al. }[11]^{2} \\
\text { Macklin and Gibbons [12] }\end{array}$ & $63 \pm 12$ & $63 \pm 12$ \\
\hline${ }^{120} \mathrm{Sn}$ & $\begin{aligned} 36.0 & \pm 0.5 \\
31.8 & \pm 1.2 \\
41.0 & \pm 3.3 \\
41 & \pm 8\end{aligned}$ & $\begin{array}{c}\text { present work }{ }^{1} \\
\text { Käppeler et al. }[15] \\
\text { Timokhov et al. }[11]^{2} \\
\text { Macklin and Gibbons [12] }\end{array}$ & $39 \pm 7$ & $39 \pm 7$ \\
\hline
\end{tabular}

${ }^{1}$ The $1.5 \%$ uncertainty of the gold cross section is not included, since it cancels out in most applications of relevance for nuclear astrophysics.

${ }^{2}$ Renormalized to gold cross section used in the present work [29]. 


\section{SUMMARY}

The Karlsruhe $4 \pi$ Barium Fluoride Detector has been improved by replacing the six crystals with the highest $\alpha$ background. In this way, the electronic threshold in the $\gamma$-ray spectrum could be reduced to $1.6 \mathrm{MeV}$, resulting in an improved detection efficiency of $97 \%$ and $99 \%$ for neutron captures in the even and odd $\mathrm{Sn}$ isotopes, respectively.

The total cross sections and the $(n, \gamma)$ cross sections were measured for the stable isotopes ${ }^{114} \mathrm{Sn},{ }^{115} \mathrm{Sn},{ }^{116} \mathrm{Sn},{ }^{117} \mathrm{Sn},{ }^{118} \mathrm{Sn}$, and ${ }^{120} \mathrm{Sn}$. The total cross sections could be determined from 10 to $200 \mathrm{keV}$ with typical uncertainties from 2 to $10 \%$, but for the odd isotopes, where the transmission was larger than $99 \%$, the uncertainties were $20-30 \%$. The neutron capture cross sections were measured from 3 to $225 \mathrm{keV}$. In this case, corrections for the sizable isotopic impurities of the ${ }^{114} \mathrm{Sn}$ and ${ }^{115} \mathrm{Sn}$ samples could be made reliably due to the spectroscopic qualities of the $\mathrm{BaF}_{2}$ detector. Maxwellian averaged $(\mathbf{n}, \gamma)$ cross sections were derived for thermal energies from 10 to $100 \mathrm{keV}$. The astrophysically relevant cross section ratios could be determined with an overall uncertainty of typically $1-2 \%$, an improvement by factors of five to ten compared to existing data. In general the present results agree within $\sim 10 \%$ with the data from literature, except for the very small ${ }^{120} \mathrm{Sn}$ cross section.

An updated analysis of the s-process reaction flow in the mass region of $\mathrm{Cd}-\mathrm{In}-\mathrm{Sn}$ will be presented in a forthcoming publication [18].

\section{ACKNOWLEDGMENTS}

We would like to thank F.H. Fröhner and B. Krieg for providing us with the JEF data. The continuous support of the Van de Graaff crew, D. Roller, E.-P. Knaetsch and W. Seith, who ran the accelerator in a most efficient way, is gratefully acknowledged. We are particularly indebted to G. Rupp for his skill and patience in optimizing the experimental setup. 


\section{References}

[1] Zs. Németh, T. Belgya, S.W. Yates, Ch. Theis, and F. Käppeler, Proc. $2^{\text {nd }}$ International Symposium Nuclei in the Cosmos, Eds. F. Käppeler and K. Wisshak, Karlsruhe Germany 6-10 July 1992, IOP Publishing, Bristol and Philadelphia (1993) p219.

[2] Zs. Németh, F. Käppeler, Ch. Theis, T. Belgya, and S.W. Yates, Astrophys. J. 426, 357 (1994).

[3] N. Prantzos, M. Hashimoto, M. Rayet, and M. Arnould, Astron. Astrophys. 238, $455(1990)$.

[4] W. Howard, B. Meyer, and S. Woosley, Ap. J. 373, L5 (1991).

[5] D.D. Clayton, Astrophys. J. 244, L93 (1978).

[6] R.A. Ward and H. Beer, Astron. Astrophys. 103,189 (1981).

[7] K. Wisshak, F. Voss, F. Käppeler, and G. Reffo, Phys. Rev. C 45, 2470 (1992).

[8] K. Wisshak, K. Guber, F. Voss, F. Käppeler, and G. Reffo, Phys. Rev. C 48, 1401 (1993).

[9] F. Voss, K. Wisshak, K. Guber, F.Käppeler, and G. Reffo, Phys. Rev. (: 50, 2582 (1994).

[10] K. Wisshak, F. Voss, F. Käppeler, K. Guber, L. Kazakov, N. Kornilov, M. Uhl, and $\mathrm{X}$. Reffo, report FZKA-5510, Forschungszentrum Karlsruhe (1995) and Phys. Rev. C. submitted for publication.

[11] V.M. Timokhov, M.V. Bokhovko, A.G. Isakov, L.E. Kazakov, V.N. Kononov, G.N. Manturov, E.D. Poletaev, and V.G. Pronyaev, Sov. J. Nucl. Phys. 50, 375 (1990).

[12] R.L. Macklin and J.H. Gibbons, Rev. Mod. Phys. 37, 166 (1965).

[13] H. Beer, G. Walter, and F. Käppeler, Astron. Astrophys. 211,245 (1989).

[14] W. Schanz Diploma Thesis University of Karlsruhe 1990, unpublished.

[15] F. Käppeler, W. Schanz, K. Wisshak, and G. Reffo, Astrophys. J 410, 370 (1993).

[16] F. Käppeler, R. Gallino, M. Busso, G. Picchio, and C. Raiteri, Astrophys. J. 354, 630 (1990).

[17] O. Straniero, R. Gallino, M. Busso, A. Chieffi, C. Raiteri, M. Limongi, and M. Salaris, Astrophys. J. 440, L85 (1995).

[18] Ch. Theis, Thesis, University of Heidelberg (1995) unpublished. 
[19] K. Wisshak, K. Guber, F. Käppeler, J. Krisch, H. Müller, G. Rupp, and F. Voss, Nucl. Instr. Meth. A 292, 595 (1990).

[20] K. Wisshak, F. Voss, F. Käppeler, and G. Reffo, Phys. Rev. C 42, 1731 (1990).

[21] F. H. Fröhner, Technical report, Gulf General Atomic (unpublished).

[22] C. Nordborg, H. Gruppelaar, and M. Salvatores, in Nuclear Data for Science and Technology, edited by S. Qaim (Springer, Berlin, 1992), p. 782.

[23] F. Voss, K. Wisshak, and F. Käppeler, Phys. Ref. C in print

[24] G. Reffo, F. Fabbri, K. Wisshak, and F. Käppeler, Nucl. Sci. Eng. 80, 630 (1982).

[25] N. Weber, diplom thesis, University of Karlsruhe (1993).

[26] A. Gilbert and A.G.W. Cameron, Can.J.Phys. 43,1446 (1965).

[27] R. L. Macklin, private communication (unpublished).

[28] W. Ratynski and F. Käppeler, Phys. Rev. C 37, 595 (1988).

[29] Z. Y. Bao, private communications 1995.

[30] J. F. Mughabghab, M. Divadeenam, and N. E. Holden, in Neutron Cross Sections, Vol. 1, Part A (Academic Press, New York, 1981).

[31] Z. Y. Bao and F. Käppeler, Atomic Data Nucl. Data Tables 36, 411 (1987).

[32] H. Beer, F. Voss, and R.R. Winters, Astrophys. J. Suppl. 80, 403 (1992). 